
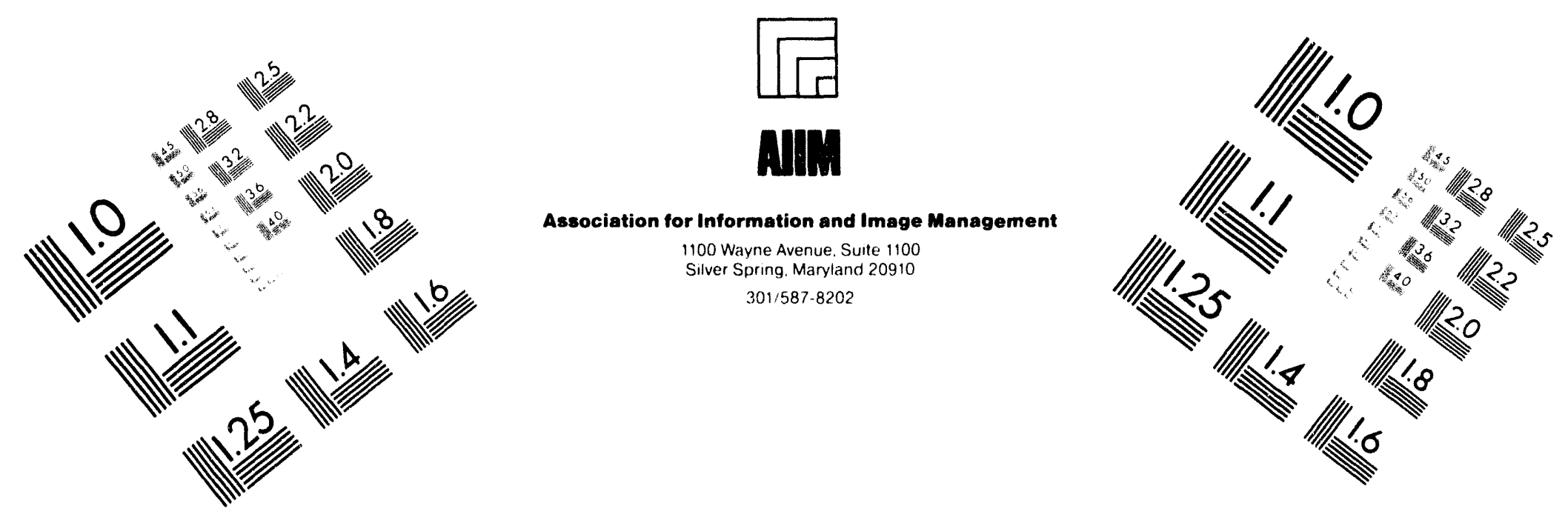

Centimeter

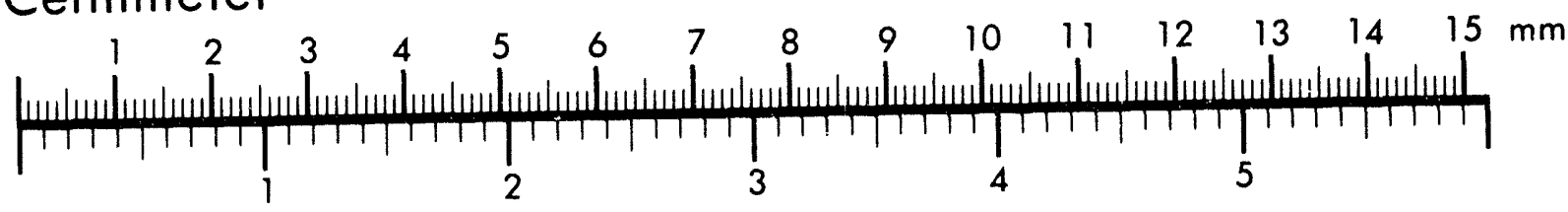
Inches
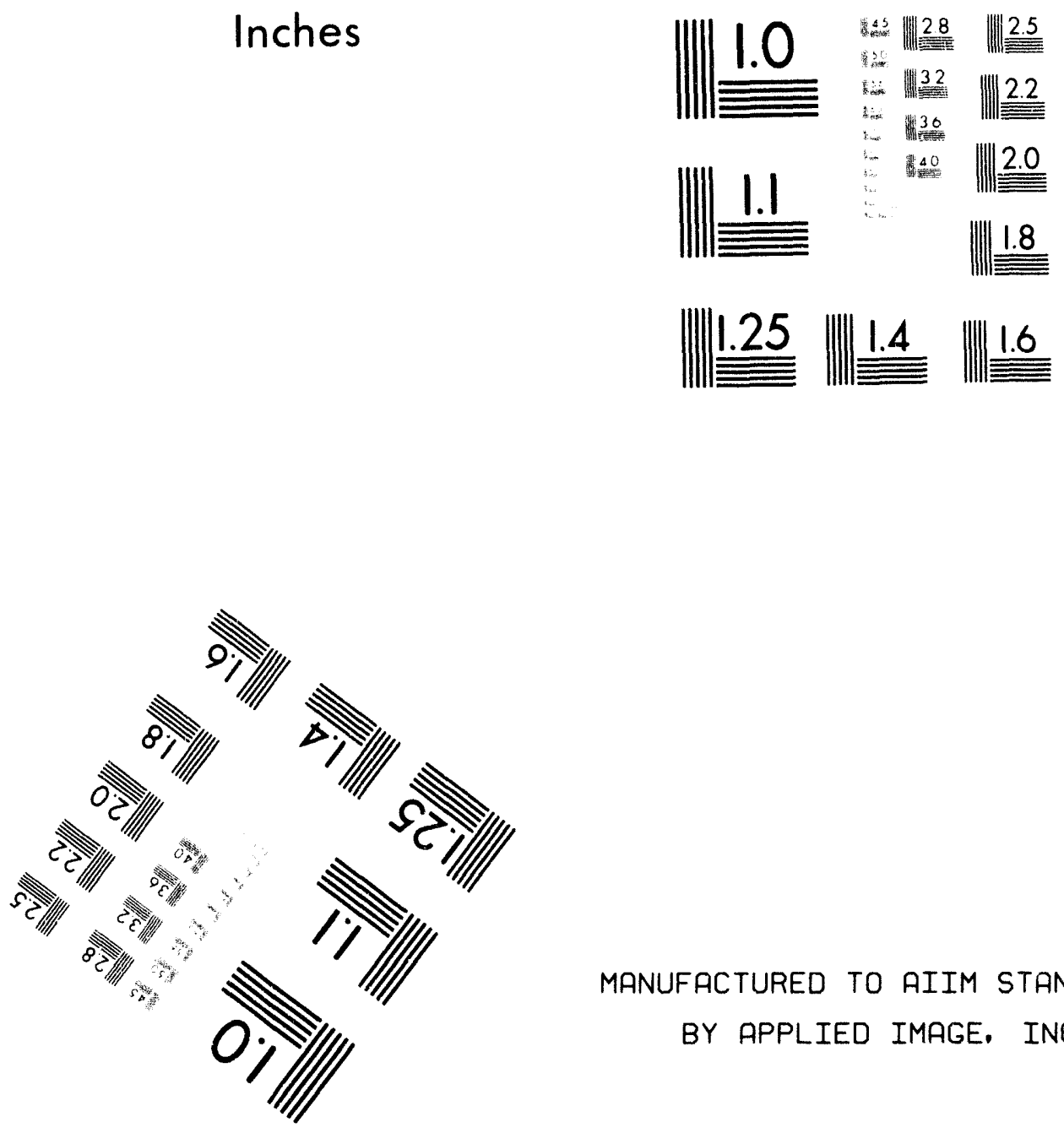

MANUFACTURED TO AIIM STANDARDS BY APPLIED IMAGE, INC.

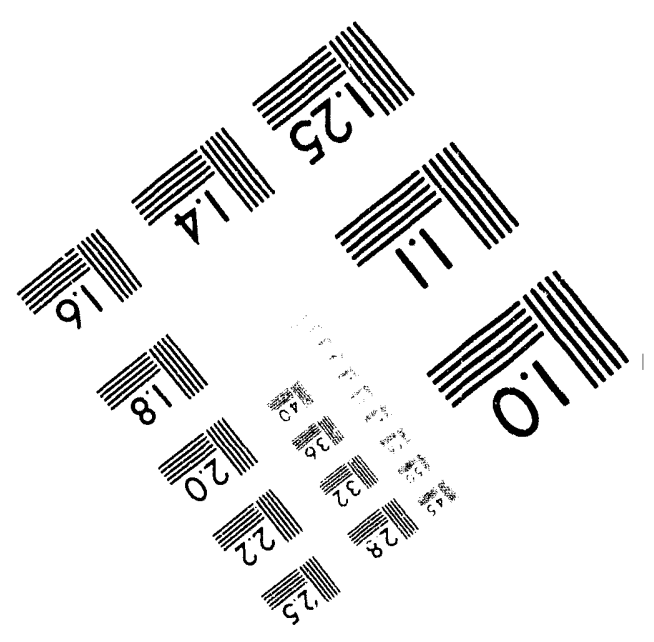



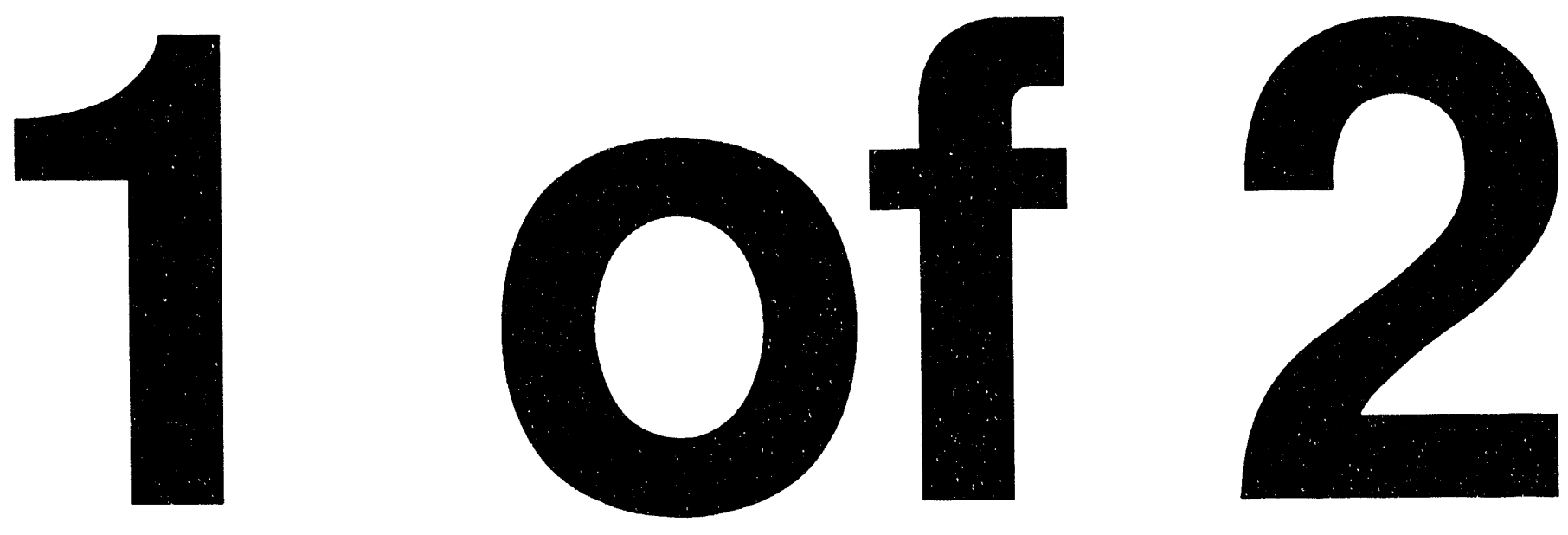
LBL-35021

UC-350

\title{
Review of Demand-Side Bidding Programs: Impacts, Costs, and Cost-Effectiveness
}

\author{
Charles A. Goldman and M.S. Kito
}

\author{
Energy \& Environment Division \\ Lawrence Berkeley Laboratcry \\ University of California \\ Berkeley, California 94720
}

May 1994

The work described in this study was funded by the Assistant Secretary of Energy Efficiency and Renewable Energy, Office of Utility Technologies, Office of Energy Management Division of the U.S. Department of Energy under Contract No. DE-AC03-76SF00098.

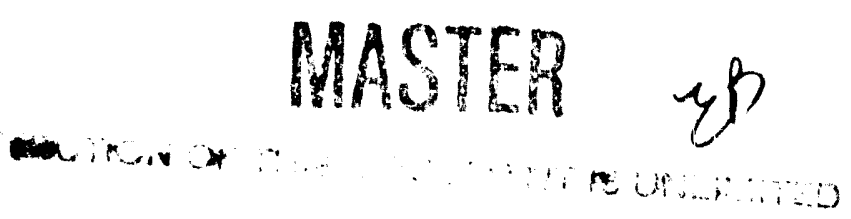




\section{Contents}

Acknowledgements $\ldots \ldots \ldots \ldots \ldots \ldots \ldots \ldots \ldots$ vii

Acronyms and Abbreviations $\ldots \ldots \ldots \ldots \ldots \ldots \ldots \ldots$ ix

Executive Summary $\ldots \ldots \ldots \ldots \ldots \ldots \ldots \ldots \ldots \ldots \ldots \ldots$

CHAPTER 1

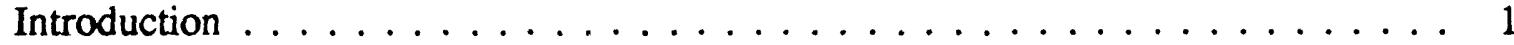

CHAPTER 2

Trends in DSM Bidding Programs ................. 5

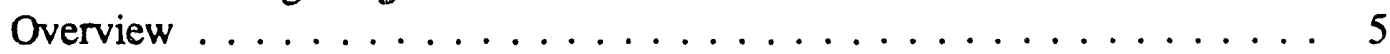

Market Response ....................... 5

Summary of Utility Bidding and Performance Contracting Programs . . . 15

CHAPTER 3

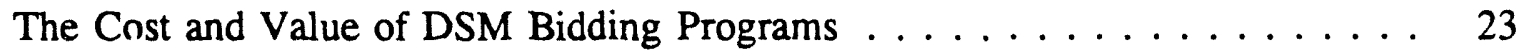

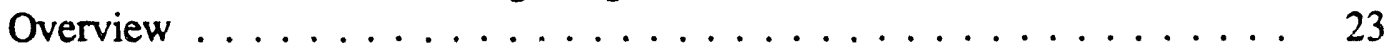

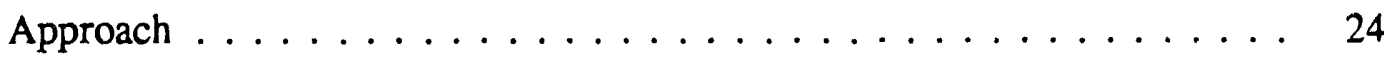

Total Resource Costs of DSM Bidding Programs . . . . . . . . . . . . . . . . 29

Analysis of Program Cost Components . . . . . . . . . . . . . . 32

Cost Comparison of DSM Bidding vs. Other Utility DSM Programs . . . 45

Value of DSM Bidding Programs . . . . . . . . . . . . . . 47

CHAPTER 4

Risk Allocation in DSM Bidding Contracts . . . . . . . . . . . . . . . . . . . 49

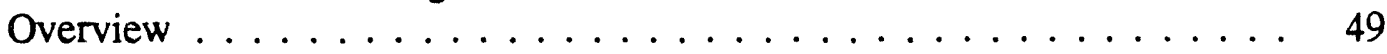

Risks Associated With DSM Resources . . . . . . . . . . . . . . . 50

Comparative Analysis of Development and Performance Risks in DSM

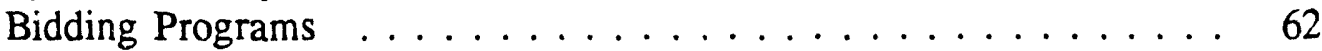

Summary . . . . . . . . . . . . . . . . . . . . . 69 
CHAPTER 5

Implications for DSM Policy and Bidding Program Design . . . . . . . . . 71

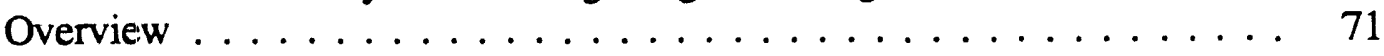

Recommendations on the Design and Implementation of DSM Bidding

Programs ............................... 71

Efficient Allocation of Performance and Development Risks . . . . . . 77

Summary and Policy Implications . . . . . . . . . . . . . 79

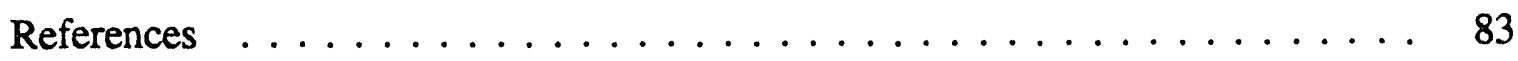

APPENDIX A

Summary of Utility DSM Bidding Programs . . . . . . . . . . . . . . . 91

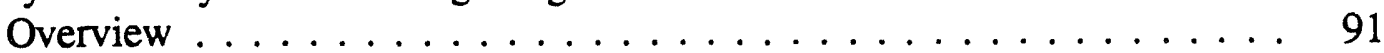

Resource Block Size . . . . . . . . . . . . . . . . . . . . . . . . . . . . . . . .

Type of Solicitation . . . . . . . . . . . . . . . . . 93

Bid Evaluation Design Philosophy . . . . . . . . . . . . . . . . . 97

Eligibility Requirements . . . . . . . . . . . . . . . . . . . . . 98

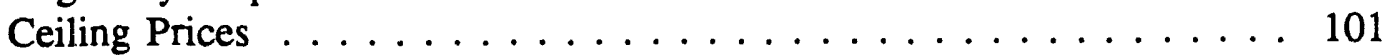

Form of Bid Payment (Basis) . . . . . . . . . . . . . . 102

APPENDIX $B$

Calculating Levelized Bid Prices $\ldots \ldots \ldots \ldots \ldots \ldots \ldots$

APPENDIX $C$

Review and Analysis of Bidding Contracts . . . . . . . . . . . . 113 


\section{Tables}

Table ES-1. C/I Comprehensive Contracts: Savings from Measures Actually

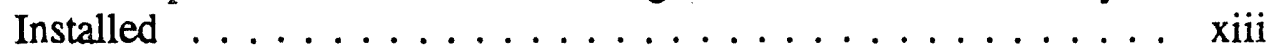

Table 2-1. Summary of Utility DSM Bidding Programs $\ldots \ldots \ldots \ldots \ldots$

Table 2-2. Activity of ESCOs in Utility DSM Bidding Market . . . . . 11

Table 3-1. Confidence Rankings for Program Costs . . . . . . . . . 30

Table 3-2. Total Resource Costs of Ten DSM Bidding Programs . . . . . 31

Table 3-3. DSM Bidding Program Cost Components ........... 33

Table 3-4. Distribution of Contract Savings by Sector and Measure . . . . . 41

Table 3-5. C/I Comprehensive Contracts: Savings from Measures Actually Installed . . . . . . . . . . . . . . . . . . . . . 43

Table 4-1. Risk Allocation in Utility Rebate vs. DSM Bidding Program . . . 51

Table 4-2. DSM Risks and Contractual Risk Mitigation Options . . . . . . 53

Table 4-3. Deposit Requirements . . . . . . . . . . . . . . . 55

Table 4-4. Damage Provisions for Partial Project Completion or Project

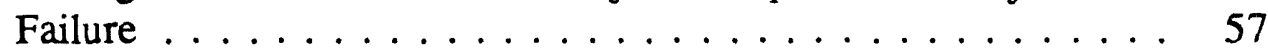

Table 4-5. Front-Loaded Security Requirements . . . . . . . . . . . 58

Table 4-6. Damages and Penalty Provisions for Savings Deterioration or Permanent Underdeliveries . . . . . . . . . . . . . . . . 60

Table 4-7. Contract Pre-Approval and Regulatory Out Provisions . . . . . 61

Table 4-8. Performance Scenarios . . . . . . . . . . . . . . . . . . 64

Table 4-9. Benefit/Cost Ratios for Prototypical Project Under Various Scenarios ...................... 66

Table 5-1. Comparability of Non-Utility Supply and DSM Options in Bidding .................... 73

Table A-1. Regulatory Oversight In Developing Bidding Programs . . . . . 92

Table A-2. Summary of Utility Demand-Side Management Bidding Solicitations . . . . . . . . . . . . . . . . . . 103

Table B-i. Illustrative Examples of Levelized Bid Price Calculations . . . . 112

Table C-1. Payments, Damages, and Penalties for Various

Performance Scenarios . . . . . . . . . . . . . . . . . . 119 


\section{Figures}

Figure ES-1. Total Resource Costs for Ten DSM Bidding Programs . . . . . . . xii Figure $1-1$. DSM Bidding Lexicon . . . . . . . . . . . . . . . 1

Figure $2-1$. DSM Bidding Programs ................... 6

Figure 2-2. Winning Bids by ESCOs and Customers ... . . . . . . 8

Figure 2-3. Utility Ownership in Winning Supply and DSM Contracts . . . . 12

Figure 2-4. Status of Winning Projects . . . . . . . . . . . . . . . . . 14

Figure 3-1. Total Resource Costs for Ten DSM Bidding Programs . . . . . . 32

Figure 3-2. Utility Payments to Bidders vs. Contract Term . . . . . . . . . . . . 36

Figure 3-3. Utility Payment to Winning Bidders . . . . . . . . . . . . . . 37

Figure 3-4. Sectoral Breakdown for 18 Bidding Programs . . . . . . . . . . . 39

Figure 3-5. Other Factors that Influence Bid Payments . . . . . . . . . . . . . . . 39

Figure 3-6. Distribution of DSM Measures for 18 Programs . . . . . . . . . . 40

Figure 3-7. Comparison of Utility C/I Lighting Programs with Bidding

Programs for Lighting Measures . . . . . . . . . . . . 46

Figure 4-1. Deposit Requirements . . . . . . . . . . . . . . . . 56

Figure 4-2. Damage Payments for Project Failure and Partial Project Completion ....................... 65

Figure 4-3. Payments with 50\% Savings Deterioration in Years 6-10 as a Percentage of Base Case Payments . . . . . . . . . . . 67

Figure 4-4. Termination for Partial Project Completion . . . . . . . . . . . . . . 69

Figure A-1. Types of Solicitations . . . . . . . . . . . . . . . . . 93

Figure A-2. Integrated Supply and DSM RFP . . . . . . . . . . . . 94

Figure A-3. Parallel Common Block RFP . . . . . . . . . . . . . . . . 95

Figure A-4. Separate RFPs for Supply and DSM . . . . . . . . . . . . . 96 


\section{Acknowledgements}

We would like to express our appreciation to those utilities, ESCOs, and state agencies that either contributed data or provided comments on a draft of this report. This report would not have been possible without their willingness to share information, however, the views and opinions expressed in this report are strictly those of the authors. Specifically, we would like to thank:

\section{Douglas Auburg \\ Bonneville Power \\ Administration}

Fred Avril and Paul

Velsenbach

Long Island Lighting

Company

Bob Bannister and

Suzanne Frew

Puget Power

John Berlin

Northern California Power

Agency

Jan Berman, Kathy

Berman, Angela

Comstock, Bill

Washburn

Pacific Gas \& Electric

Meng Chi, Jane

Finleon, Dee Lield

Public Service of Colorado

Jim Cuccaro and

Charmaine Ciglianr

Orange \& Rockland

Brian Daly

Public Service Electric \& Gas

Elizabeth Hicks and
Don Robinson
New England Electric System
Carol Johnstone
New York Electric \& Gas
Jim Keating
Consolidated Edison

Mike Kelleher and

John Hartnett

Niagara Mohawk

John Linn

Central Maine Power

Gordon McDonald

Pacific Power \& Light

Steve Murphy and

Kathleen Kelly

Boston Edison

Rob Roth

Sacramento Municipal

Utilities District

Linda Saalman

Rochester Gas \& Electric

Chris Sieben

Jersey Central Power \& Light
Wayne Brown
Planergy

Cary Bullock

KENETECH Energy Services

Dave Dayton

HEC, Inc.

Joe Fitzpatrick and Art

Lennon

EUA Cogenex

Andrew Glace

CES/Way

Bill Machold and

Dennis Wilson

Enersave Inc.

Frank Mazanec and

Rich Sperberg

Onsite Energy

George Sakellaris NORESCO

Bill Mills and

Pat Barnes

New York Public Service

Commission 


\section{Dian Grueneich \\ Grueneich Resource \\ Associates}

Terry Singer

NAESCO

George Caan

Washington

State Energy Office

Steve Harding

Harding Consulting
Marc Vallen

Demand-Side Resources

Richard Ottinger

Pace University School of

Law

Eric Hirst

Oak Ridge National

Laboratory

Mike Ambrosio \&

Mona Mosser

New Jersey Board

of Regulatory Commissioners
Theo MacGregor

Massachusetts Department of Public Utilities

Brad Davids

ESource

Hossein Haeri

Panalytics

Mike Messenger

California Energy

Commission

Review comments were also provided by Joe Eto and Edward Kahn (LBL). The authors would like to give special thanks to Ellen Hodges for report design, graphics, and production.

The work described in this study was funded by the Assistant Secretary of Energy Efficiency and Renewable Energy, Office of Utility Technologies, Office of Energy Management Division of the U.S. Department of Energy under Contract No. DEAC03-76SF00098. 


\section{Acronyms and Abbreviations}

$\begin{array}{ll}\text { ESCO } & \text { Energy Service Company } \\ \text { M\&V } & \text { Measurement \& Verification } \\ \text { RFP } & \text { Request for Proposal } \\ \text { PUC } & \text { Public Utility Commission } \\ \text { TRC } & \text { Total Resource Cost }\end{array}$

\section{Utilities}

Anaheim

Anaheim Public Utilities Department

BECo

Boston Edison Company

BPA

Central Hudson

CMP

ComElec

Con Edison

Duke

HL\&P

JCP\&L

LILCO

MECo

Montana-Dakota

MPC

NPC

NEES

NYSEG

NMPC

NCPA

ORU

PG\&E

PGE

PP\&L

PSE\&G

PSI

Puget or PSP\&L

RG\&E

PSColo

SCE

SDG\&E

SMUD

Snohomish

TU

WWP

Bonneville Power Administration

Central Hudson Gas \& Electric

Central Maine Power

Commonwealth Electric

Consolidated Edison

Duke Power

Houston Light \& Power

Jersey Central Power \& Light

Long Island Lighting Company

Massachusetts Electric Company

Montana-Dakota Utilities

Montana Power Company

Nevada Power Company

New England Electrical System

New York State Electric \& Gas

Niagara Mohawk Power Corporation

Northern California Power Agency

Orange \& Rockland Utilities

Pacific Gas \& Electric

Portland General Electric

Pacific Power \& Light

Public Service Electric \& Gas

Public Service of Indiana

Puget Sound Power \& Light

Rochester Gas \& Electric

Public Service of Colorado

Southern California Edison

San Diego Gas \& Electric

Sacramento Municipal Utilities District

Snohomish Public Utilities Department

Texas Utilities

Washington Water Power 


\section{Executive Summary}

This study reviews the experiences of U.S. electric utilities with demand-side management (DSM) bidding programs. In these programs, a utility requests proposals from third party (e.g., energy service companies) and customer bidders offering $\mathrm{kW}$ demand reductions, $\mathrm{kWh}$ savings, or some combination of both at a specified price for a fixed time period. DSM bids can be solicited as part of a competitive bidding program that includes supply-side providers or as a stand-alone program.

Since 1987, about 30 utilities in 14 states have solicited bids from ESCOs and customers to reduce demand in commercial and industrial facilities and residences. DSM bidding has spread from its original roots in New England to other states and regions, driven both by regulatory policy and the capacity needs of utilities. In this study, we examine 18 programs in which utilities have selected winning bidders and information is available on program costs.

Based on our analysis of these programs, we found the following trends:

\section{Market Response}

- As of October 1993, DSM bidders have offered over 1,500 MWs of demand reductions in response to bidding solicitations. Utilities have selected over 170 bids for about $425 \mathrm{MWs}$ of demand reductions with ESCOs responsible for about $87 \%$ of this amount. About $50 \mathrm{MWs}$ are on-line through these programs; most projects are still under development. Few utilities have received many bids from individual customers because of high transaction and bid preparation costs and perceived risks compared to other utility DSM programs.

- Market response by DSM developers has increased significantly since the late 1980 s as indicated by the number of bids and quantity of demand reduction offered. In recent solicitations, it is not uncommon for utilities to receive $30-45$ bids from DSM developers proposing 100 - $150 \mathrm{MWs}$ of demand reductions in aggregate compared to 10 - 15 DSM bids in early bidding programs. This trend reflects both increasing maturity of the ESCO industry and entry by new energy service firms.

- $\quad$ Success rates for DSM bidders (i.e., the percent of winning bids compared to bio's initially proposed) have been relatively high (25-40\%), particularly in auctions in which both supply and DSM bidders compete. 
- A number of ESCOs have developed a limited national presence through their involvement in utility DSM bidding programs. Currently, the DSM bidding market is nnt dominated by firms that are utility affiliates or subsidiaries.

- As of October 1593, about 75 MWs of DSM bids have either failed to develop or been cancelled by utilities ( $34 \mathrm{MWs).} \mathrm{In} \mathrm{many} \mathrm{cases,} \mathrm{utilities} \mathrm{have} \mathrm{claimed} \mathrm{that}$ the economics of a DSM bid were no longer favorable because of declining avoided costs.

\section{Program Costs}

- Levelized total resource costs range between $5.4-8 \mathrm{c} / \mathrm{kWh}$ (using an $11 \%$ discount rate) for ten DSM bidding programs where complete information on program costs is available (see Figure ES-1). This cost range is higher than values typically cited by DSM proponents for measures that primarily target commercial and industrial customers. Payments to bidders account for between

Figure ES-1. Total Resource Costs for Ten DSM Bidding Programs

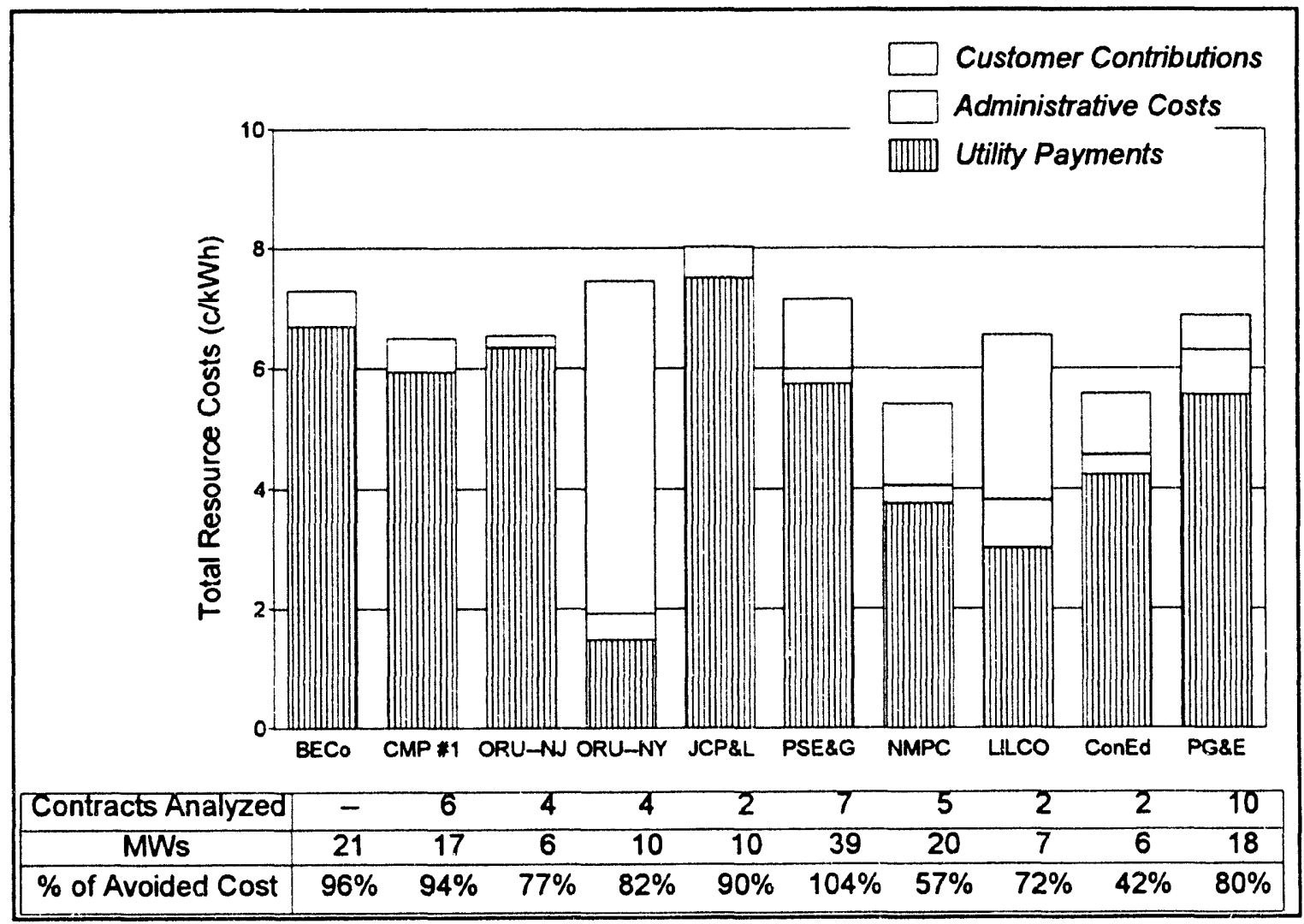


$70-90 \%$ of total program rosts in most bidding programs. Increased competition, the result of an expanding energy services industry and bidding programs with small resource blocks (e.g., 10-20 MWs), appears to be driving bid prices downward in several recent programs.

- We found substantial variation in the bid prices of individual contracts both within a particular utility DSM bidding program as well as across utilities. Our analysis suggests that much of the observed variation in bid prices can be explained by differences in allowed ceiling prices, mix of measures, services offered, markets targeted by DSM developers, and the degree to which DSM developers bear performance risks. For example, bids targeting residential customers averaged 6.2 $\mathrm{c} / \mathrm{kWh}$ compared to about $5 \mathrm{c} / \mathrm{kWh}$ for commercial/industrial bids.

- $\quad$ DSM developers offering comprehensive packages of measures to $\mathrm{C} / \mathrm{I}$ customers account for almost $50 \%$ of the contracted MWs (199 MWs) in this sample of programs. However, ESCOs generally do not provide contractual guarantees regarding the mix of measures to be installed. With one or two exceptions, lighting measures account for most of the savings $(70-100 \%)$ from projects completed by ESCOs with contracts for comprehensive measures (see Table ES1). These results are disappointing because utilities are paying a premium for these projects. Utilities might have judged the value of these proposals somewhat differently if they knew that almost all of the savings would ultimately be obtained from lighting measures.

Table ES-1. C/I Comprehensive Contracts: Savings from Measures Actually Installed

\begin{tabular}{|c|c|c|c|c|c|c|c|c|}
\hline Utility & $\begin{array}{l}\text { Total } \\
\text { (MW) }\end{array}$ & $\begin{array}{l}\text { On-Line } \\
\text { (MW) }\end{array}$ & $\begin{array}{c}\text { Industrial } \\
\text { Process } \\
(\%)\end{array}$ & $\begin{array}{l}\text { Lighting } \\
(\%)\end{array}$ & $\begin{array}{c}\text { Motors } \\
(\%)\end{array}$ & $\begin{array}{c}\text { HVAC } \\
(\%)\end{array}$ & $\begin{array}{c}\text { Non- } \\
\text { Electric } \\
\text { Cooling } \\
(\%)\end{array}$ & $\begin{array}{l}\text { Shell } \\
(\%)\end{array}$ \\
\hline NEES & & 17 & & 70 & & & & \\
\hline BECo & & 21 & & 90 & 3 & 7 & & \\
\hline CMP \#1 & 10 & 10 & 36 & 64 & & & & \\
\hline ORU-NY & 10 & 4 & & 100 & & & & \\
\hline ORU-NJ & 3 & 1 & & 100 & & & & \\
\hline JCP\&L & 10 & 6 & & 100 & & & & \\
\hline PSE\&G & 36 & 7 & & 85 & 5 & 10 & & \\
\hline NMPC & 8 & 5 & & 47 & 6 & 45 & & 2 \\
\hline LILCO & 7 & 3 & & 65 & & & 35 & \\
\hline Con Edison & 7 & 4 & & 98 & 2 & & & \\
\hline
\end{tabular}




\section{Cost Comparison of DSM Bidding Lighting Contracts vs. Utility Lighting Programs}

- Comparing the cost-effectiveness and value of alternative DSM program delivery mechanisms is a key policy issue for both utilities and regulators. To begin to address this issue, we compared the costs of nine bidding contracts that targeted commercial/industrial lighting measures with results from a recent study of 20 lighting rebate and direct install programs. On average, total resource costs were slightly lower in the utility-sponsored lighting programs compared to the bidding contracts $(5.6 \mathrm{vs}$. $6.1 \mathrm{c} / \mathrm{kWh})$, although there are greater uncertainties in the persistence of savings and ultimate economic lifetime of installed measures for the utility-sponsored programs.

\section{Program Cost-Effectiveress}

- Almost all DSM bidding programs have cost less than the utility's supply-side alternatives (at the time of the RFP). However, several programs appear to be only marginally cost-effective from a total resource cost perspective, given the uncertainties in customer and administrative costs and future avoided costs (see Figure ES-1).

- Substantial disagreements remain regarding the value of bidding programs to ratepayers, driven in part by differences over the appropriate figure of merit. Many utilities would argue that the costs of a "comparable" DSM program adjusted for additional risks and services provided by a DSM developer provides a better measure of the true value of a DSM bidding program to ratepayers. However, properly valuing performance and development risks and the costs of additional services compared to a utility DSM program alternative is challenging analytically.

\section{Allocation of Risks in DSM Bidding Programs}

- From the perspective of a utility and its ratepayers, the major risks associated with DSM resources can be grouped into three broad categories: development, performance, and demand risks. One of the attractive features of DSM bidding programs is that DSM developers typically bear development and performance risks. DSM developers are usually paid only for savings that must be verified over relative!y long contract terms (e.g., 7 - 15 years), which significantly reduces the uncertainties regarding the savings and, thus, the ultimate cost of the 
DSM resource. In contrast, in utility rebate programs, ratepayers implicitly bear most of the performance risks.

- Our analysis of bidding contracts focused on two major issues: (1) the extent to which contracts protected the financial interests of ratepayers in the event that the expected benefits of DSM projects did not materialize, and (2) the relative impact on bid prices of damage provisions and financial uncertainties associated with achieving satisfactory performance. We found that most bidding programs protect ratepayers quite well in situations in which projects fail to develop or energy sivings deteriorate during the last half of a contract. Our analysis also suggests that the security deposit amounts required by most utilities appear to have a fairly minimal impact on bid prices compared to the risks and payment provisions associated with "pay for performance" contracts.

\section{Suggestions on Design of Bidding Programs}

\section{Separate RFPs for DSM Resources are Preferable}

For both theoretical and practical reasons, we prefer separate solicitations for supply-side and DSM resources. Supply-side and DSM resources differ significantly in terms of market structure, inherent characteristics, and level of developrnent. Moreover, with a separate solicitation for DSM, utilities can take account of DSM market potential explicitly in determining resource block size, and thus create more competition among DSM service providers. We found that average payments to DSM developers were higher for those utilities that issued integrated supply-and DSM solicitations compared to those utilities that used either separate RFPs for DSM resources or parallel RFPs for supply and DSM.

\section{Economic Valuation of DSM Bids}

Determining the appropriate economic benchmark to use in valuing DSM bids is complicated by the fact that utilities are often trying to reconcile conflicting objectives with respect to DSM resources (e.g., maximizing economic benefits to society, limiting short-term rate impacts). In a DSM-only bidding program, we recommend using the total resource cost (TRC) test only as a threshold requirement, primarily because the TRC test often leads to perverse results when used for scoring and ranking DSM bids. DSM bidders tend to maximize payments from the utility when the TRC test is used as the economic scoring attribute. We prefer bid evaluation approaches that focus on costs or value to the utility. Scoring options can be either objective (e.g., Utility Cost Test), 
subjective (e.g., rank bids based on measures of value to utility) or incorporated in program design (e.g., set ceiling prices that are linked to utility DSM program costs in aggregate or for individual measures). Overall, these approaches will tend to encourage DSM developers to obtain maximum cost contributions from host customers. We expect this to become an even more prominent design feature of DSM programs as utilities respond to increasing competitive pressures by attempting to structure DSM programs so as to minimize rate impacts.

\section{Encouraging DSM Developers to Propose and Install Comprehensive Packages of Measures}

For some utilities, the degree of comprehensiveness of services and measures offered by DSM developers is an important element in assessing bid quality. However, our analysis indicates that utilities frequently have difficulty crafting enforceable contract provisions to ensure that DSM developers actually install comprehensive packages of measures in the commercial sector. A utility can encourage DSM developers to propose comprehensive retrofits by assigning a significant weighi to a comprehensiveness attribute in its scoring system. If the RFP is targeted to well-defined market sectors, use of threshold requirements may be an even more effective approach (e.g., limit fraction of overall savings that can be obtained from a particular end use or list measures that must be included for a market segment). Utilities can also include provisions that limit or reduce payment obligations in the event of non-performance in this area. Some utilities are experimenting with "tiered pricing" schemes, in which a DSM developer receives a higher bid payment if they achieve savings reductions that exceed a pre-specified amount (either at the end use or whole-building level). Finally, at the time utility managers approve measurement and verification plans for individual facilities, they have an opportunity to monitor the type and mix of measures being installed in aggregate by the DSM developer.

\section{Overall Assessment}

DSM bidding programs represent a set of diverse, large-scale experiments to acquire demand and energy savings from third party providers based on pay-for-performance contracts. Interest among regulators (and some utilities) in competitive procurement of DSM resources continues to increase, although DSM bidding programs account for only a small amount of the savings ( $~ 5 \%$ ) currently achieved by utility DSM efforts nationally. However, from a policy perspective, DSM bidding is an important phenomenon because it provides a competitive benchmark to help assess utility performance in acquiring cost- 
effective DSM resources and because it encourages performance-based DSM programs in which DSM savings are guaranteed and maintained over the long-term.

Our analysis suggests that the results for the first generation of DSM bidding programs are quite mixed. In assessing impacts, we would define a "successful" program as one in which the utility performed well compared to clearly articulated goals and design objectives, the utility's bid selection and evaluation processes was perceived to be fair and reasonable, and the outcome produced significant benefits to ratepayers. The costs of DSM bidding programs have been relatively high $(5.4-8 \mathrm{c} / \mathrm{kWh})$, although ratepayers are protected financially against the major risks associated with DSM resources. Almost all DSM bidding programs have been cost-effective compared to the utility's own supplyside alternatives, although there is substantial disagreement regarding the value of these programs compared to the utility's own DSM programs. Moreover, a number of utilities have encountered significant difficulties in implementing DSM bidding programs, while many ESCOs express a fair amount of dissatisfaction based on their experiences with some utilities. On the positive side, DSM bidding has contributed to increased interest and support for "pay-for-performance" DSM, advances in measurement and verification protocols, and the creation of a more vibrant, active, and maturing ESCO industry. We expect continued experimentation by utilities and PUCs in the search for competitive procurement processes and program designs that improve the efficiency and value of DSM resources and services delivered to customers. 


\section{Introduction}

U.S. utilities and public utility commissions (PUCs) continue to experiment with various approaches that allow developers of demand-side resources to propose projects in competitive bidding solicitations. In a demand-side management (DSM) bidding program, a utility requests proposals from energy service companies (ESCOs), and often customers, offering specified amounts of savings. DSM bids can be solicited as part of a competitive bidding program that includes supply-side providers or as a stand-alone program. The bids of DSM developers are typically structured as the price to supply a block of $\mathrm{kW}$ demand reductions, $\mathrm{kWh}$ savings, or some combination of both for a fixed time period. Figure 1-1 shows the major stages of a bidding program (e.g., RFP design, bid evaluation/ranking, contract negotiation, contract implementation and monitoring) and highlights the key areas that we analyze in each stage (e.g., market response, bid prices, program impacts and cost-effectiveness). A utility DSM bidding program typically consists of long-term contracts with several DSM developers based on submitted bids.

Figure 1-1. DSM Bidding Lexicon

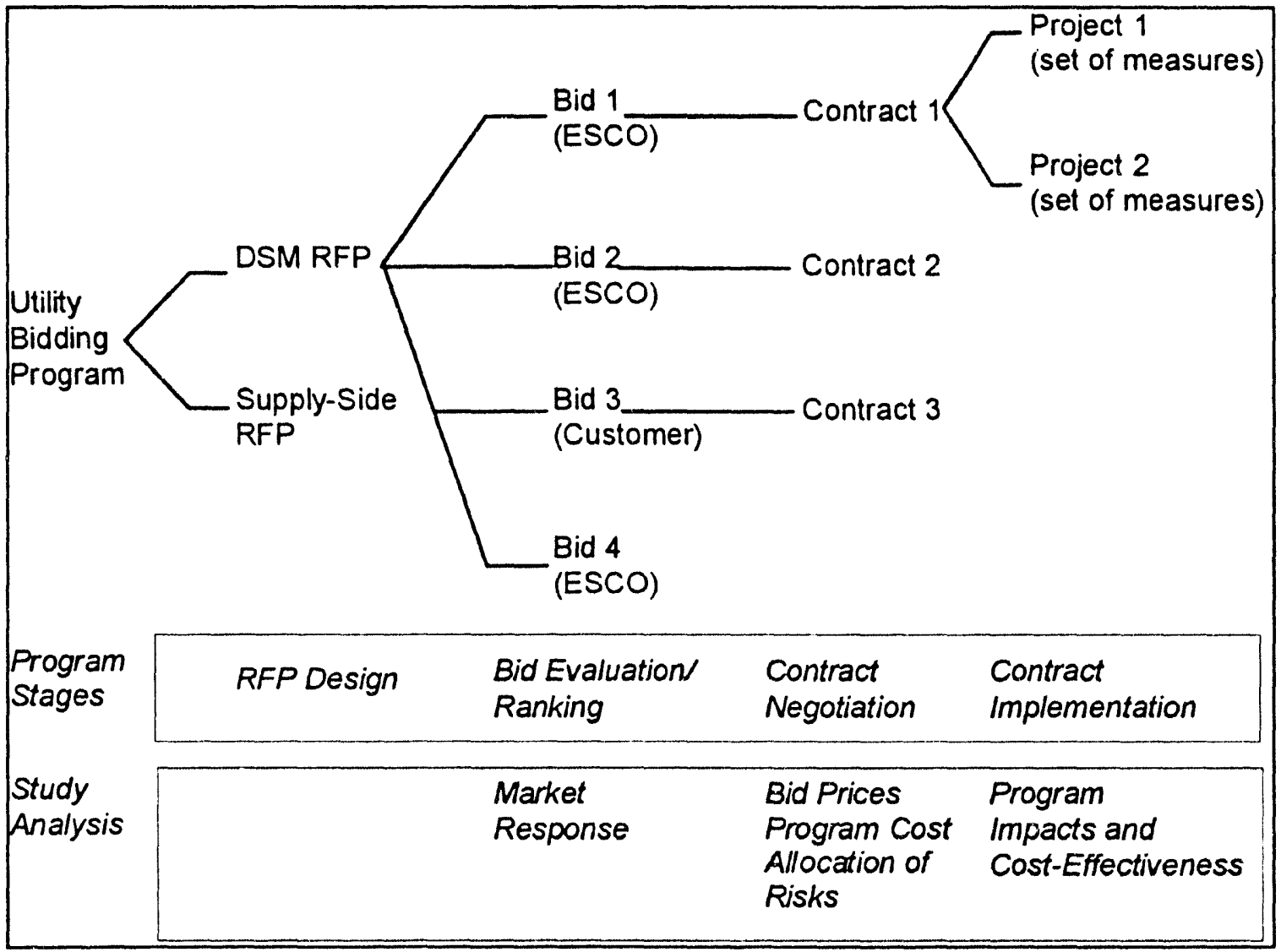


A third party bidder (i.e., ESCO) usually will develop projects at one or more customer sites in order to achieve its contracted savings or peak demand reduction goals.

DSM bidding emerged as a byproduct of several broader trends. First, a number of utilities and public utility commissions (PUCs) began to use competitive bidding as a way to ration long-term power contracts for independent power producers. They were motivated in part by the overwhelming response to open-ended, standard offer contracts. Second, regulatory requirements in support of integrated resource planning (IRP) led many utilities to develop IRP plans in which DSM resources were expected to assume a major role in meeting incremental resource needs. Some PUCs, however, were frustrated and disappointed by the lack of interest or ability of some utilities to deliver and develop large-scale DSM programs. Thus, several PUCs decided to broaden the list of eligible participants in supply-side bidding programs to include providers of DSM resources. Regulators took these actions in part as a way of signaling to utilities their continuing interest in DSM and willingness to consider alternative providers (Goldman and Wolcott 1990).

In December 1987, Central Maine Power (CMP) instituted the first competitive bidding program that allowed developers to propose installation of conservation measures. Since then, about 30 utilities in 14 states have solicited bids from ESCOs and customers to reduce energy demand in residential homes and in commercial and industrial facilities. Interest in the use of competitive procurement mechanisms for demand-side resources continues to grow. In this study, we build upon earlier work conducted by LBL in collaboration with others (Goldman and Busch 1992; Wolcott and Goldman 1992). We have developed methods to compare bid prices and program costs among utilities. We also characterize approaches used by utilities and developers to allocate risks associated with DSM resources based on our review of a large sample of signed contracts. These contracts are analyzed in some detail because they provide insights into the evolving roles and responsibilities of utilities, customers, and third party contractors in providing DSM services. Our analysis also highlights differences in the allocation of risks between traditional utility rebate programs and DSM bidding programs.

The report is organized as follows. In chapter 2 , we summarize key features of DSM bidding programs developed by individual utilities and analyze trends in the market response to these types of programs. In chapter 3 , we report findings from our analysis of the total resource cost of bidding programs, including comparisons with other utility DSM programs targeting similar market sectors. We also analyze factors that influence bid prices, including DSM ceiling prices, target markets and mix of measures, payment provisions and performance guarantees, and type and size of solicitation. In chapter 4, we examine approaches that various utilities have taken to allocating the risks associated with DSM resources in their bidding programs through an analysis of individual contract 
features. In chapter 5, we summarize key findings of this study and their implications for DSM policy and offer suggestions for improving the design of future bidding programs. 


\section{Trends in DSM Bidding Programs}

\subsection{Overview}

In this chapter, we review the market response to DSM bidding programs by energy service companies (ESCOs) and customers. The increasing maturity of the energy services industry, including entry by new firms, is one of the successful byproducts of these bidding programs. It also appears that the initial track record of DSM bidders is comparable to supply-side bidders in terms of successfully developing projects, although the majority of projects are still under development. We then focus on a subset of programs in which utilities have selected winning bidders and information is available on program costs. We provide a brief summary of these programs which includes their regulatory context, distinctive program features, and current program status. Appendix A provides a more detailed comparison of program design features and serves as a useful reference for the discussion in this chapter. The costs of these bidding programs are analyzed in Chapter 3 and contract features and risk allocation issues are discussed in Chapter 4.

\subsection{Market Response}

According to a recent survey, as of October 1993, 28 U.S. utilities had conducted bidding programs in which DSM projects were eligible (Robertson 1993a). DSM bidding has spread from its initial roots in New England, New York, and New Jersey to other regions of the U.S. (e.g., Colorado, California, Indiana, Pacific Northwest, North Carolina, Texas), driven both by regulatory policy and the capacity needs of utilities (see Figure 2-1). In these solicitations, DSM bidders have offered over 1,500 MWs of demand reductions and utilities have selected over 170 projects offering about $425 \mathrm{MW}$ of demand reductions.

Table 2-1 shows the following information for each solicitation: type of auction, when the request for proposal (RFP) was issued, the resource need requested by the utility in MW (including both supply and DSM blocks in the case of an integrated auction), the number of DSM bids received and awarded, and the demand reductions associated with these proposals and awards. In the column for Winning DSM Bids, utilities that have signed contracts with DSM developers are indicated in bold; in other cases, the utilities have announced bidders in the final award group. In some cases, the utility has not yet selected winning bidders (indicated by NS), typically in the more recent solicitations. In terms of auction type, we distinguish between an integrated RFP that includes both 
Figure 2-1. DSM Bidding Programs

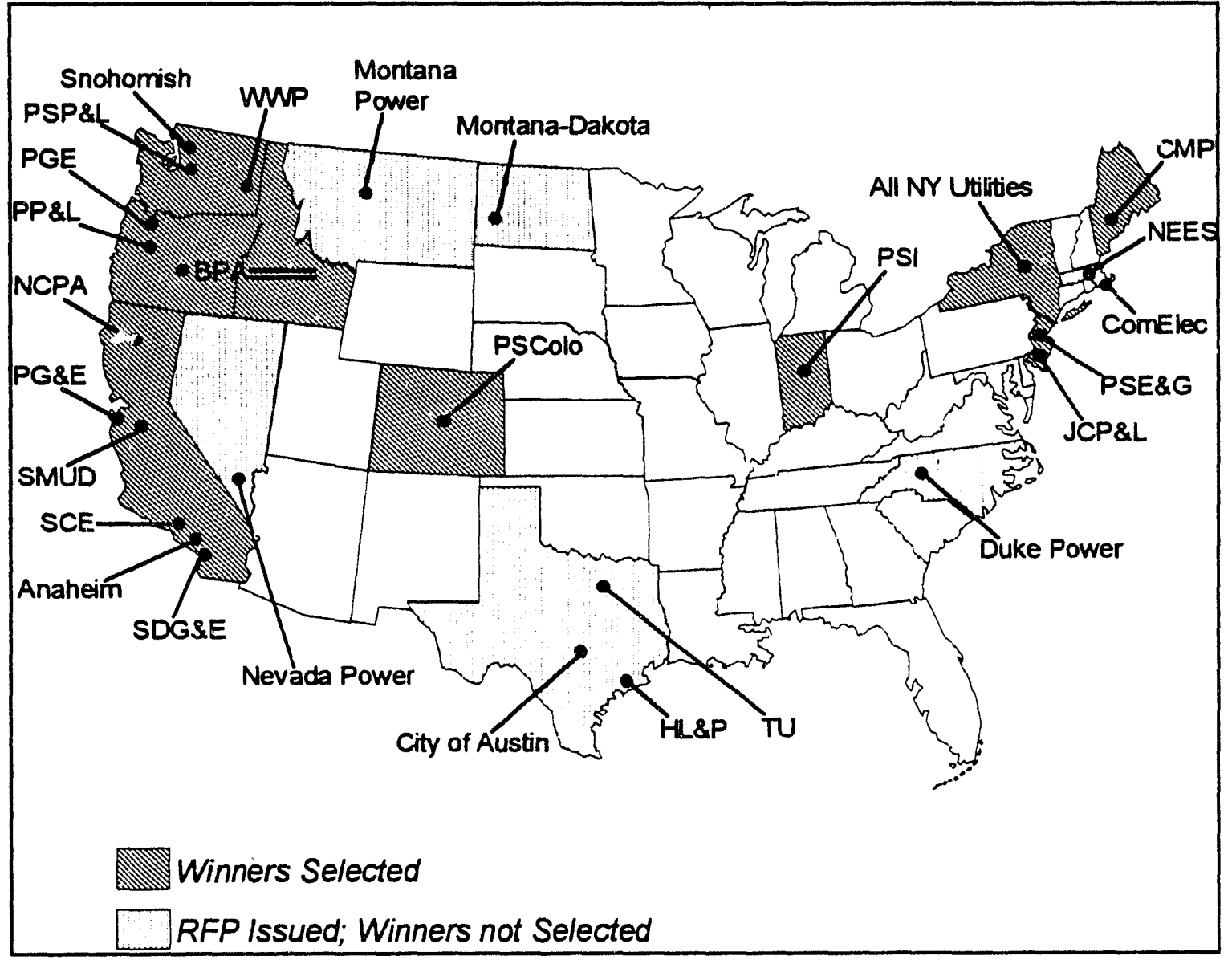

supply-side and DSM options, parallel RFPs for supply and DSM resources that the utility issues to fill a common resource block, and separate RFPs for DSM (or supply) only (see Appendix A for criteria and definitions). For comparison, Table 2-1 also presents the market response of supply-side bidders in solicitations in which supply and DSM projects were both eligible to participate.

The following trends emerge:

- $\quad$ Bids by third parties (e.g., ESCOs) dominate the DSM bidding market; few utilities have received many bids from individual customers.

Most utilities received few bids from individual customers, with the notable exception of Public Service of Colorado (PSColo). In its first bidding RFP, PSColo awarded 19 
Table 2-1. Summery of Utility DSM Bidding Programs

\begin{tabular}{|c|c|c|c|c|c|c|c|c|c|c|c|}
\hline \multirow[b]{2}{*}{ Uvility } & \multirow{2}{*}{$\begin{array}{l}\text { Auction } \\
\text { Type }\end{array}$} & \multirow{2}{*}{ RFP. } & \multirow{2}{*}{$\begin{array}{l}\text { Amount } \\
\text { Roquented (MWVI }\end{array}$} & \multicolumn{4}{|c|}{ DSMI Bida } & \multicolumn{4}{|c|}{ supply blds } \\
\hline & & & & $\begin{array}{r}\text { Proponod } \\
\text { MW } \\
\end{array}$ & $\begin{array}{ll}8 \text { of } \\
\text { efde }\end{array}$ & $\begin{array}{r}\text { Winning } \\
\text { MW }\end{array}$ & Bide & $\begin{array}{l}\text { Proposod } \\
\text { MW }\end{array}$ & $\begin{array}{l}\text { oof } \\
\text { Bios }\end{array}$ & $\begin{array}{l}\text { Winning: } \\
\text { MW } \\
\end{array}$ & Bide \\
\hline \multicolumn{12}{|l|}{ DSM Bidding } \\
\hline $\begin{array}{l}\text { CMP } 11 \\
\text { CMP }: 2(1)\end{array}$ & 1 & $\begin{array}{l}12 / 87 \\
6 / 88\end{array}$ & $\begin{array}{r}100 \\
160-300\end{array}$ & $\begin{array}{l}36 \\
31\end{array}$ & $\begin{array}{r}13 \\
8\end{array}$ & $\begin{array}{l}17 \\
24\end{array}$ & i & $\begin{array}{r}688 \\
2,338\end{array}$ & $\begin{array}{l}45 \\
41\end{array}$ & $\begin{array}{l}0 \\
50\end{array}$ & 0 \\
\hline ORU & P & $6 / 88$ & 160 & 28 & 16 & $\begin{array}{l}24 \\
10\end{array}$ & $\begin{array}{l}3 \\
8\end{array}$ & 1,396 & 25 & $18 i$ & 2 \\
\hline Pusat : & 1 & 8/89 & 100 & 24 & 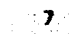 & 10 & 8 & 1,281 & 34 & 127. & 3 \\
\hline JCPAL & $\mathbf{P}$ & $8 / 89$ & 270 & 68 & 8 & 27 & 4 & 712 & 11 & $23 \mathrm{~F}$ & 3 \\
\hline PSEAO & 1 & $8 / 88$ & 200 & 63 & 8 & 82 & 8 & 846 & 8 & 310 & 4 \\
\hline NMPC & $\mathbf{P}$ & $11 / 89$ & 360 & 183 & 33 & 20 & 8 & 7.116 & 76 & 406 & 2 \\
\hline LILCO & $\mathbf{s}$ & $11 / 88$ & $160 / 16$ & 22 & 7 & 10 & 3 & 1,785 & $21:$ & 132 & 1 \\
\hline PSI & $\mathbf{P}$ & $12 / 80$ & 660 & 76 & 9 & 10 & 2 & 1,800 & 12 & 840 & 4 \\
\hline Con Edizon & $\mathbf{P}$ & $2 / 80$ & 200 & 12 & 4 & 7 & 2 & 2,878 & 36 & 204 & 8 \\
\hline NYSEG & $s$ & $7 / 80$ & $100 / 30$ & 98 & 31 & 16 & $\boldsymbol{B}$ & 596 & 11 & 0 & 0 \\
\hline ROAE & $s$ & $9 / 80$ & $60 / 20$ & 87 & 18 & 23 & 6 & 69 & 3 & & \\
\hline Central Hudson & $\mathbf{s}$ & $11 / 80$ & $50 / 20$ & 33 & 7 & 0 & 0 & 680 & 16 & & \\
\hline$P S C d 0=1$ & $\mathbf{s}$ & 12100 & 60 & 130 & 83 & 65 & 32 & & & & \\
\hline BPA & $\mathbf{P}$ & $1 / 91$ & 300 & 110 & 41 & 26 & 8 & 6.209 & 82 & 297 & 3 \\
\hline Anshoim 1 & $s$ & $2 / 91$ & 100 & 67.68 & 13 & 8 & 1 & & & & \\
\hline Anaheim 12 & $\mathbf{s}$ & 4/81 & 160 & $20-24$ & 35 & NA & 1 & & & NS: & NS \\
\hline NCPA & 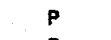 & $8 / 81$ & 200 & 138 & 12 & NS & NS & $\begin{array}{l}8,860 \\
1,288\end{array}$ & $\begin{array}{l}68 \\
30\end{array}$ & $\begin{array}{r}\text { NS } \\
6\end{array}$ & 2 \\
\hline PP\&L & $\mathbf{P}$ & $10 / 81$ & 60 & 81 & 18 & 16 & 3 & & 73 & NS & NS \\
\hline Momane Pow or & 1 & $3 / 81$ & 160 & 67 & 3 & NS & NS & $\begin{array}{r}8.018 \\
280\end{array}$ & 10 & 0 & 0 \\
\hline WWP & 1 & 8/81 & 30 & 16 & 5 & 0 & 0 & & & & \\
\hline SMUD & s & $1 / 82$ & 10 & 143 & 36 & 9 & 3 & & & & \\
\hline MECO & $\mathbf{s}$ & 192 & 6 & 33 & 18 & NS & NS & & & & \\
\hline PGE & $\begin{array}{l}\mathbf{s} \\
\text { s }\end{array}$ & 192 & 3 & 81 & 3 & $\begin{array}{l}3 \\
60\end{array}$ & $\begin{array}{l}1 \\
\text { NA }\end{array}$ & & & & \\
\hline PSColo $\# 2$ & $\begin{array}{l}\text { s } \\
\text { s }\end{array}$ & $8 / 92$ & $\begin{array}{l}60 \\
25\end{array}$ & $\begin{array}{l}81 \\
38\end{array}$ & $\begin{array}{l}36 \\
16\end{array}$ & $\begin{array}{l}60 \\
\text { NS }\end{array}$ & NS & & & & \\
\hline $\begin{array}{l}\text { Ouke Power } \\
\text { PGEE }\end{array}$ & $\begin{array}{l}s \\
\text { s }\end{array}$ & $9 / 92$ & $\begin{array}{l}25 \\
20\end{array}$ & 136 & 42 & 18 & 10 & & & & \\
\hline $\begin{array}{l}\text { PGQE } \\
\text { SOGEE }\end{array}$ & & $\begin{array}{l}10 / 92 \\
1 / 93\end{array}$ & 6 & 11 & 6 & NS & NS & & & & \\
\hline $\begin{array}{l}\text { SOGEE } \\
\text { SCE-Small Cn }\end{array}$ & $\begin{array}{l}s \\
s\end{array}$ & $\begin{array}{l}1 / 93 \\
4 / 83\end{array}$ & 5 & $38 \mathrm{GWh}$ & 4 & NS & NS & & & & \\
\hline $\begin{array}{l}\text { SCE-Small Cn } \\
\text { SCE-targo C } n\end{array}$ & $\begin{array}{l}\mathbf{s} \\
\mathbf{s}\end{array}$ & $\begin{array}{l}4 / 83 \\
4 / 83\end{array}$ & 14 & $287 \mathrm{GWh}$ & 17 & NS & NS & & & & \\
\hline $\begin{array}{l}\text { SCE-Larpe Cn } \\
\text { Novade Power }\end{array}$ & $\mathbf{s}$ & $\begin{array}{l}4 / 83 \\
8 / 93\end{array}$ & no limit & 27 & 7 & NS & NS & & & & \\
\hline \multirow{2}{*}{\multicolumn{2}{|c|}{$\begin{array}{l}\text { Parformence Contractno } \\
\text { NEES }\end{array}$}} & 8/93 & & & & & & & & & \\
\hline & & $\begin{array}{l}10 / 87 \\
5 / 88\end{array}$ & $\begin{array}{l}36 \\
36\end{array}$ & $\begin{array}{l}\mathrm{NP} \\
\mathrm{NP}\end{array}$ & & $\begin{array}{l}17 \\
21\end{array}$ & 3 & & & & \\
\hline
\end{tabular}

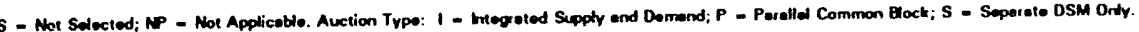

.

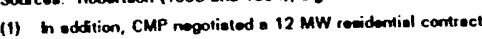


ESCO contracts and 33 customer contracts. In contrast, among 19 other utilities that have announced winning bids, ESCOs received 64 contracts, while customers received 15 contracts. ${ }^{1}$ In terms of MWs, ESCO bids account for $87 \%$ of the demand reductions (see Figure 2-2).

Customers have offered various reasons for their low (direct) participation rates in process evaluations conducted for several DSM bidding programs. First, many customers commented that bid preparation was very costly and time-consuming. In Colorado, one customer, who hired an engineer to develop a proposal for several facilities, paid about $\$ 27,000$ in fees (Barakat \& Chamberlin Inc. 1992). Successful customer bidders also indicated that proposals typically required between two and three months and several hundred hours to prepare. Bidders in Maine indicated that proposals cost between $\$ 5,000$

Figure 2-2. Winning Bids by ESCOs and Customers

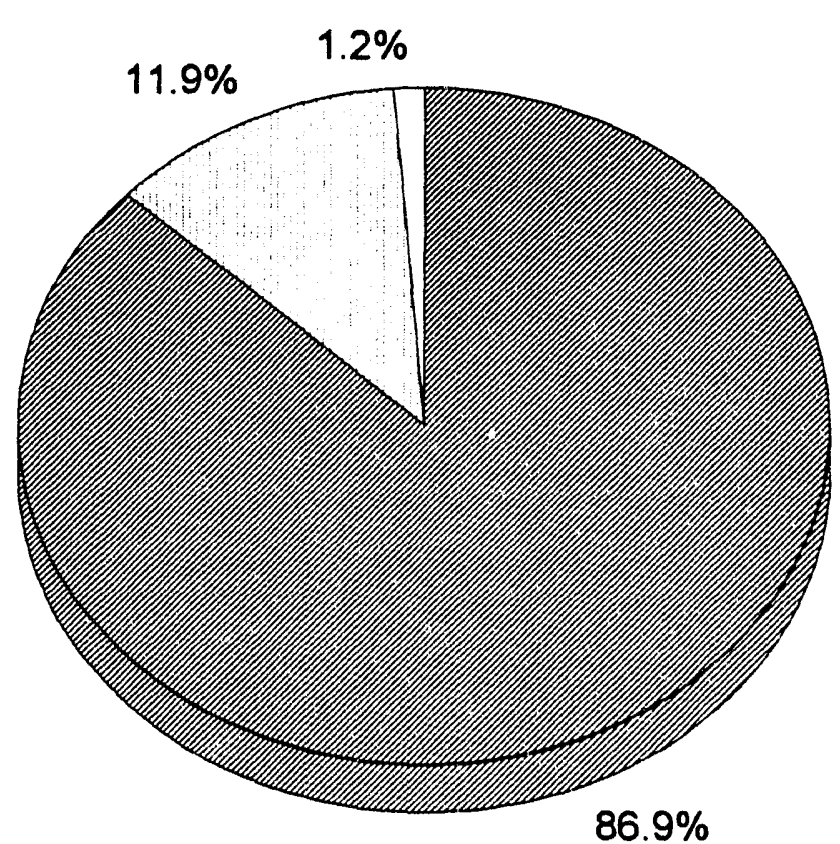

ESCOs, $358 \mathrm{MW}$

Customers, $49 \mathrm{MW}$

Other, $5 \mathrm{MW}$

$86.9 \%$

Notes: Includes results fom the 21 programs that have announced winning bidders.

Sources: Signed cortracts, trade publications, and personal communications with program managers.

1 These numbers include DSM bidders selected by utilities for final award groups and may change if bidders and utilities are unable to complete contract negotiations successfully. 
and $\$ 50,000$ to prepare (ERCE 1991). Second, perceived risks are high compared to opportunities offered through utility rebate programs (Barakat \& Chamberlin Inc. 1992). Some customers indicated that they prefer utility rebate programs because they do not have to guarantee energy savings over long contract terms.

- $\quad$ Market response by DSM providers, as indicated by MWs offered and number of bids submitted, has increased significantly since the late $1980 \mathrm{~s}$, although ESCOs are becoming more selective in their participation.

In more recent solicitations (e.g., 1991-92), utilities have typically received between 1040 DSM proposals, with one or two exceptions. It is not uncommon for DSM bidders in aggregate to propose over $100 \mathrm{MW}$ in demand reductions in response to RFPs issued by larger utilities. In contrast, the number of DSM bids submitted in the 1987-89 time period typically ranged between eight and fifteen bids in RFPs issued by utilities in Maine, New Jersey, and Washington. The increasing number of DSM bids and MWs offered in these solicitations is attributable both to entry by new firms and larger bid size.

In interpreting these trends, it is important to note that many utilities allow potential DSM bidders to submit more than one proposal. To illustrate, Southern California Edison received multiple bids from four of the ten ESCOs that submitted proposals in its DSMonly bidding program. ESCOs are also becoming more selective in deciding whether or not to participate in bidding programs. Given the proliferation of bidding programs, ESCOs that operate nationally have indicated that they also consider such factors as the utility's motivation (e.g., utility-initiated or mandated by regulators), program objectives, and attitude toward ESCOs in deciding whether to invest resources in bid preparation. Program design features, including threshold and eligibility requirements, can also have a significant effect on the number of bids submitted. For example, Con Edison received only four DSM bids for $12 \mathrm{MWs}$ in response to an integrated, all-source RFP for 200 MW. Threshold and eligibility requirements established by Con Edison apparently discouraged many prospective DSM bidders (Goldman et al. 1993).

- Demand reductions offered by ESCOs and customer bidders in bidding programs have typically been insufficient to fill the entire capacity needs of utilities with large resource blocks (200 - $300 \mathrm{MWs).}$

On average, DSM bids represented only about $40 \%$ of the quantity requested by the utility in those solicitatiuns that included both supply and DSM options (i.e., either an integrated or parallel common block RFP). However, these solicitations tend to be heavily over-subscribed by private power producers who typically have proposed between three to 20 times the capacity need requested by utilities. DSM bidders proposed about 
three times the quantity of capacity savings requested by those utilities that conducted separate auctions for DSM. This result is not surprising because the integrated or parallel common block RFPs tend to be significantly larger than separate auctions for DSM (i.e., 200 MWs where both supply and DSM options are included vs. 40 MWs in DSM-only).

- Success rates for DSM bidders have been relatively high (25 - 40\%), particularly in auctions in which both supply and DSM bidders compete. ${ }^{2}$

On average, DSM bidders had a success rate of nearly 40 percent in 13 of the integrated and parallel auctions that have been completed, while supply-side bidders had an average success rate of 13 percent (see Appendix A). ${ }^{3}$ On average, DSM bidders had about a $25 \%$ chance of being awarded contracts for RFPs that were limited to DSM projects only. The high success rates of DSM bidders compared to supply-side bidders reflect both their favorable economics as well as the degree of market maturity. In reviewing results from the first round of bidding in New Jersey, a report prepared by commission staff concluded that:

The fact that virtually all DSM proposals were awarded contracts, combined with the fact that the total capacity offered by DSM projects is significantly less than the bid block, indicates that DSM projects are not required to compete to any significant degree with other DSM projects in order to be awarded a contract.... Compared to the market for supply side projects, the DSM market is in its relative infancy and has not yet demonstrated a proven ability to offset large (100 MW) blocks of capacity (Chilton and Ambrosio 1992).

- A number of ESCOs have developed a limited national presence through their involvement in utility DSM bidding programs. The DSM bidding market is not dominated currently by firms that are utility affiliates or subsidiaries.

A handful of ESCOs have developed a national presence, in the sense that they have signed contracts in DSM bidding programs in different regions of the U.S. (see Table $2-2){ }^{4}$

2 We define success rates as the percent of winning DSM bids compared to bids initially proposed.

3 A comprehensive survey by Current Competition (Robertson 1993a) of all utility bidding programs found that DSM and supply-side bidders had success rates of $25 \%$ and $6 \%$ respectively (both in terms of numbers of bids and MWs). This survey also included supply-side only bidding programs, while the LBL sample was more limited.

4 This table does not include results for utilities that have announced Final Award Group but have not yet signed contracts (e.g. Southern California Edison, San Diego Gas \& Electric, Duke Power, Puget Power's 2nd RFP, and Nevada Power). 
Table 2-2. Activity of ESCOs in Utility DSM Bidding Market

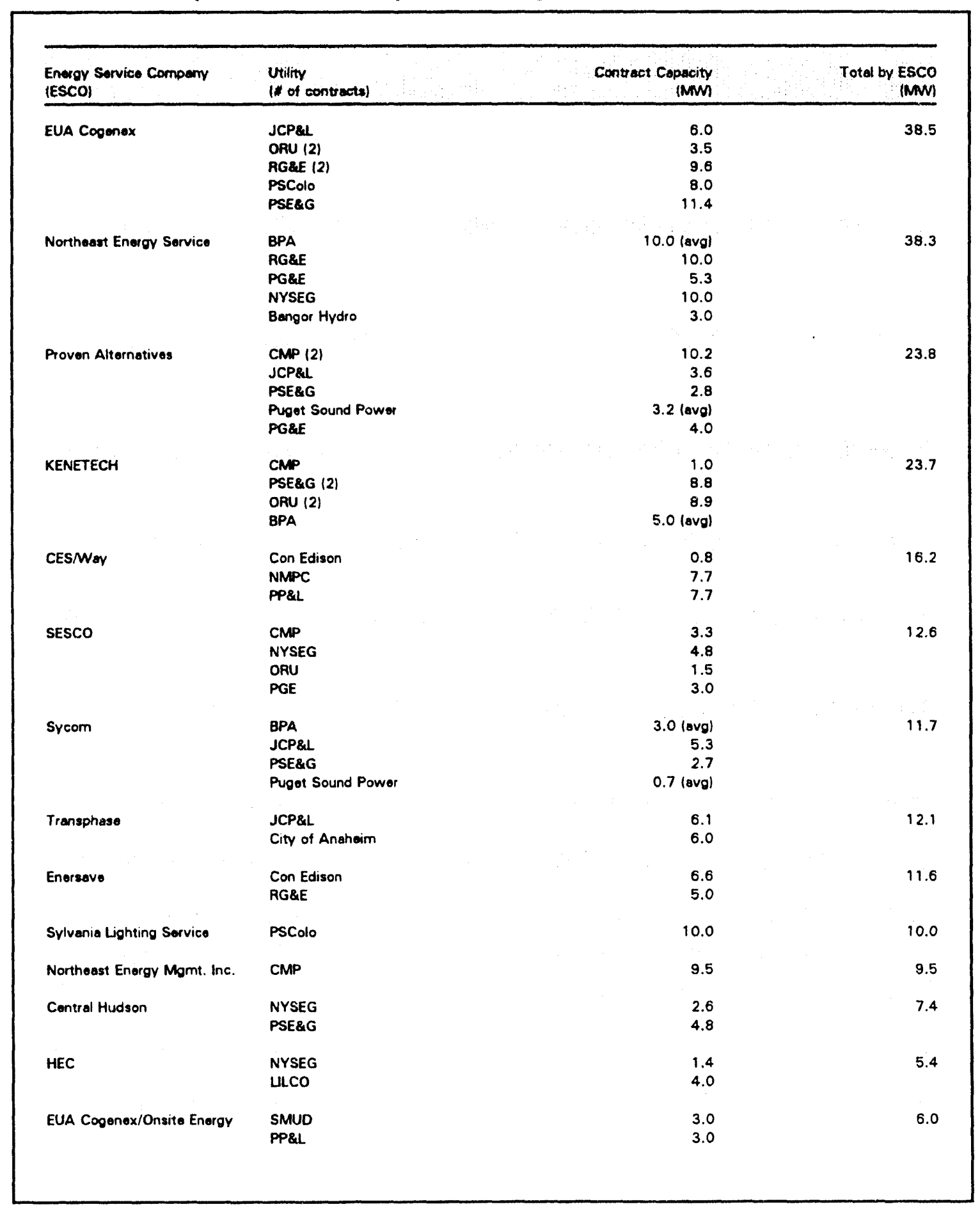


Figure 2-3. Utility Ownership in Winning Supply and DSM Contracts

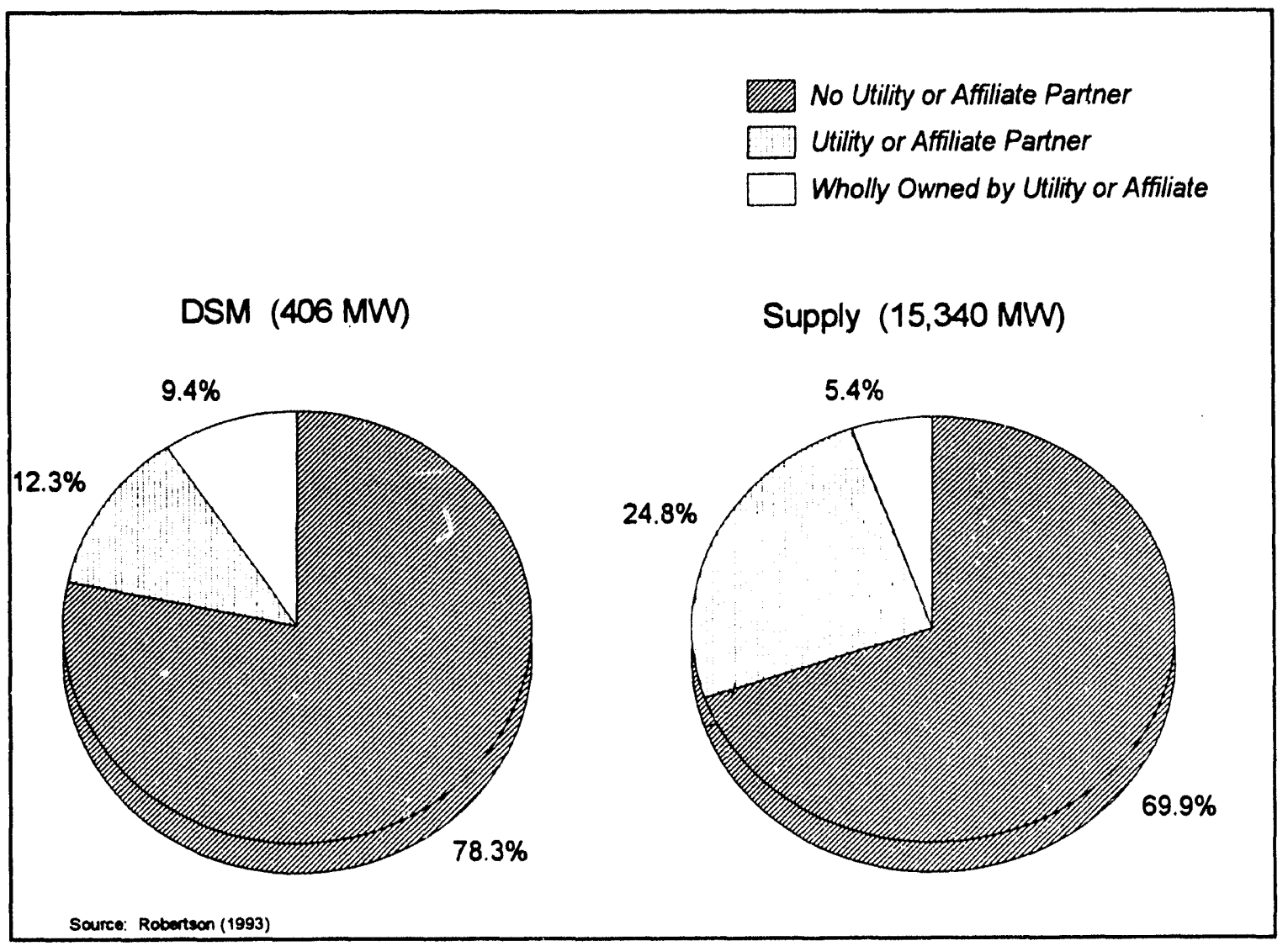

Several of these ESCOs are either affiliates or subsidiaries of electric utilities: EUA Cogenex, Sycom, Central Hudson, HEC Inc., and Northeast Energy Management. ${ }^{5}$ Other ESCOs (e.g., CES/Way, Enersave, KENETECH Energy Management, Northeast Energy Services, Onsite Energy, Proven Alternatives, and SESCO) that have been active in utility DSM bidding programs are "independents" in the sense that they are not utility affiliates or subsidiaries. At the present time, the DSM bidding market does not appear to be dominated by ESCOs that are utility affiliates or subsidiaries. For example, a recent survey found that among the 128 ESCO projects awarded contracts through DSM bidding (representing over $400 \mathrm{MW}$ ), $79 \%$ had no utility affiliation, $12 \%$ had a utility or utilityaffiliated partner, and $9 \%$ are wholly owned by a utility or utility affiliate (Robertson 1993b). ${ }^{6}$

5 EUA Cogenex recently announced its intention to acquire Northeast Energy Management, Inc. (NEMI) (Demand-Side Report 1993a).

6 These figures are percentages in terms of total MW. 
By comparison, utility affiliates or subsidiaries have been more involved in the independent power market. Among 218 winning supply projects (representing about $15,340 \mathrm{MW}), 70 \%$ had no utility affiliation, $25 \%$ had a utility or utility-affiliated partner, and $5 \%$ were wholly-owned by a utility or utility affiliate (see Figure 2-3). However, as more utilities analyze the potential business opportunities in the energy services industry, this situation could easily change.

- Barriers to entry appear low in the DSM bidding market as a number of local firms have attempted to enter the market.

New players continue to enter the DSM bidding market as barriers to entry appear low for energy service companies. While customer participation as bidders has not increased much, barriers to entry appear low for new energy service companies. Often, new entrants in the DSM bidding market are local firms that have traditionally offered various types of energy services (e.g., energy audits, design and engineering, installation services). For example, Pacific Gas \& Electric's initial award group of 13 projects consisted of four customer bids and six bids from local energy service firms that had not previously offered these services (PG\&E 1993b). In Public Service of Colorado's second $50 \mathrm{MW}$ RFP, the initial award group consisted of eight local firms that proposed about 23 MWs of demand reductions (Demand-Side Report 1993b).

- $\quad$ Development failure rates for DSM bidders are comparable to supply-side bidders (about 20\%). In some cases, utilities cancelled projects rather than developers, often claiming that projects had become uneconomic because avoided supply costs had declined.

DSM bidders have a fairly good track record of successfully developing projects, although the majority of MWs awarded through DSM bidding programs are still under development (see Figure 2-4). According to a recent survey, 24 DSM bids representing over 75 MWs have been cancelled (Robertson 1993a). In terms of MWs, these cancelled projects represent about 18 percent of the DSM bids awarded contracts. In most cases, contracts were cancelled prior to contract execution; only four contracts (representing 21 MW) were cancelled subsequent to contract execution. ${ }^{7}$ Utilities initiated the cancellation decision in many cases (for bids representing $34 \mathrm{MWs}$ of the $75 \mathrm{MWs}$ that have been cancelled), often claiming that the economics of a DSM bid were no longer favorable because of declining avoided costs.

7 There were unusual circumstances in several of the contracts that were cancelled after execution. For example, Transphase accepted an offer by PSE\&G to cancel its contract and sign up under the utility's Standard Offer program. Similarly, Sycom accepted an offer by JCP\&L to participate in a new performance contracting program developed by the utility. 
Figure 2-4. Status of Winning Projects

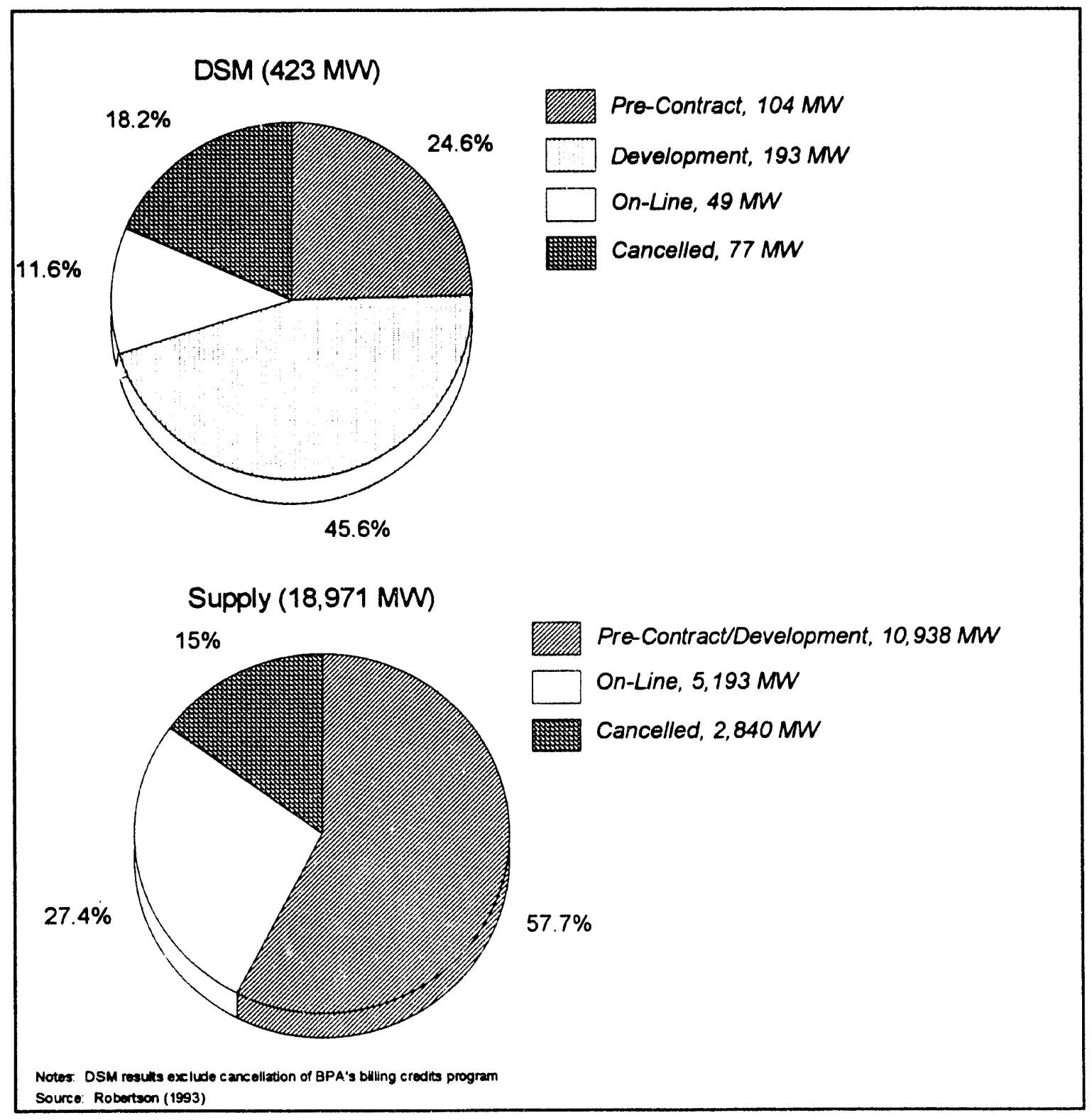




\subsection{Summary of Utility Bidding and Performance Contracting Programs}

Most bidding programs are still in relatively early stages of implementation. Few utilities have completed the entire program cycle from initial solicitation, to achievement of contract savings goals, to maintenance of ongoing projects over the contract lifetime. This section provides a brief overview of those bidding programs that are farthest along in the program cycle as defined by the utility having signed contracts with winning bidders and the availability of information on bid prices and program costs. For each program, we describe its regulatory context, highlight distinctive program design features, and summarize current status. Several early performance contracting programs that relied on ESCOs to deliver energy conservation services are also included: New England Electric Systems' Performance Contracting Program and Boston Edison's Energy Conservation Retrofit (ENCORE) Program. ${ }^{8}$ These programs were the precursors to DSM bidding programs in that competitive solicitations were used to select qualified ESCOs and that payments to ESCOs were based on energy and demand savings. These two programs are included primarily because they have completed the program cycle and information is available on costs and savings. Historically, most performance contracting programs were developed by utilities in the context of experiments with alternative DSM program delivery mechanisms, whereas DSM bidding programs are generally instituted as part of a formal integrated resource planning and acquisition process.

\subsubsection{New England Electric System: Performance Contracting Program}

In NEES' Performance Contracting Program, begun in 1987, third parties were asked to propose a total demand reduction and payment per $\mathrm{kW}$ of reduction for specific groups of large C/I customers. ESCOs were selected mostly on bid price, although qualifications were a major factor. Distinctive features include: (1) one-time, up-front payments to ESCOs, (2) payments based on engineering estimates of demand reduction which were adjusted to represent the load shape impacts of various conservation measures, and (3) performance bond requirements equal to one-half the dollar amount of the bid (subsequently changed to one-third). ${ }^{9}$ As of April 1991, the three ESCOs selected as contractors had delivered $17 \mathrm{MWs}$ of demand reductions. The program ended in 1991,

8 Other utilities have experimented with performance contracting programs, but are not included because program results were not readily available.

9 NEES developed adjustment factors for three types of facilities (based on hours of operation) for some 30 measures (Michaels 1988). The goal was to convert the design demand reduction for each standard measure into an approximate uniform demand reduction during all hours of the day for a period of ten years. 
but NEES continues to work with ESCOs on various types of performance contracting programs.

\subsubsection{Boston Edison Company: Encore Program}

In 1987, Boston Edison (BECo) initiated its ENCORE program in response to a Massachusetts Department of Public Utilities (DPU) order that directed the utility to test third-party delivery mechanisms. In the ENCORE program, ESCOs competitively bid a price for measured $\mathrm{kWh}$ savings on a project-by-project basis. BECo utilized a group of pre-approved energy service contractors that marketed the program to large $\mathrm{C} / \mathrm{I}$ customers. The ENCORE program featured a three-party contract between the utility, ESCO, and customer. The utility reviewed ESCOs' proposals and had to approve the measurement and verification method. Contractors were paid periodically over the contract term, which was typically ten years. Customers were required to obtain several bids from ESCOs. Under the ENCORE program, BECo signed contracts with ESCOs and customers representing about $21 \mathrm{MWs}$ of demand reductions before the program was ended in 1991. Currently, BECo continues to monitor savings through its annual payments.

\subsubsection{Maine}

Central Maine Power (CMP) was the first utility to implement an integrated bidding program in which DSM projects competed with supply-side resources. Under its Power Partners Program, CMP has issued two Request for Proposals (RFPs), in December 1987 and May 1989, that built upon previous supply-only auctions and the utility's experiences with performance contracting with ESCOs.

Distinctive features of CMP's bidding program include: (1) all projects were required to have a payback period of one year or greater, and pass the equivalent of the Total Resource Cost test, ${ }^{10}$ (2) the utility retained substantial discretion during the bid evaluation process to select among competing projects and placed a strong emphasis on negotiations to resolve implementation issues, (3) the sample contract included security deposits to ensure project completion which were relatively high compared to most other utilities $(\$ 108 / \mathrm{kW}$ vs. $\$ 15-18 / \mathrm{kW})$ CMP also made a number of modifications in its second Power Partners RFP. These changes included placing additional value on

10 The total resource cost test compares the benefits from DSM (in terms of avoided costs) to the $t$ tal costs, including measure, installation, incremental operation and maintenance, and any program administration costs regardless of who bears the costs. 
measured savings in bid evaluation and lack of a posted benchmark or ceiling price (CMP 1987; CMP 1989; Linn 1992).

CMP has the most actual field experience implementing DSM bidding programs. Nearly all of the projects from the first RFP are on-line, and a few of the projects from the second RFP have begun delivering energy savings.

\subsubsection{New Jersey}

New Jersey's bidding program was the result of a 1988 settlement agreement among the state's four electric investor-owned utilities, the New Jersey Board of Regulatory Commissioners (NJBRC), and various interested parties. The settlement agreement was quite comprehensive and detailed, and was designed to address problems that had arisen under PURPA because of the "first-come, first serve" standard offer contracts for Qualified Facilities. The agreement established the frequency of competitive solicitations (annually, if required), placed limits on participation by utility affiliates, prescribed methods to be used in determining capacity need and bid ceiling price, established security provisions and performance guarantees, and included certain limits on the weights to be assigned to various categories in the ranking of project bids (NJBRC 1988).

As a result of the settlement agreement, Public Service Electric \& Gas (PSE\&G), Jersey Central Power \& Light (JCP\&L), and Orange and Rockland (ORU) issued all-source solicitations in 1989 in which supply and demand-side resources effectively competed against one another. ${ }^{11}$ Distinctive features of the initial RFPs issued by New Jersey utilities were: (1) exclusive reliance on an objective, self-scoring system to select and rank winning bidders, (2) DSM ceiling price based on the utility's avoided cost of supply, (3) non-refundable application fees of \$5,000 for both JCP\&L and PSE\&G, and (4) emphasis on payment for delivered energy savings over the term of the contracts.

ESCOs are fairly far along in terms of implementing the initial contracts signed with utilities in New Jersey. Those ESCOs working in the ORU service territory in New Jersey have nearly completed their projects, while several ESCOs are still attempting to meet their contract obligations with JCP\&L and PSE\&G.

11 ORU issued a solicitation for $150 \mathrm{MWs}$ for both supply and demand-side resources. ORU's territory spans both New Jersey and New York and thus found itself in the unique position of designing a bidding system that was acceptable to two regulatory commissions. Ultimately, ORU decided that the best way to handle concerns raised by the various parties in each state and the constraints of the regulatory process was to issue separate demand-side RFPs for its New York and New Jersey service territories. 
In 1991, the BRC made several major changes in its DSM policies and regulations that strongly influenced the implementation and evolution of DSM bidding in New Jersey. The BRC approved two different types of financial incentives for utility shareholders. Utilities could apply for a "shared savings" incentive mechanism in which the utility would retain a share of the net benefits obtained from specified DSM resource programs. Alternatively, the utility could issue a DSM standard offer under which a single price is offered for delivered savings under specified terms and conditions. Under the DSM standard offer, qualifying energy service companies (including utility affiliates) would be allowed to retain any profits over their costs. In terms of resource acquisition, integrated bidding was effectively discontinued under the DSM standard offer approach, while utilities that chose the shared savings incentive approach were still required to comply with the existing BRC regulations on competitive bidding for supply and DSM (Goldman 1992). In May 1993, PSE\&G issued a standard offer for 150 MWs of DSM, which has received strong interest from the ESCO industry (Demand-Side Report 1993c). JCP\&L prefers the shared savings incentive and has developed a partnership approach with ESCOs as its delivery arm.

\subsubsection{New York}

In June 1988, the New York Public Service Commission (NYPSC) issued an order that directed each of New York's seven investor-owned utilities to develop bidding programs that "provide a comprehensive test of their future power supply choices, including load management" (NYPSC 1988). The PSC established minimum requirements for the initial auctions including requirements that supply and DSM options be included and environmental externalities be considered (Mills 1989).

The PSC provided utilities with considerable latitude in developing their bidding programs and did not specifically require integrated auctions. Nonetheless, four utilities, Niagara Mohawk Power Corporation (NMPC), Consolidated Edison (Con Edison), New York State Electric and Gas (NYSEG), and Orange and Rockland (ORU) conducted integrated auctions that included parallel scoring methods for supply and DSM proposals in the initial stage. In contrast, Long Island Lighting Company (LILCO), Rochester Gas \& Electric (RG\&E), and Central Hudson conducted separate DSM and supply bidding programs with a specified capacity block for each resource.

The distinctive features of each utility's bidding program include:

- $\quad$ ORU had a common resource block, but established ceiling prices for DSM at about $\$ 500 / \mathrm{kW}$, which was well below the avoided cost of supply. One-time upfront payments were made to winning DSM bidders based upon the installation 
of pre-specified demand reduction measures. ORU relied upon an objective, selfscoring system and limited the number of winning bidders to three ESCOs (and an unlimited number of customers) in each of two New York franchise areas.

- NMPC conducted an integrated auction for $350 \mathrm{MW}$, although the company established a goal of $50 \mathrm{MWs}$ for DSM. NMPC used a two-phase scoring system. Initially, an independent third party ranked bids using a self-scoring system. In phase two, the utility selected a final award group after conducting a more detailed evaluation of individual projects and alternative portfolios using system optimization models and management judgment. This two-phase approach was used in part because NMPC submitted a plant refurbishment project as a bid in its own RFP.

- LILCO modelled its DSM bidding program after its commercial/industrial rebate program (i.e., Dollars and Sense). The utility set ceiling prices at 30 percent above its own program costs for seven separate measures. LILCO agreed to provide up-front payments based on verified measure installation and to award contracts to two or more ESCOs (and to an unlimited number of customers) in each of two franchise areas. LILCO also agreed not to compete with contractors for a specified period of time.

- $\quad$ Con Edison developed an integrated bidding system that ranked supply and DSM bids using a common scoring system and relied on relatively stringent threshold requirements for non-price factors. Specifically, Con Edison required DSM bidders to have signed letters of intent from all participating customers as a threshold requirement. Con Edison limited eligible measures to those offered under its current DSM rebate programs and set ceiling prices at 50 percent above its own program cost for a variety of commercial, industrial and residential measures. All measures were required to have payback period of two years or more. Con Edison agreed to provide payments based upon demand reductions that persisted over the life of the contracts. The minimum contract term was ten years.

- $\quad$ NYSEG's conducted a $130 \mathrm{MW}$ bidding program, but specified a $30 \mathrm{MW}$ goal for DSM. Eligible measures included those that were "technically proven and commercially available," but excluded measures that relied "upon continuing customer behavior" such as lowering thermostats. NYSEG set no ceiling price, but scored its own alternative to set the minimum qualifying score.

- $\quad$ RG\&E and Central Hudson each developed parallel but separate auctions for supply and DSM options for 50 and $20 \mathrm{MWs}$ respectively. One distinctive feature of RG\&E's bidding program was its use of a scoring system in which points were 
computed by multiplying (rather than adding) scores of various factors (e.g., price, likelihood of success, longevity). Central Hudson's RFP focused on supply and DSM options that provided summer peak demand reductions to the utility.

The utilities issued their RFPs in 1989 and 1990 and are currently at different stages of implementation. Contracts have been signed with winning bidders at six utilities. Central Hudson rejected all DSM bids.

\subsubsection{Washington}

In July 1989, the Washington Utilities and Transportation Commission (WUTC) issued regulations governing acquisition of resources from qualifying facilities, independent power producers, utility subsidiaries and other utilities, as well as conservation measures. ${ }^{12}$ Among other provisions, the regulations allowed utility affiliates to participate in bidding, established method to determine avoided costs, specified ranking criteria, including price, dispatchability, ratepayer risks, and environmental effects, and required front-loaded project security (WUTC 1989).

Consistent with draft WUTC regulations, Puget Power issued its first RFP in June 1989, which specified evaluation criteria for generation and DSM projects (Puget 1989). Eligible DSM bids were limited to conservation measures in the commercial and industrial sectors. The RFP had several distinctive features: (1) the utility listed its ranking criteria qualitatively, did not assign explicit weights to various factors, and relied on a subjective evaluation process, (2) DSM ceiling prices were set slightly below the avoided cost of supply in order to account for customer contributions, and (3) Puget allowed unregulated utility subsidiaries and affiliates to bid with relatively few restrictions.

In September 1991, Puget issued its second RFP, which consisted of six separate solicitations: an RFP for general conservation, three RFPs for conservation in multifamily dwellings (insulated doors, insulated glass, and building insulation), one RFP for conservation by large customers, and a generation resources RFP (Puget 1991). The utility identified six general evaluation criteria but, again, did not assign quantitative weights. In contrast to its first RFP, the utility did not establish a ceiling price for DSM bids, but used the avoided cost of supply as a reference in scoring bids.

12 These rules were a continuation of the process that initially resulted in the development of integrated resource planning rules. 
Puget signed contracts for $10 \mathrm{MW}$ of DSM from its first RFP, but does not expect all projects to come on-line. One ESCO cancelled its contract because customers were unwilling to sign and take the risks associated with 10-year contracts. Puget has not yet negotiated contracts with initial award group winners from its second RFP.

Washington Water Power (WWP) issued an integrated RFP for $150 \mathrm{MW}$ in September 1991. WWP initially rejected all supply bids and selected one DSM bidder for two MW. The utility ultimately deferred the DSM bid because load growth was lower than projected, reducing the utility's reed for new resources.

\subsubsection{Colorado}

Public Service of Colorado (PSColo) has issued two $50 \mathrm{MW}$ DSM-only RFPs (PSColo 1990). PSColo was primarily interested in reducing electricity use during its peak period ( 8 a.m. to 10 p.m. weekdays). While these bidding programs were utility-initiated, the Colorado Public Utilities Commission has approved a settlement agreement that provides for special cost recovery treatment and the opportunity for utility shareholders to earn financial incentives (Finleon et al. 1992). ${ }^{13}$

PSColo's bidding program provided DSM developers with one-time up-front payments for demand reduction measures with lifetimes of at least ten years. The bidding program had a number of distinctive features: (1) DSM developers were allowed to propose a wide variety of demand reduction measures including fuel-switching projects (electric to gas) and new construction projects, (2) the utility did not reveal its avoided costs or bid ceiling prices, but set a relatively low reference price of $\$ 240 / \mathrm{kW}$, (3) bidders were required to self-score their proposals and submit a separate score for each measure, (4) and winning bidders were required to provide a cash deposit of $\$ 20 / \mathrm{kW}$ that would be returned at the end of the contract term. ${ }^{14}$

PSColo has completed negotiations for most projects in its first RFP and bidders are implementing their proposals. PSColo recently announced the initial award group for its second RFP (Demand-Side Report 1993b).

13 Under the terms of the agreement, PSColo may begin recovering program costs in the year following the expenditures for the DSM bidding program and will receive an incentive equal to five percent of the annual avoided cost if the DSM measures average $\$ 240 / \mathrm{kW}$ and have a life of 13 years.

14 Most other utilities allow bidders to provide other forms of security (e.g., letter of credit) and return the deposit after the project has been completed rather than at the end of the contract term. 


\subsubsection{California}

In 1990, the California Public Utilities Commission (CPUC) and the state's investorowned utilities were directed in a law passed by the State Legislature to conduct several types of pilot bidding programs. The law requires one or more electric utilities to test the ability of DSM bidding to deliver benefits to utility customers; another bidding RFP is to be issued to assess "the feasibility of an integrated bidding system that includes both generation resource and demand side programs;" and gas utilities are also to conduct a pilot DSM bidding program (CPUC).

In March 1992, the CPUC approved a $20 \mathrm{MW}$ pilot DSM bidding program for Pacific Gas and Electric (PG\&E) (CPUC 1992b). Distinctive features of PG\&E's approach include: (1) an explicit attempt to create a partnership with winning bidders during program implementation, and (2) a scoring system in which the utility specified quantitative weights for various criteria that would be used in its bid evaluation for various evaluation criteria, but which was not self-scoring. PG\&E completed negotiations with winning bidders and ten contracts have been be approved by the CPUC. PG\&E is currently developing a pilot integrated bidding RFP, which will be issued in late 1994.

Southern California Edison (SCE) and San Diego Gas \& Electric (SDG\&E) issued DSMonly RFPs that are designed to compete directly with and potentially replace existing utility DSM programs (CPUC 1992a). SCE's two RFPs targeted large and small commercial/industrial customers in two geographic regions of its service territory. SDG\&E's solicitation requested proposals from third party firms that targeted existing residential customers. As of March 1994, both utilities have announced winning bidders and are currently involved in contract negotiations.

Two municipal utilities have also initiated DSM bidding programs: the City of Anaheim and the Sacramento Municipal Utilities District. Both utilities have completed contract negotiations. The Northern California Power Agency, a California Joint Powers Agency, issued a 200 MW RFP in 1991 and has completed contract negotiations with one ESCO. 


\section{The Cost and Value of DSM Bidding Programs}

\subsection{Overview}

This chapter examines the costs of DSM acquired through bidding programs. Developing estimates of the total resource cost of DSM bidding programs is important for two reasons. First, a number of analysts have raised concerns that the actual societal cost of acquiring DSM resources through utility programs is significantly understated, in part because utilities are relying on pre-program savings estimates that are often too optimistic and an incomplete accounting of total costs (i.e., customer cost contribution) (Joskow and Marron 1992). In DSM bidding programs, utilities typically only pay for energy savings that are verified over the contract term, which reduces one major source of uncertainty in the actual costs of these programs. Second, some proponents of DSM bidding argued that these programs could provide a benchmark against which to judge utility DSM efforts. Thus, analyzing information on the costs of acquiring DSM resources through bidding programs can provide insights on the relative merits of DSM bidding compared to other types of utility DSM program designs. As a starting point, we compared bid projects that target similar end uses, specifically lighting opportunities for large $\mathrm{C} / \mathrm{I}$ customers, with other utility-sponsored DSM programs in order to facilitate a more direct comparison of the cost-effectiveness of alternate program delivery mechanisms. We find that the total resource costs of DSM bidding projects are slightly higher than those for a sample of utility lighting programs, although the distribution of costs differs significantly among the two types of programs.

We collect data on the various cost components - prices paid to winning bidders, the utility's costs of administering these programs, and costs incurred by host customers. We analyze factors that influence DSM bid prices in some detail because payments to winning bidders are currently the major cost component in these programs. This issue is important because utilities are increasingly concerned about minimizing costs to the utility of acquiring DSM resources and encouraging participants to bear a greater share of DSM program costs.

We comment briefly on the net resource benefits of DSM bidding programs, which depends on both the cost and value of these programs. Value is traditionally measured with utility-specific avoided costs that can vary significantly over time and across regions. We compare the utility's avoided supply costs to total resource costs to provide some indication of overall cost-effectiveness from a societal perspective. Not surprisingly, we find a strong correlation between a utility's DSM bidding program costs and its avoided supply costs. We also discuss the limitations of using avoided supply costs as the metric for determining "value" in DSM bidding programs. 


\subsection{Approach}

In order to calculate the total resource cost of each bidding program, we collected information on program costs (including utility payments to DSM developers, utility administrative costs, and costs incurred by host customer), annual energy and peak demand savings, and contract and project lifetimes. One difficulty in comparing costs among programs is that payment structures vary from contract to contract and also among utilities. Winning bidders typically receive either a one-time upfront payment, payments that are front-loaded in the early years of the contract, or payment streams that are levelized or ramped upward over the contract term. Payments for energy savings and demand reductions are often time- or seasonally-differentiated as well. In order to compare contracts with varying payment streams, levelized costs (in c/kWh) were calculated for each individual contract. ${ }^{15}$ We first estimated the net present value (NPV) of the payment stream, which was then levelized over the contract term, and then divided this levelized payment stream by the annual energy savings, which were also levelized. Because of confidentiality concerns, levelized costs of individual contracts were then aggregated to the utility program level, weighted by energy savings. ${ }^{16}$

We report levelized costs in nominal dollars and do not adjust for the effects of varying start dates among projects. Converting nominal costs into constant (e.g., 1993) dollars would have a relatively small impact on overall results among utilities because inflation rates have been low during the past five years and are expected to remain so for the near future. If we had made this adjustment, costs of recent bidding programs would appear relatively more favorable compared to early programs. We indicate the approximate start dates for contract implementation for each utility bidding program. Levelized total resource costs (TRC) were calculated as follows:

$$
\text { Levelized TRC }=(B P+A C+C C) x\left[i(1+i)^{n} /(1+i)^{n}-1\right] / k W h \text { savings }
$$

where:

$\begin{array}{lll}\mathrm{BP} & = & \text { Bid Payments from Utility } \\ \mathrm{AC} & = & \text { Utility's Administrative Costs } \\ \mathrm{CC} & = & \text { Customer Cost Contributions }\end{array}$

15 Levelized costs provides an indication of the cost of each $\mathrm{kWh}$ saved assuming all project costs are financed with a mortgage-type loan, with the term equal to the economic lifetime of the measure (e.g., we used the contract term) and the interest rate equal to the utility's discount rate.

16 Utility program costs are also adjusted for actual implementation experience (e.g., if projects failed to develop, payments and savings are excluded from the program average). 


$\begin{array}{lll}\mathbf{i} & = & \text { Discount Rate } \\ \mathbf{n} & = & \text { Economic Lifetime } \\ \text { kWh savings } & = & \text { Levelized Annual Energy Savings }\end{array}$

\subsubsection{Annual Energy and Peak Demand Savings}

Contracts between DSM developers and utilities typically specify a peak demand reduction goal and annual energy and demand savings over the contract term which includes a ramp-up period ranging between 1-3 years. ${ }^{17}$ When the ramp-up schedule for savings is specified in the contract or is known based on actual implementation experience, we use a method from the engineering economics literature which levelizes an escalating stream of energy savings as well as utility payments (see Appendix B) (Leung and Durning 1978). While most contracts pre-specified the annual energy savings, contracts executed by four utilities specified only the required demand reductions (e.g., two MWs). In these cases, we developed estimates of annual hours of operation in order to estimate electricity savings. ${ }^{18}$

The contracts also include a measurement and verification plan that specifies monitoring procedures and analytic techniques that will be used by the DSM developer to verify energy savings for various types of DSM measures installed at facilities and which provide the basis for the utility's payments to the DSM developer. Not surprisingly, we found that measurement and verification (M\&V) plans tend to be application-specific, varying for individual measures, type of building and market segment, and among utilities and ESCOs. ${ }^{19} \mathrm{M} \& \mathrm{~V}$ techniques include end-use metering, analysis of utility bills before and after installation of DSM measures with normalization for effects of weather and occupant behavior, and measurements of peak demand reduction coupled with various techniques used to estimate hours of operation.

17 Bid payments to developers are typically expressed in terms of $c / k W h, \$ / k W$, or combination of both. Thus, we collect information on the stream of $\mathrm{kWh}$ savings for each contract in order to calculate levelized costs of the other program cost components (i.e., utility administrative costs and customer cost contribution) in $\mathrm{c} / \mathrm{kWh}$.

18 Con Edison provided estimates of annual hours of operation for its contracts. For the ORU (NY) projects, we used a lighting schedule for commercial facilities in New York based on contract analyses prepared by the utility. The LILCO contracts had two years of operating data. PSColo was unable to provide data on estimated hours of operation for individual measures; thus, we made a conservative estimate of minimum hours of operation for all measures in aggregate over an assumed 15-year contract term.

19 The energy service company industry and utilities and PUCs in several states have made initial efforts to develop standardized measurement and verification protocols (NAESCO 1992; PG\&E et al. 1992; PSE\&G 1989). 
In reviewing signed contracts, we found that "free riders" are rarely considered in measurement and verification (M\&V) plans. These $M \& V$ plans focus on techniques for measuring savings from installed measures at project sites, which involves an initial determination of "baseline" energy use and adjustments for other factors (e.g., weather, hours of operation) that might influence savings. However, ESCOs typically do not use comparison groups to establish "net" savings. It is more common for utilities to address "free rider" concerns during the design of bidding programs (e.g., threshold requirements that establish minimum payback period for DSM measures) or in selecting among competing bidders during bid evaluation. ESCOs would also argue that concern over "free riders" is unwarranted in bidding programs, because few host customers would enter into these long-term contracts. ${ }^{20}$ In any event, in most situations, "free riders" will have a relatively small effect on the total resource cost of DSM bidding programs, only to the extent that they cause the utility to incur additional administrative costs (Eto et al. 1993).

\subsubsection{Economic Lifetime of Savings}

The economic lifetime of savings from DSM measures is a critical input to the calculation of total resource costs of energy efficiency. In our analysis, we used the contract term to establish economic lifetimes of individual projects. This approach is quite conservative and is likely to overstate the total resource costs to the extent that actual energy savings extend beyond the term of the contract. In contrast, in determining economic lifetimes, evaluations of utility DSM rebate programs often use equipment lifetimes, which represent an upper bound. In these programs, there are significant uncertainties associated with the duration and persistence of savings, because expected lifetimes are generally much longer than the period over which programs have to date been evaluated (e.g., 1 - 2 years). Recently, a number of utilities have begun to take account of application-specific considerations (e.g., remodeling of office space, probability of premature retirement) explicitly in their estimates of economic lifetime of DSM measures (Eto et al. 1993).

Contract terms ranged between three and 25 years for individual projects. We then computed an average contract term for each utility program, weighting individual contracts by their $\mathrm{kWh}$ savings. At this more aggregate level, contract terms ranged between 7 - 16 years. In theory, one would want to normalize all projects to a standardized planning horizon in order to account for "end effects." However because of methodological difficulties and data limitations, we concluded that it was preferable

20 However, several utilities have raised concerns that some customers would have installed these measures in the absence of the bidding program at some future time while the contract was still in effect. 
to report levelized costs for bidding programs and indicate assumed economic lifetimes explicitly, rather than introduce additional uncertainties into the analysis. ${ }^{21}$

\subsubsection{Program Costs}

In developing estimates of program costs, it was necessary to incorporate information from multiple sources: contracts between winning bidders and utilities, interviews with utility program managers, ESCOs and regulatory staff, and financial reports filed by utilities with regulatory commissions.

Information on bid payments was typically obtained from signed contracts between DSM developers and utilities. We obtained approximately 50 contracts between winning bidders and utilities in New Jersey, New York, California, Colorado, Massachusetts, and Washington. In most cases, bid prices are known and payments can be calculated fairly accurately. However, other utilities have not been required to file contracts with their state regulatory commission or have indicated that their contracts are confidential. In these situations, we relied on information obtained directly from utility program managers, from program evaluations sponsored by the utility, or from trade publications. In some cases, we estimated the likely range of utility payments to DSM developers for the program overall, based on aggregate information provided by utility staff.

Estimates of utility administrative costs were obtained from DSM filings or provided by program managers. The cost to utilities of administering DSM bidding programs includes RFP development costs; time spent on project evaluation, selection, and contract negotiation; regulatory review and possibly approval; and program implementation, monitoring, and verification of savings. In this category, we included costs associated with program implementation and monitoring, but did not account explicitly for costs associated with RFP development, bid evaluation/ranking, and contract negotiations.

Administrative costs appear to be significant in some cases during the initial phases of a bidding program, although many utilities did not track these costs separately. However, several utilities provided rough estimates of internal resources and staff time spent on initial phases. Staffing estimates among utilities range between 2 - 15 full-time equivalent

21 Adjusting for "end effects" would involve adjustments to the cost of shorter term projects because the utility would have to purchase power in order to meet additional demand over the standardized planning horizon. Long-run avoided costs were not readily available for all utilities. 
(FTE) person-years (Peters et al. 1992a). ${ }^{22}$ Based on this information, we estimate that administrative costs for bid evaluation are less than $0.1 \mathrm{c} / \mathrm{kWh}$ and costs incurred by these utilities during contract negotiations range between $0.03-0.3 \mathrm{c} / \mathrm{kWh}$. Variations in administrative costs of RFP development were greatly influenced by the utility's regulatory review and approval process and type of auction (integrated supply and DSM vs. DSM only). We excluded administrative costs incurred during the initial phase for all utilities because of data quality problems and methodological concerns. ${ }^{23}$

Overall, we found that few utilities have systematically collected data on actual customer contributions to the costs of installed measures. In many of the early DSM bidding programs, the program design and scoring system allowed ESCOs to structure their bids so as to recover the bulk of project costs from utility bid payments with little or no cost contribution from host facilities. Thus, customer costs were not a significant consideration for these programs. For more recent programs, estimated customer costs were obtained from interviews with utility program managers and/or ESCOs. Finally, a number of utilities either did not collect or would not provide information on estimated customer costs or did not monitor customer cost contributions during program implementation.

\subsubsection{Discount Rate}

A common discount rate was used in order to facilitate comparisons among utility bidding programs. For this purpose, we chose a nominal discount rate of $11 \%$, which is representative of the weighted average cost of capital for utilities in this study at the time bidding RFPs were issued.

22 For example 4 FTE person-years of staff effort is equivalent to four staff working full time for one year on a bidding program. This effort could be costed out at roughly $\$ 75,000-100,000$ per person year or $\$ 325,000-400,000$ for this hypothetical program.

2 For example, in New York, New Jersey, and California, bidding RFPs were designed over several years in litigated regulatory processes. Utilities in other states (e.g., Jolorado, Indiana, and North Carolina) developed and issued their RFPs without any formal regulatory approval upfront. For bidding programs that included both supply and DSM resources, it would be necessary to develop a method to allocate administrative costs between both resources. 


\subsubsection{Data Quality}

The quality of data on program costs and energy savings are quite uneven among utilities. We developed confidence rankings in three major areas for each utility, which indicates our assessment of data quality: payments to winning bidders (including accuracy of energy savings), the utility's program administrative costs, and costs incurred by the customer (see Table 3-1). Data quality is primarily related to the type and scope of program information that is publicly available, the extent to which utilities (and ESCOs) were willing to provide data, and program maturity. We estimate total resource costs only for those DSM bidding programs that had a confidence ranking of $\mathrm{C}$ or higher for each cost component. Using this criteria, we calculated total resource costs for only ten of 18 bidding programs.

\subsection{Total Resource Costs of DSM Bidding Programs}

Levelized total resource costs (TRC) range between $5.4-8.0 \mathrm{c} / \mathrm{kWh}$ for ten utility DSM bidding programs (see Table 3-2) For comparison, we include the number of contracts analyzed, the actual or expected peak demand reductions, the average contract term and approximate start date for projects, and each utility's avoided supply costs at the time of the RFP for the selected projects. While the sample is small, there is some evidence that total resource costs are coming down somewhat over time, both in terms of absolute costs and as a percentage of the utility's avoided supply costs. For example, total resource costs in the more recent programs in New York and California are in the 5 $6 \mathrm{c} / \mathrm{kWh}$ range compared to the initial programs offered by New Jersey utilities, where total resource costs ranged from $6.5-8 \mathrm{c} / \mathrm{kWh}$. Total resource costs were between 77 $104 \%$ of avoided costs among New Jersey utilities compared to $42-82 \%$ of avoided costs among utilities in New York and California.

The results in New Jersey may be an artifact of the program design implemented by the utilities based on a settlement agreement. DSM bids were evaluated and scored relative to each utility's avoided supply costs as part of integrated supply and DSM solicitations. Estimated customer costs were not included in the price score explicitly, but were capped at the difference between bid price and avoided supply cost as a threshold requirement. Although the bidding programs of several other utilities were integrated supply and DSM RFPs, maximum DSM bid prices were constrained either by lower ceiling prices (Con Edison), an economic analysis that utilized multiple benefit-cost tests (NMPC), or program designs which explicitly indicated that bids would be judged on value relative to the utility's own DSM programs and avoided supply costs (CMP). 
Table 3-1. Confidence Rankings for Program Costs

Confidence

Ranking

Comments

Payments to Bidders

A LBL. reviewed individual contracts and analyzed payment schedules

B Utility provided payment schedules for individual contracts with

C Utility provided aggregated (i.e., program-level) information on utility payments and estimated savings; or contract provides for payment in $\$ / k W$ based on demand reduction and LBL obtained information on actual or estimated hours of operation

D Utility provided average levelized bid prices or range of values without documentation

F Utility provided average payment in terms of $\$ / \mathrm{kW}$, but was unable to provide estimated hours of operation

Administrative Costs

A Utility provided administrative costs based on actual implementation experience, with actual expenditures and projected budgets

B Utility provided administrative costs based on projected budgets

C Utility provided steady-state staffing estimates

D Utility provided estimated administrative costs without

documentation

F Utility unable to provide any information on administrative costs

Customer Cost Contributions

A Utility or ESCO provided information on customer contributions on a contract-by-contract basis, with good documentation

B Contract caps customer cost contributions at difference between bid payments and avoided supply costs; maximum customer cost value shown

C ESCOs provided estimates of customer contributions; quality of the data varies across contracts

D LBL developed estimates of customer contributions by analyzing Utility Cost Test and TRC Test results from utility's bid evaluation;

$F$ these are rough estimates only No information on estimated or actual customer costs 
Table 3-2. Total Resource Costs of Ten DSM Bidding Programs

\begin{tabular}{|c|c|c|c|c|c|c|}
\hline Utility & $\begin{array}{l}\text { Contracts } \\
\text { Analyzed } \\
\text { (\#/MW) }\end{array}$ & $\begin{array}{l}\text { Levelized } \\
\text { Total } \\
\text { Resource Cost } \\
\text { (TRC)(1) } \\
\text { (c/kWh) }\end{array}$ & $\begin{array}{l}\text { Utility } \\
\text { Avoided } \\
\text { Supply } \\
\text { Cost } \\
\text { (c/kWh) }\end{array}$ & $\begin{array}{l}\text { TRC as } \\
\% \text { of } \\
\text { Avoided } \\
\text { Cost }\end{array}$ & $\begin{array}{l}\text { Avg. } \\
\text { Contract } \\
\text { Term } \\
\text { (years) }\end{array}$ & $\begin{array}{l}\text { Approx. } \\
\text { Start } \\
\text { Date of } \\
\text { Contracts }\end{array}$ \\
\hline $\begin{array}{l}\text { BECo } \\
\text { CMP } \\
\text { ORU--NJ } \\
\text { ORU-NY(2) } \\
\text { JCP\&L(3) } \\
\text { PSE\&G(4) } \\
\text { NMPC } \\
\text { LILCO } \\
\text { Con Edison } \\
\text { PG\&E(5) }\end{array}$ & $\begin{array}{c}84+121 \\
6 / 17 \\
4 / 6 \\
4 / 10 \\
2 / 10 \\
7 / 39 \\
5 / 20 \\
2 / 7 \\
2 / 6 \\
10 / 18\end{array}$ & $\begin{array}{l}7.3 \\
6.5 \\
6.5 \\
7.5 \\
8.0 \\
7.1 \\
5.4 \\
6.6 \\
5.6 \\
6.9\end{array}$ & $\begin{array}{c}7.6 \\
6.9 \\
8.5 \\
9.0 \\
8.9 \\
6.9 \\
9.6 \\
9.2 \\
13.3 \\
8.6\end{array}$ & $\begin{array}{c}96 \\
94 \\
77 \\
82 \\
90 \\
104 \\
57 \\
72 \\
42 \\
80\end{array}$ & $\begin{array}{l}10 \\
14 \\
15 \\
10 \\
15 \\
10 \\
15 \\
7 \\
14 \\
10\end{array}$ & $\begin{array}{l}1988 \\
1989 \\
1991 \\
1990 \\
1991 \\
1992 \\
1991 \\
1991 \\
1992 \\
1994\end{array}$ \\
\hline
\end{tabular}

Notes to Table 3-2:

(1) Shareholder incentives not included in these calculations.

(2) The utility includes all bill savings paid from the customer to the ESCO as part of customer contributions.

(3) Includes results for only 2 of 4 contracts. One project was cancelled, the other is a thermal storage project.

(4) Includes all but the thermal storage project. Includes upper bound of customer contributions (which explains why TRC exceeds avoided cost).

(5) In many cases, PG\&E believes measure lifetime exceeds contract term. Levelized TRC values would be 5.1 $\mathrm{C} / \mathrm{kWh}$ and the avoided supply cost $11.0 \mathrm{G} / \mathrm{kWh}$ if these additional sevings are included.

Payments to bidders account for between $70-90 \%$ of total costs in most programs. Cost contributions from host customers are not particularly significant, with two notable exceptions: LILCO and ORU (NY) (see Figure 3-1). At these two utilities, it appears that host customers did pay or will ultimately pay a significant portion of the installed costs of projects at their facilities either through upfront payments or out of bill savings, in part because payments to DSM bidders were constrained rather sharply by low ceiling prices. However, the total resource costs of the LILCO and ORU (NY) bidding programs are not among the lowest in our sample of utilities either in absolute terms or as a percentage of the utility's avoided supply costs. 
Figure 3-1. Total Resource Costs for Ten DSM Bidding Programs

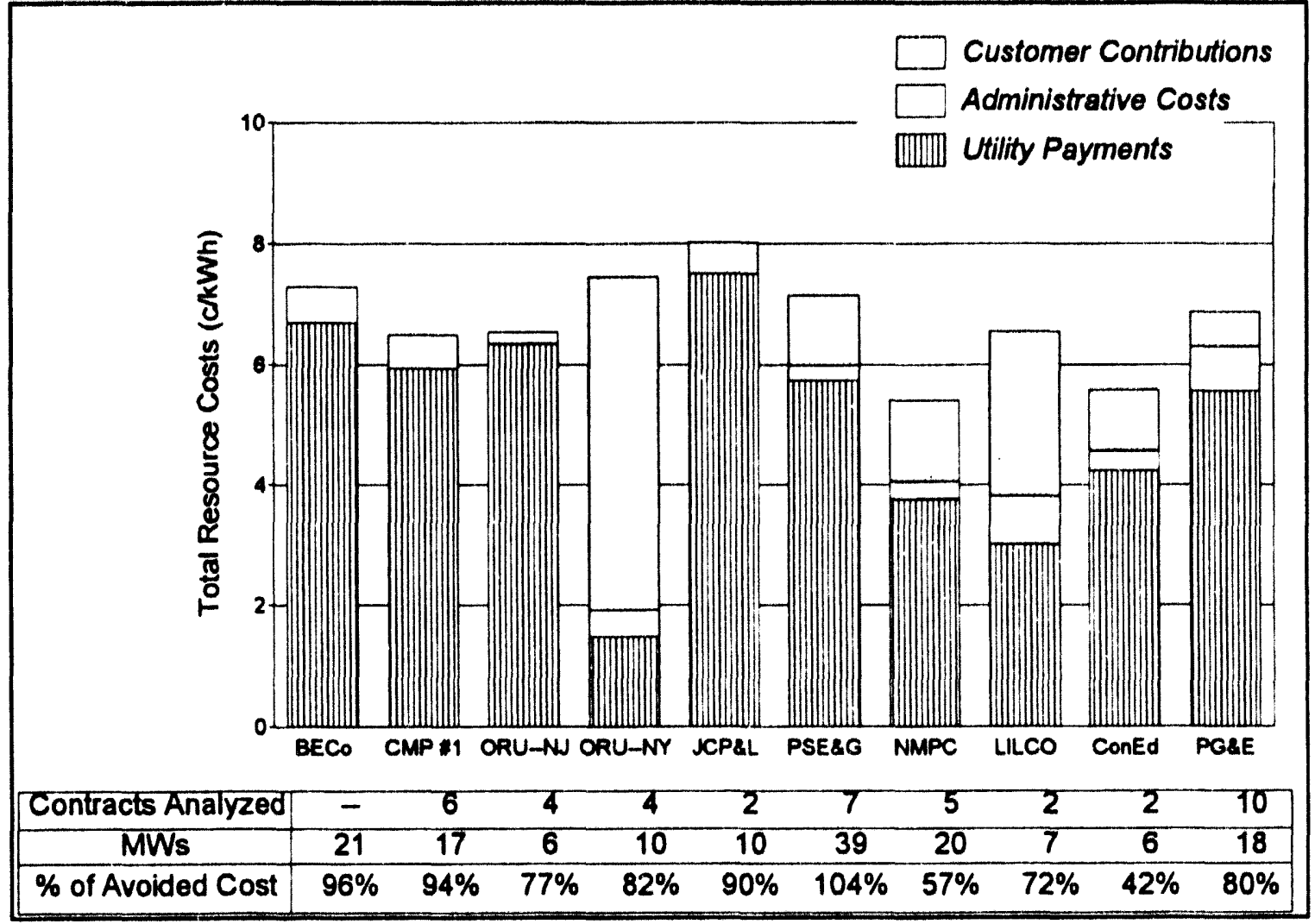

\subsection{Analysis of Program Cost Components}

Table 3-3 summarizes aggregated results for a larger sample of 18 programs for the various program cost components: utility payments to DSM bidders, utility administrative costs, and estimated customer cost contributions (when available). Information is also included on confidence rankings for each cost component, ceiling prices for DSM bids, bid payments as a percent of ceiling price, and estimated start dates and the weightedaverage of contract terms. 
Table 3-3. DSM Bidding Program Cost Components

\begin{tabular}{|c|c|c|c|c|c|c|c|c|c|c|}
\hline Utility & $\begin{array}{c}\text { [A] } \\
\text { Leveliz'd } \\
\text { Utility } \\
\text { Pymts. } \\
\text { to } \\
\text { Bidders } \\
\text { (C/kWh) }\end{array}$ & $\begin{array}{l}\text { Conf. } \\
\text { Renk. }\end{array}$ & $\begin{array}{l}\text { Utility } \\
\text { Admin. } \\
\text { Costs } \\
\text { (c/kWh) }\end{array}$ & $\begin{array}{l}\text { Conf. } \\
\text { Rank }\end{array}$ & $\begin{array}{c}\text { Cust. } \\
\text { Contr. } \\
\text { (c/kWh) }\end{array}$ & $\begin{array}{l}\text { Conf. } \\
\text { Rank }\end{array}$ & $\begin{array}{c}\text { [G] } \\
\text { DSM } \\
\text { Bid } \\
\text { Celling } \\
\text { Price } \\
\text { (C/kWh) }\end{array}$ & $\begin{array}{c}\text { [H] } \\
\text { Bid } \\
\text { Pymts. } \\
\text { as } \\
\% \\
\text { Cailing } \\
\text { Price }\end{array}$ & $\begin{array}{l}\text { Avo. } \\
\text { Contr. } \\
\text { Torm }\end{array}$ & $\begin{array}{c}\text { Approx. } \\
\text { Prom. } \\
\text { Stert } \\
\text { Date }\end{array}$ \\
\hline NEES ${ }^{\prime}$ & $3.5-6.1$ & C & NA & $F$ & NA & $\mathbf{F}$ & NP & $\cdots$ & $3-7$ & 1989 \\
\hline $\begin{array}{l}\text { BECo } 0^{2} \\
C M P \| 1^{3}\end{array}$ & $\begin{array}{c}6.7 \\
5.8-6.1\end{array}$ & $\begin{array}{l}\mathbf{C} \\
\mathbf{B}\end{array}$ & $\begin{array}{l}0.6 \\
0.6\end{array}$ & $\hat{A}$ & $\begin{array}{l}0.0 \\
0.0\end{array}$ & $\begin{array}{l}\mathbf{A} \\
\mathrm{C}\end{array}$ & $\begin{array}{c}7.6 \\
6.6 \cdot 7.2\end{array}$ & $\begin{array}{l}88 \% \\
85- \\
88 \%\end{array}$ & $\begin{array}{l}10 \\
14\end{array}$ & $\begin{array}{l}1988 \\
1989\end{array}$ \\
\hline CMP $\approx 2^{4}$ & $5.6-6.0$ & $\mathbf{B}$ & 0.8 & A & NA & $F$ & NP & $\ldots$ & 11 & 1990 \\
\hline ORU-NY' & 1.5 & C & 0.4 & A & 5.5 & C & 1.8 & $81 \%$ & 11 & 1990 \\
\hline ORU.NS & 6.4 & $\mathbf{A}$ & 0.2 & A & 0.0 & A & 8.5 & $75 \%$ & 15 & 1991 \\
\hline Puget $=1^{\circ}$ & 4.9 & D & 0.1 & D & NA & $\mathbf{F}$ & 5.0 & $98 \%$ & 11 & 1990 \\
\hline JCP\&L' & 7.5 & $\mathbf{A}$ & 0.0 & A & 0.5 & B & 8.9 & $84 \%$ & 15 & 1991 \\
\hline PSE\&G ${ }^{\circ}$ & 5.7 & A & 0.3 & C & 1.2 & B & 6.9 & $83 \%$ & 10 & 1992 \\
\hline NMPC ${ }^{\circ}$ & 3.8 & $\mathbf{A}$ & 0.3 & A & 1.4 & C & 9.6 & $39 \%$ & 15 & 1992 \\
\hline LILCO $^{10}$ & 3.0 & C & 0.8 & A & 2.7 & C & 3.5 & $86 \%$ & 7 & 1991 \\
\hline Con Edison" & 4.2 & B & 0.3 & B & 1.0 & C & 5.5 & $77 \%$ & 14 & 1992 \\
\hline NYSEG $^{12}$ & 4.5 & A & NA & $F$ & 0.7 & $D$ & 9.9 & $46 \%$ & 16 & 1992 \\
\hline RG\&E ${ }^{13}$ & 4.2 & A & NA & $F$ & 1.5 & C & 5.4 & $77 \%$ & 15 & 1993 \\
\hline PSColo $\# 1^{14}$ & 2.7 & $\mathbf{F}$ & 0.8 & D & NA & $\mathbf{F}$ & NP & - & 15 & 1991 \\
\hline SMUD & 3.2 & A & 0.6 & D & 1.9 & C & 4.9 & $66 \%$ & 10 & 1994 \\
\hline PG\&E 10 & 5.6 & $\mathbf{A}$ & 0.7 & B & 0.6 & A & 8.6 & $65 \%$ & 10 & 1994 \\
\hline PSColo $* 2^{17}$ & 2.8 & $\boldsymbol{F}$ & 0.9 & D & NA & $\mathbf{F}$ & NP & - & 15 & 1994 \\
\hline
\end{tabular}

- Confiden ie Ranking

Notes to Table 3-3: NA = Not Aveileble; NP $=$ Not Applicable.

'Renge represe its contrect term (three years) and estimated measure lifetime (seven years).

'BECo (1993).

'The lower bounc excludes residentid contract.

"The lower bounc excludes residential contract.

'The weighted bd price is $\$ 448 / \mathrm{kW}$ and the ceiling price is $\$ 550 / \mathrm{kW}$. Annual energy savings calculated from load factors provided by the utility. Cuss smer cost contributions include bill savings from customer to ESCO.

'Puget provided eog ecote information on peyments to bidders for three of five contracts.

'includes two of foul contracts because one contractor dropped out and other is a thermal storege contract.

"includes ell but the thermal storege project.

Includes date on fiv e contracts: two were cancelled.

10 includes two of tilree contracts; one project was cancelled. The averege bid price is $\$ 485 / \mathrm{kW}$ and the ceiling price is $\$ 562 / \mathrm{kW}$. Energy saving estim stes developed besed on hours of operation provided by the utility and estimated measure lifetimes of 7 vears.

"The weighted bid price is ebout $\$ 1440 / \mathrm{kW}$ in net present value terms. Estimated energy savings provided by the utility.

"Includes soven sontrects; NYSEG is still negotiating with two bidders.

'Includes resulti for two contracts.

"The averege bif price is $\$ 240 / \mathrm{kW}$. This calculation assumes a 15 year contract life and a capacity factor of $12.6 \% 14.25$ hours a der. fivi deys a weekl. Administrative costs ore estimated as $30 \%$ of bid poyments

'includes results for two of three contracts.

10The lovelized prices over messure lives, which ore estimated up to 22 years, are $3.7 \mathrm{C} / \mathrm{kWh}$ (bid price) and $0.4 \mathrm{c} / \mathrm{kWh}$ (customer contribution). Shareholder incentives as 0.2 and $0.4 \mathrm{c} / \mathrm{kWh}$ over the contract lives and moasure lives, respectively, but are not included in this table.

"The averege bid price is $\$ 250 / \mathrm{kW}$. Identical assumptions were mede for loed factor as indicated in "4. 


\subsubsection{Utility Administrative Costs}

Administrative costs range between $0.0-0.8 \mathrm{c} / \mathrm{kWh}$, with a median value of $0.4 \mathrm{c} / \mathrm{kWh}$, for the 15 bidding programs where data are available (see Table 3-3). The variation in administrative costs among utilities is partly attributable to varying degrees of marketing support and assistance offered to ESCOs. In most bidding programs, utility field staff are not involved in program marketing, although a few utilities have taken a proactive role in providing marketing support (e.g., informational brochures and meetings, customer account representatives refer leads to ESCOs).

Different approaches to allocating costs for utility staff time for monitoring contract implementation as well as the scope of program evaluation activities are other factors that explain the variance in administrative costs. For example, JCP\&L and PSE\&G minimized their own administrative costs by recharging winning DSM bidders for costs associated with verifying project savings. These two utilities require ESCOs to pay the utility about $\$ 12,000$ per year to offset utility costs associated with verifying savings. We also found that only a few utilities (e.g., NMPC, LILCO) included the costs of impact and process evaluations in their administrative costs. For other utilities, these costs either were not shown separately or, in many cases, are not anticipated.

Differences in cost accounting procedures among utilities may explain some of the variance, given the lack of standardization in the utility industry in reporting DSM administrative costs. Several utilities could not provide implementation and monitoring costs for DSM bidding programs separately because administrative costs were aggregated together for the relevant market segment (e.g., residential) or for all DSM programs.

The costs of financial incentives to utility shareholders are not included in our analysis, primarily because of lack of data. The DSM bidding programs of utilities in New York, California, and Colorado may be eligible for shareholder incentives, although the amount of these incentives usually depends on the net benefits actually realized by the program.

In Colorado, PSColo is allowed to receive $5 \%$ of the estimated monthly cost per $\mathrm{kW}$ of an alternate supply source on the capacity associated with the DSM projects (Colorado Public Utilities Commission 1990). This amounts to about $\$ 8.4 / \mathrm{kW}$ per year in nominal dollars over a 10 year period. ${ }^{24}$ PG\&E shareholder incentives could add about $0.3 \mathrm{c} / \mathrm{kWh}$ to the total resource costs of its DSM bidding program, if winning bidders achieve $100 \%$ of their contract goals. We do not have information on the costs associated with capacity. 
shareholder incentives for New York utilities, but expect that they would be somewhat less than PG\&E's payments.

To our knowledge, only one utility, CMP, has compared the administrative costs of its DSM bidding program with other DSM programs targeted at similar market sectors. CMP reported that the administrative costs for its bidding program were about 0.6 $\mathrm{c} / \mathrm{kWh}$ compared to approximately $2.0 \mathrm{c} / \mathrm{kWh}$ for its $\mathrm{C} / \mathrm{I}$ rebate program (Linn 1992).

\subsubsection{Customer Costs}

Lack of data on actual customer costs and the poor quality of existing data on estimated customer cost contributions among utilities limits our ability to draw more definitive conclusions on this cost component. Thus, we offer only a few preliminary observations. First, with several exceptions, it is unlikely that customer costs represent a significant portion of total program costs in the first generation of DSM bidding programs. Customer costs range between $0.0-1.3 \mathrm{c} / \mathrm{kWh}$ for 10 of 12 utility bidding programs where this information could be collected. ${ }^{25}$ Second, ESCOs that target projects at C/I customers have been able to get some host customers to pay a significant fraction of project costs, depending on the design of the bidding program. Third, it appears that ESCOs involved in the residential market typically have not obtained cost payments from participating households.

\subsubsection{Utility Payments to DSM Developers}

Not surprisingly, there is substantial variation in the bid prices of individual contracts both within a particular utility DSM bidding program as well as across utilities. For example, winning bid prices range between one to five $\mathrm{c} / \mathrm{kWh}$ for one utility in New York. In this section, we explore factors that may account for these variations.

We would expect some variation in bid prices simply because of differences in economic lifetimes of individual projects. However, for our data set, we have accurate information only on the term of each contract, which may tend to understate the actual lifetimes of the installed measures. For example, several utilities (e.g., PSE\&G, ORU-NY, and PG\&E) linited the maximum contract term to ten years. Figure 3-2 shows payments by utilities for individual as a function of contract term. We observe that bid payments vary

25 The exceptions are ORU (NY) and LILCO. At ORU (NY), the utility and ESCOs report that most of the customer's cost contribution comes from sharing a percentage of the utility bill savings with the ESCO. Actual dollar reductions in utility bills are a function of energy savings and projected retail rates. 
by a factor of 5-7 at any particular contract term (e.g., 10 or 15 years). There is a very slight upward trend in bid prices for longer contract terms, although differences in the mix of measures (e.g., lighting vs. comprehensive) or market sector targeted (e.g., residential vs. commercial) appear to account for some of the variation in bid prices.

Figure 3-2. Utility Payments to Bidders vs. Contract Term

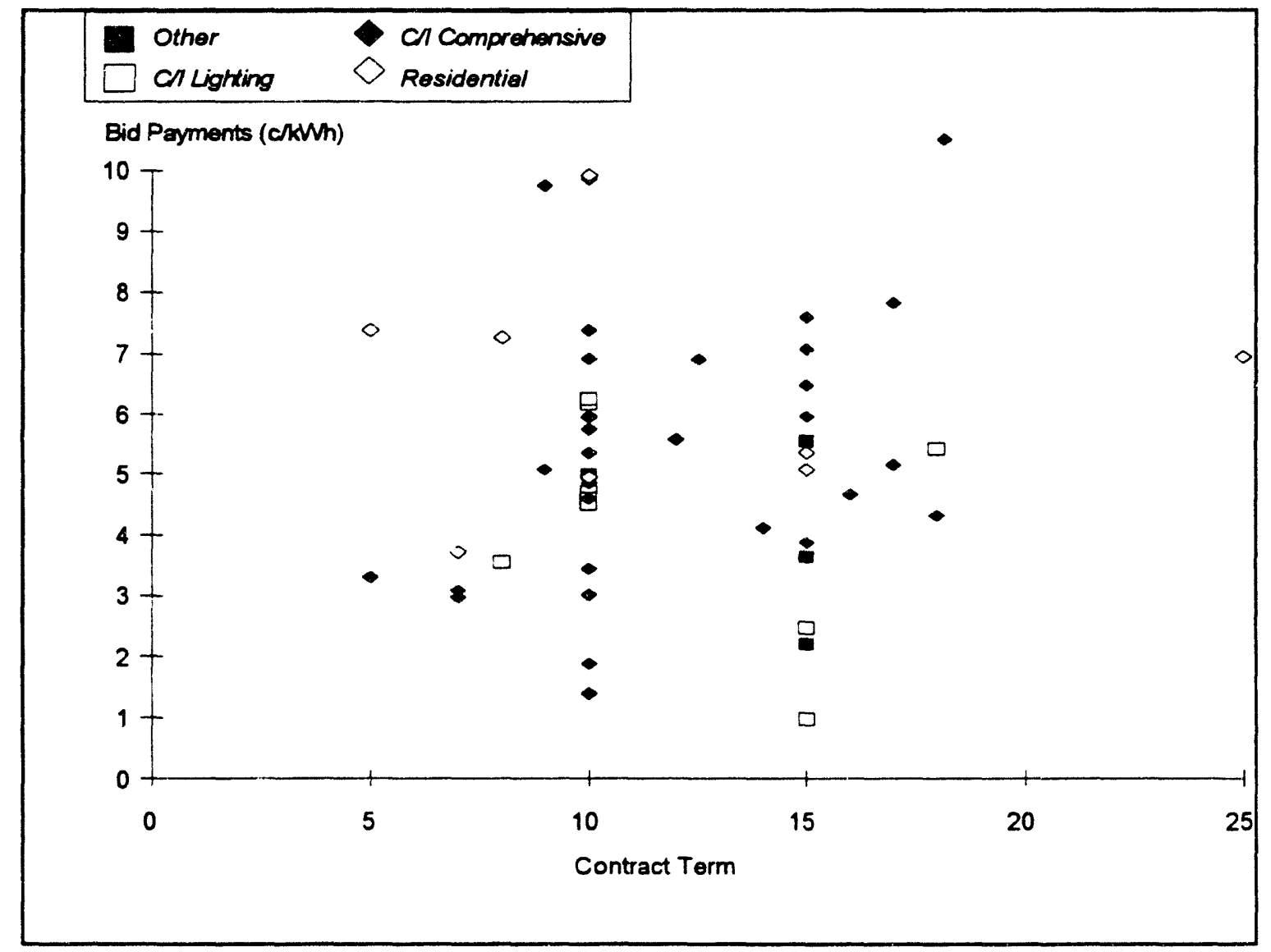

Other factors that account for variation in bid prices among individual contracts and utility programs in aggregate are: (1) differences in the allowed ceiling prices of DSM bids among utilities, (2) maturity of energy services industry, (3) differences in mix of measures, services offered, and market sectors targeted by DSM bidders, (4) the degree to which performance risks are borne by DSM bidders as reflected in contract provisions, and (5) perceived competitors. Each of these factors is explored in more detail in the following sections. 


\section{DSM Bid Ceiling Prices}

Figure 3-3 shows aggregated bid payments for 18 bidding programs, the DSM bid ceiling price (shown with a line) in those solicitations that included a ceiling price, and, for comparison, the utility's avoided supply costs (shown by a diamond). Our results suggest that differences in allowed ceiling prices explain much of the observed variation in average payments among DSM bidding programs.

Utilities have used several approaches to determine DSM ceiling prices in their bidding programs (see Appendix A). Avoided supply costs have been used to set the DSM ceiling price in many solicitations and have been favored in integrated, all-source auctions. For example, in New Jersey, where avoided supply costs were relatively high at the time of the bidding RFPs, utility payments to DSM developers were correspondingly high, ranging from $5.8-7.5 \mathrm{c} / \mathrm{kWh}$.

Several utilities (e.g., PSColo and CMP in its second RFP) did not announce or include ceiling prices in their DSM bidding RFPs. However, PSColo did include a reference price $(\$ 240 / \mathrm{kW})$ which was used only for scoring purposes. The reference price, though

Figure 3-3. Utility Payment to Winning Bidders

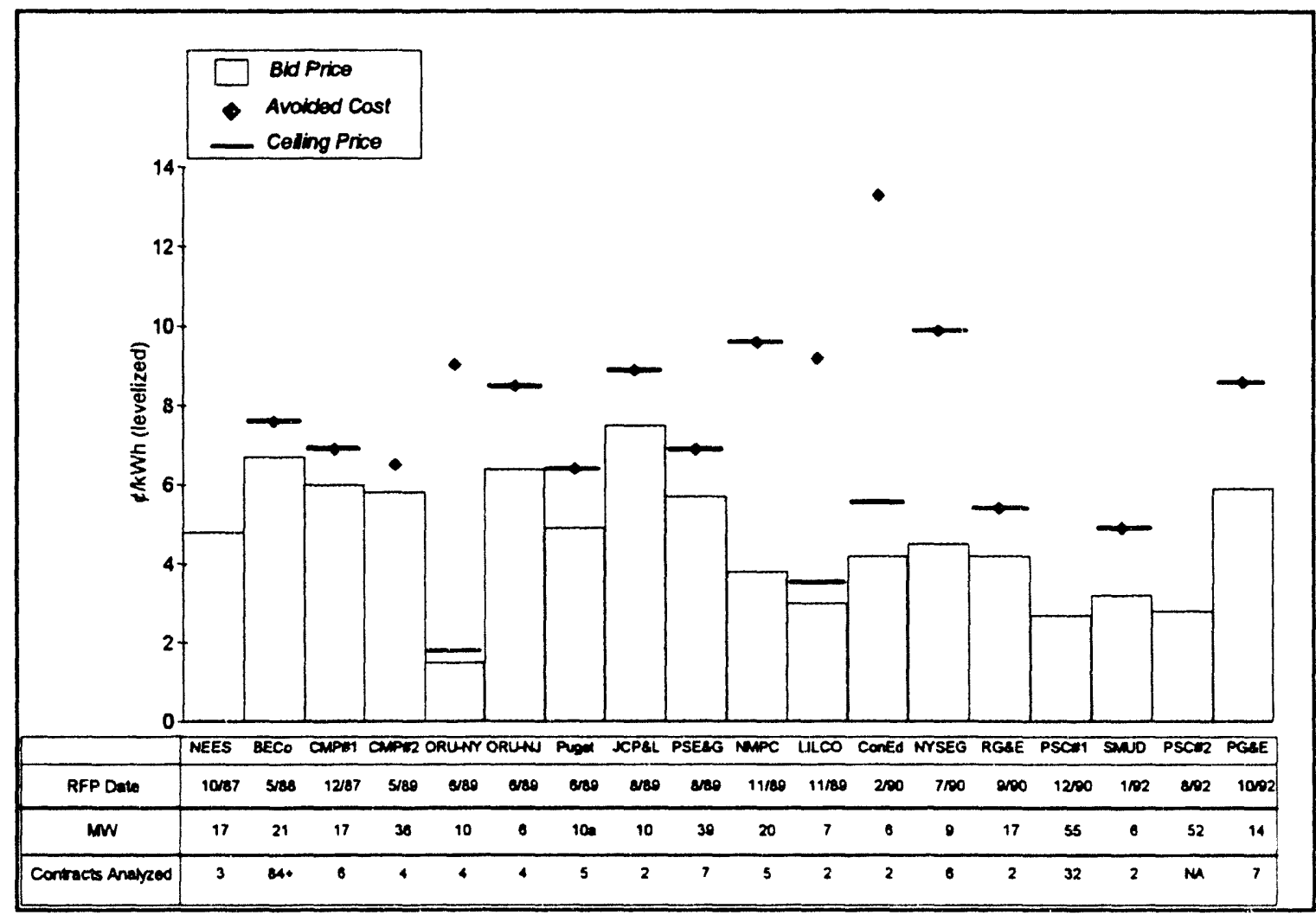


not a ceiling, appears to have affected the outcome as bid prices tended to be clustered near the reference price.

Average payments to winning DSM bidders tend to be substantially lower $(1.5-4.9$ c/kWh) for four utilities (e.g., LILCO, ORU-NY, Puget Power, and Con Edison) that established DSM ceiling prices in relation to their ow'n costs of delivering comparable planned or existing DSM programs. For example, Con Edison and LILCO established different ceiling prices for individual DSM measures. Con Edison's ceiling price levels were set at $150 \%$ of the estimated cost of various individual measures in its own program and ranged between $\$ 725-\$ 2,700 / \mathrm{kW}$ for commercial and industrial sector measures. Puget Power set the ceiling price level for conservation resources equal to the net present value of the utility's avoided cost of supply minus the net present value of the anticipated savings from the installed measures during the first two years of operation (Puget 1989). ESCOs argue that low ceiling prices make it more difficult for them to make comprehensive retrofit projects financially attractive to host customers. In contrast, some utilities view low ceiling prices as a program design feature that sends a message to potential DSM bidders that a substantial share of project costs should ultimately be borne by host customers.

While it is clear that DSM ceiling price levels were particularly important in early DSM bidding programs, they appear to be less determinative in several recent auctions. For example, PG\&E recently signed contracts with ten projects with average bid prices of $5.6 \mathrm{c} / \mathrm{kWh}$, which was far below the utility's avoided cost ceiling price average of 8.6 $\mathrm{c} / \mathrm{kWh}$. SMUD has signed three contracts with average prices of $3.2 \mathrm{c} / \mathrm{kWh}$, which was also well below the avoided cost ceiling price of $4.9 \mathrm{c} / \mathrm{kWh}$. These results suggest that the increased competition which is created by an expanding energy services industry and bidding programs with small resource blocks (e.g., 10-20 MWs) may be driving bid prices downward.

\section{Maturity of Energy Services Industry}

All else being equal, one would expect that bid prices would decrease over time as DSM developers gain experience with bidding and as a result of increased competition among bidders (as the energy service industry matures). Market response by potential DSM bidders is one way to assess the relative maturity of the energy services industry (see section 2.2). Figure 3-3 provides a rough indication of trends in bid prices over time as DSM bidding programs are ordered by the date of the RFP. Bid prices are presented in nominal dollars; the downward trend in winning bid prices would be even more evident if results were expressed in real dollars. 
Target Markets and Mix of Measures

DSM bid prices also vary because bidders target different market segments and offer varying mixes of measures and services. For example, in our sample of 18 utility DSM bidding programs, slightly less than $90 \%$ of the contracted demand reduction is targeted at commercial/industrial (C/I) facilities, while about $10 \%$ is aimed at residential customers (see Figure 3-4). Contracts that target residential customers average $6.2 \mathrm{c} / \mathrm{kWh}$

Figure 3-4. Sectoral Breakdown for 18 Bidding Programs

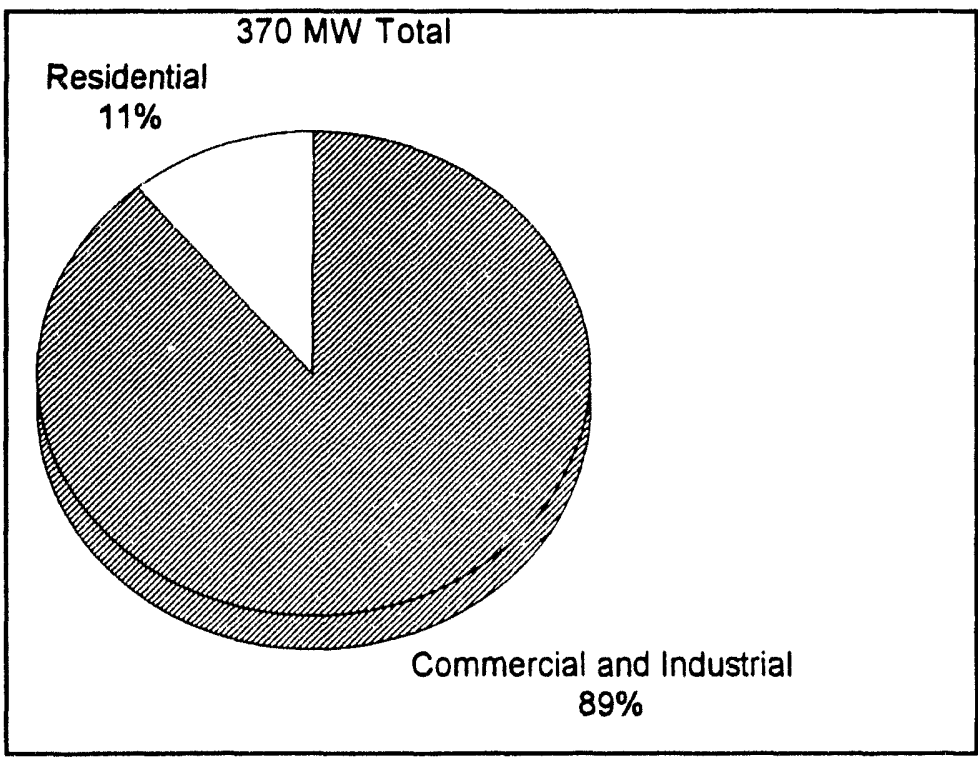
compared to $5.0 \mathrm{c} / \mathrm{kWh}$ for contracts that target C/I customers (see Figure 3-5).

Figure 3-5. Other Factors that Influence Bid Payments

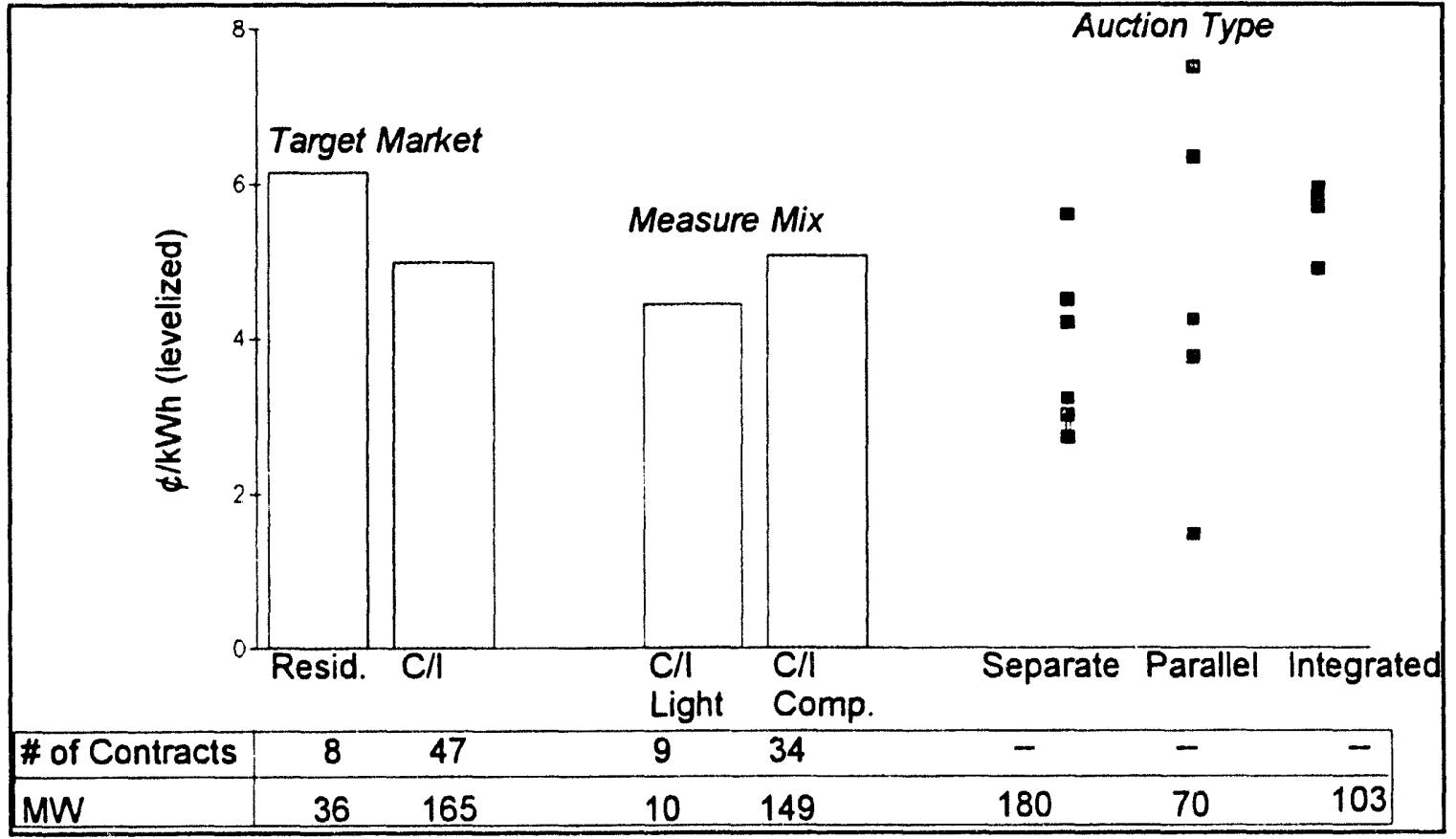


Figure 3-6. Distribution of DSM Measures for 18 Programs

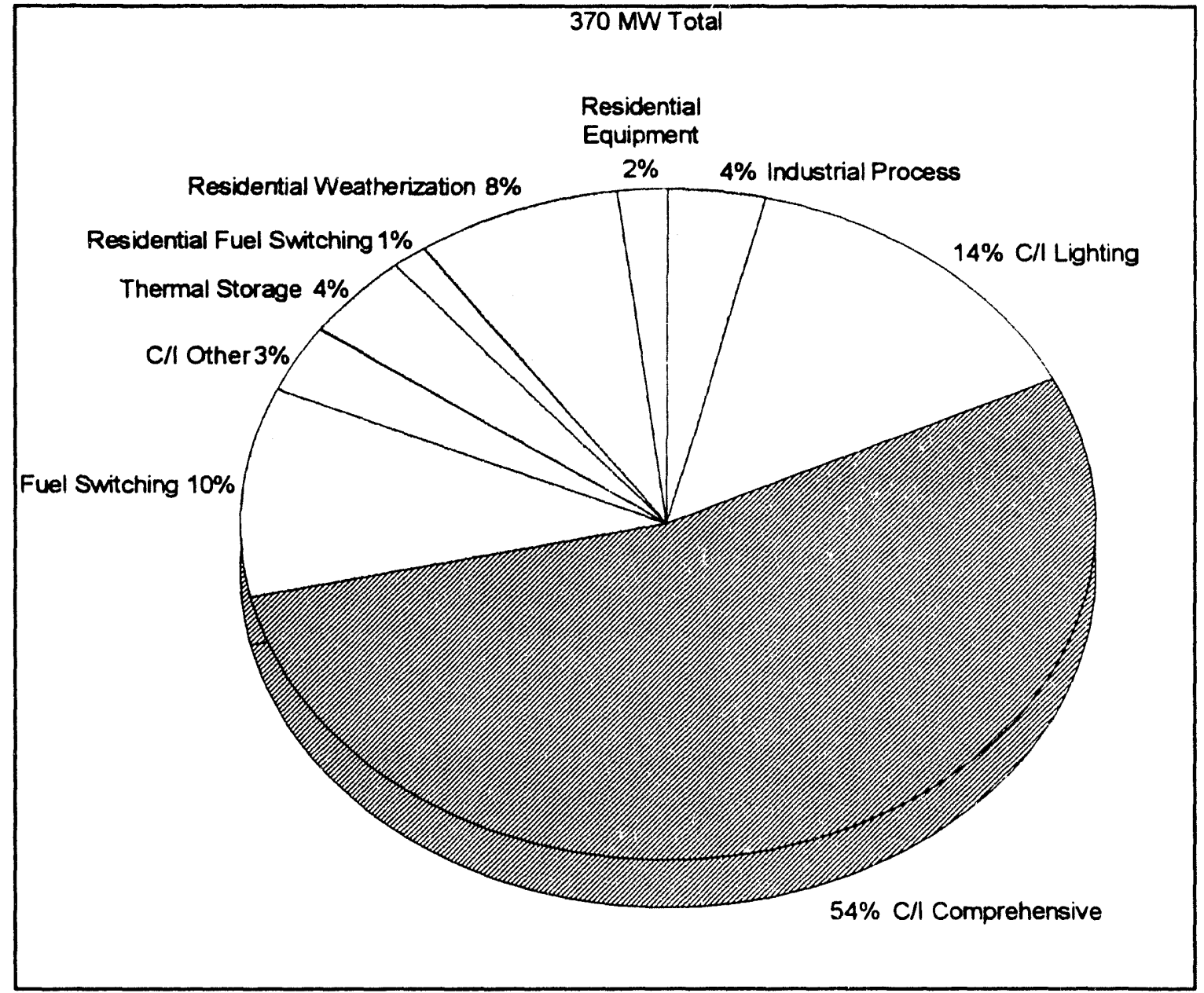

Individual DSM measures also vary significantly in terms of their lifecycle cost, which should affect bid prices. We categorized each contract by sector and type of measures offered to customers. Figure 3-6 provides a breakdown of the distribution of the contract demand savings for 18 programs in aggregate by these categories; Table 3-4 summarizes this information for individual utilities. DSM developers targeting residential customers offer weatherization-type programs (e.g., building shell measures, lighting and low-cost equipment measures), fuel-switching measures (e.g., conversion of space and hot water heating equipment from electric to gas), or appliances (e.g., early retirement of second refrigerators). For the $\mathrm{C} / \mathrm{I}$ sector, we grouped contracts into five categories: (1) $\mathrm{C} / \mathrm{I}$ comprehensive (2) C/I lighting, (3) thermal storage, (4) fuel switching, and (5) industrial process. 
Table 3-4. Distribution of Contract Savings by Sector and Measure

\begin{tabular}{|c|c|c|c|c|c|c|c|c|c|c|}
\hline Utility & $\begin{array}{l}\text { Indus. } \\
\text { Process } \\
\text { (\%) }\end{array}$ & $\begin{array}{c}c / \\
\text { Light. } \\
(\%)\end{array}$ & $\begin{array}{c}C / 1 \\
\text { Comp. } \\
(\%)\end{array}$ & $\begin{array}{c}\text { Motors } \\
(\%)\end{array}$ & $\begin{array}{l}\text { EMS } \\
(\%)\end{array}$ & $\begin{array}{c}\text { Thermal } \\
\text { Storage } \\
\text { (\%) }\end{array}$ & $\begin{array}{c}\text { Fual } \\
\text { Switch. } \\
(\%)\end{array}$ & $\begin{array}{c}\text { Resid. } \\
\text { (\%) }\end{array}$ & $\begin{array}{l}\text { Other } \\
\text { (\%) }\end{array}$ & $\begin{array}{l}\text { TOTAL } \\
\text { (MW) }\end{array}$ \\
\hline NEES & & & 100 & & & & & & & 17 \\
\hline BECO & & & 100 & & & & & & & 21 \\
\hline CMP \#1 & 13 & 7 & 60 & & & & & 19 & & 17 \\
\hline CMP 2 & 1 & & 66 & & & & & 33 & & 36 \\
\hline ORU-NY & & 100 & & & & & & & & 10 \\
\hline ORU-NJ & & & 47 & & & & & 53 & & 6 \\
\hline Puget & & 7 & 93 & & & & & & & 10 \\
\hline JCP\&L & & & 44 & & & 56 & & & & 22 \\
\hline PSE\&G & & 8 & 92 & & & & & & & 39 \\
\hline LULCO & & & 100 & & & & & & . & 7 \\
\hline NMPC & 2 & 6 & 39 & & & & & 55 & & 20 \\
\hline Con Edison & & & 100 & & & & & & & 7 \\
\hline NYSEG & & 3 & 31 & & & 27 & & 40 & & 12 \\
\hline RG\&E & & & 100 & & & & & & & 16 \\
\hline PSColn \#1 & 14 & 32 & & 1 & 8 & & 33 & 4 & 8 & 54 \\
\hline SMUD & & & 100 & & & & & & & 9 \\
\hline PG\&E & & 26 & 51 & 15 & & & & 8 & & 18 \\
\hline PSColo *2 & 6 & 48 & & & & & 39 & 6 & & 50 \\
\hline
\end{tabular}

DSM developers that offer comprehensive packages of measures in major end uses (e.g., lighting, HVAC, and motors) to $\mathrm{C} / \mathrm{I}$ customers account for over $50 \%$ of the contracted MW (199 MWs) in our sample of bidding programs, while C/I lighting contracts account for another 14 percent (53 MWs). Utility payments to DSM developers offering comprehensive packages are somewhat higher on average than payments for C/I lighting only contracts: $5.1 \mathrm{c} / \mathrm{kWh}$ vs. $4.5 \mathrm{c} / \mathrm{kWh}$ (see Figure $3-5$ ).

A number of contracts involve fuel switching measures (38 MW), which were successful in PSColo's DSM bidding programs. Several contracts focus on changes in industrial processes (14 MW). ${ }^{26}$ Thermal storage and other types of load management projects account for about 5 percent of the contracted demand reductions (15 MW). ${ }^{27}$ It appears that there is some variation in bid prices for thermal storage projects that use similar type of technology. Bid prices range from $\$ 500-730 / \mathrm{kW}$ among four winning bids.

25 Examples of industrial process retrofits include installation of compressed air system controls or new pulping equipment for formed-fiber product operations.

27 These cost figures exclude a number of thermal storage contracts that were cancelled after contract execution. 
Within most categories, there is substantial variation in bid prices. For example, levelized bid prices range from about 1.0 to $6.2 \mathrm{c} / \mathrm{kWh}$ among winning $\mathrm{C} / \mathrm{I}$ lighting bidders. The low bid price represents a small industrial lighting project (with a contract term of 15 years) and the high bid price represents a commercial lighting project proposed by a customer bidder in California (with a contract term of 10 years). It is difficult to explain the variance in bid prices because, in many cases, we have limited information on the types and distribution of lighting efficiency measures that have been proposed or installed. Lower cost measures include relamping, replacement of incandescent lamps with fluorescent lamps, and installation of optical reflectors, while higher cost measures include changeouts of existing lighting systems, electronic ballasts, and various types of lighting controls. We do know that a few utilities valued lighting measures quite differently in their bidding programs. ${ }^{28}$

Bid prices ranged between $1.4-9.9 \mathrm{c} / \mathrm{kWh}$ in contracts where DSM developers offered comprehensive projects to customers in the $\mathrm{C} / \mathrm{I}$ sector. This group of contracts is somewhat of a catchall category. Some of the variation in bid prices can be explained by the fact that DSM developers' projects will vary in the degree of comprehensiveness of services or measures offered. Conceptually, it is helpful to think about comprehensiveness and associated measure costs in terms of "depth" and "width." "Width" refers to the range and breadth of end uses addressed by a DSM developer in their installations (e.g., lighting, HVAC, and motors). The extent to which savings occur across multiple end uses is a good indicator of comprehensiveness in terms of "width." "Depth" refers to the comprehensiveness of measures installed for a particular end use at facilities (e.g., for lighting, simple screw in, system upgrade, complete redesign and changeout of existing lighting system). Percentage reductions in usage in a particular end use is a good indicator of comprehensiveness in terms of "depth."

On first glance, the fact that $\mathrm{C} / \mathrm{I}$ comprehensive is the largest category might suggest that DSM bidding programs will ultimately result in the installation of comprehensive packages of retrofits at host facilities. However, ESCOs generally do not provide contractual guarantees regarding the mix of measures actually installed. Table 3-5 shows the estimated distribution of savings by end use, based on interviews with utility managers and ESCOs and program evaluations. In most bidding programs, it appears that lighting measures account for most of the savings (70-100\%) from projects completed by ESCOs with comprehensive bids. The performance of CES/Way in Niagara Mohawk's bidding program is the notable exception to this trend. Various types of HVAC measures (new chillers, ground source heat pumps, economizers, new controls) 
Table 3-5. C/l Compreh, sive Contracts: Savings from Measures Actually Installed

\begin{tabular}{|c|c|c|c|c|c|c|c|c|}
\hline Utility & $\begin{array}{l}\text { Total } \\
\text { (MW) }\end{array}$ & $\begin{array}{l}\text { On- } \\
\text { Line } \\
\text { (MW) }\end{array}$ & $\begin{array}{l}\text { Ind. } \\
\text { Process } \\
(\%)\end{array}$ & $\begin{array}{l}\text { Lighting } \\
(\%)\end{array}$ & $\begin{array}{c}\text { Motors } \\
(\%)\end{array}$ & $\begin{array}{c}\text { HVAC } \\
(\%)\end{array}$ & $\begin{array}{c}\text { Non- } \\
\text { Electric } \\
\text { Cooling } \\
(\%)\end{array}$ & Comments \\
\hline NEES & & 17 & & 70 & & & & \multirow{9}{*}{$\begin{array}{l}\text { Initially, no M\&V } \\
\text { protocol for HVAC } \\
\text { Initially, no M\&V } \\
\text { protocol for HVAC } \\
\text { Initially, no M\&V } \\
\text { protocol for HVAC } \\
2 \% \text { shell messures }\end{array}$} \\
\hline BECo & & 21 & & 90 & 3 & 7 & & \\
\hline CMP \#1 & 10 & 10 & 36 & 64 & & & & \\
\hline ORU-NY & 10 & 4 & & 100 & & & & \\
\hline ORU-NJ & 3 & 1 & & 100 & & & & \\
\hline JCP\&L & 10 & 6 & & 100 & & & \multirow{5}{*}{35} & \\
\hline PSE\&G & 36 & 7 & & 85 & 5 & 10 & & \\
\hline NMPC & 8 & 5 & & 47 & 6 & 45 & & \\
\hline LILCO & 7 & 3 & & 65 & & & & \\
\hline Con Edison & 7 & 4 & & 98 & 2 & & & $\begin{array}{l}\text { Limited number of } \\
\text { eligible messures }\end{array}$ \\
\hline
\end{tabular}

account for about $45 \%$ of the electricity savings from CES/Way's installations, which are targeted mainly at large institutional sector customers (NMPC 1993).

At other utilities, the results thus far have been disappointing. For example, in a program evaluation that compiled results through 1992 (with $2.8 \mathrm{MWs}$ of demand reduction installed), LILCO found that its DSM contractors had installed only lighting and nonelectric cooling measures, even though the contracts called for a broad range of comprehensive measures (Applied Energy Group Inc. 1992). In New Jersey, several utility program managers reported that difficulties and delays in developing acceptable measurement and verification techniques for certain customized HVAC measures was an important factor contributing to the low penetration of HVAC measures. At ORU, the company reported that bidders offering comprehensive packages have delivered only lighting measures.

In utility rebate programs, lighting measures have typically accounted for most of the savings. However, for some utilities that have been leaders in DSM, the mix of measures is changing. For example, PG\&E reported that about 58\% of the savings from its 1992 commercial/industrial rebate program came from lighting measures, $28 \%$ from HVAC options, $7 \%$ from industrial process changes, $6 \%$ from refrigeration measures, and $<1 \%$ 
from motor efficiency improvements (PG\&E 1993a). To sum up, at least in terms of the "width" dimension, the limited success of DSM developers in installing comprehensive packages of measures across multiple end uses is somewhat disappointing for at least two reasons. First, bid prices for these "comprehensive" contracts were evaluated and judged to be a good deal by utilities under the assumption that, in aggregate, ESCOs would convince customers to select DSM options that improved energy efficiency among the major end uses. To the extent that utilities believe that they could obtain lighting savings with comparable reliability and persistence at lower cost, utilities might conclude that too much was being paid for this DSM resource. Second, if DSM developers install only lighting, they may be creating "lost opportunities" which the comprehensive contracts were designed to avoid. ${ }^{29}$ In order to assess how well DSM developers are performing on comprehensiveness in terms of "depth", we would need detailed information on installed lighting measures and percentage reductions in lighting energy use at individual projects.

\section{Payment Provisions and Performance Guarantees}

The degree of performance risk borne by DSM developers also appears to influence bid prices. For example, ESCOs were only required to verify that equipment had been installed properly in order to receive payments in LILCO's and ORU (NY)'s bidding program, which averaged $3.0 \mathrm{c} / \mathrm{kWh}$ and less. In contrast, contracts signed by utilities in New Jersey required ESCOs to demonstrate energy savings over a $10-15$ year time period in order to receive payments, which averaged between $6-7 \mathrm{c} / \mathrm{kWh}$. In Chapter 4 , we analyze the risks for DSM developers created by various performance and security provisions in DSM bidding contracts.

\section{Affect of Auction Type and Size on Perceived Competitors}

Average payments to DSM bidders have been significantly higher for utilities that conducted integrated "all-source" RFPs which included both supply and DSM resources compared to those utilities that conducted DSM-only RFPs or issued supply and DSM RFPs in parallel to meet a common resource block (see Figure $3-5$ ).$^{30}$ The resource block

29 "Lost opportunities" occur when measures that can be installed cost-effectively are not offered to customers. Lost opportunity measures are either not cost-effective to install later as single measures or are too difficult to sell to customers at a later date because the customer prefers to make all energy efficiency decisions during the initial retrofit (PG\&E 1992).

30 The effect of confounding factors must also be considered, in particular the fact that ceiling prices also tended to be higher in integrated auctions compared to DSM-only RFPs. 
size in DSM-only RFPs tends to be significantly smaller than in integrated, "all-source" RFPs. Although integrated bidding RFPs include more potential competitors (i.e., independent power producers), the success rates of DSM bidders have been higher in auctions that include supply-side options compared to DSM-only RFPs (40 vs. 25\%). DSM bidders probably make some initial assessment of potential competitors and their relative competitive position, which may affect their bid pricing strategy, particularly if they are national ESCOs that have experience with various types of auctions. DSM-only solicitations may create more competition among potential DSM service providers as compared to integrated, all-source RFPs, in part because utilities can take account of DSM market potential explicitly in determining the size of the resource block.

\subsection{Cost Comparison of DSM Bidding vs. Other Utility DSM Programs}

There have been few studies that systematically attempt to compare the relative effectiveness of varying DSM delivery mechanisms that target similar customers (Vine et al. 1990). In evaluating different DSM program delivery mechanisms, we believe it is useful to limit the comparison to programs that target similar customer classes and end uses. DSM bidding programs make such comparisons problematic because utilities typically sign contracts that encompass several customer classes and end uses. We decided to focus on $\mathrm{C} / \mathrm{I}$ lighting because a reasonable sample of bidding contracts was available (i.e., nine) and there was also less ambiguity regarding actual measures installed (compared to $C / I$ comprehensive or residential projects). In addition, results were available from a recent study from the Database on Energy Efficiency Programs (DEEP) of utility-sponsored lighting programs (Eto et al. 1993). ${ }^{31}$ Note that, in aggregate, the lighting programs in the DEEP report are much larger in size than the bidding projects (e.g., an order of magnitude in terms of savings).

As Figure 3-7 shows, total resource costs of the nine C/I lighting contracts from bidding programs are slightly higher on average compared to the 20 utility-sponsored lighting programs (6.1 vs. $5.6 \mathrm{c} / \mathrm{kWh}$ ). For each group, the reported mean value represents a weighted average, which was computed by weighting the costs of each bidding contract or utility lighting program by its $\mathrm{kWh}$ savings. The fact that levelized TRC costs are almost comparable is somewhat surprising because we would expect DSM bidding programs to be significantly more expensive than lighting programs given the

31 The Eto et al. study included $20 \mathrm{C} / \mathrm{I}$ lighting programs with detailed information on program costs and savings based on impact evaluations. Sixteen programs used rebatus (either fixed or customized), while four programs were direct install. In order to compare the results of the C/I lighting study directly with our sample of bidding contracts, we recalculated levelized costs using an $11 \%$ discount rate to conform to the convention used in this study. The Eto et al study used a $5 \%$ real discount rate. 
Figure 3-7. Comparison of Utility C/I Lighting Programs with Bidding Programs for Lighting Measures

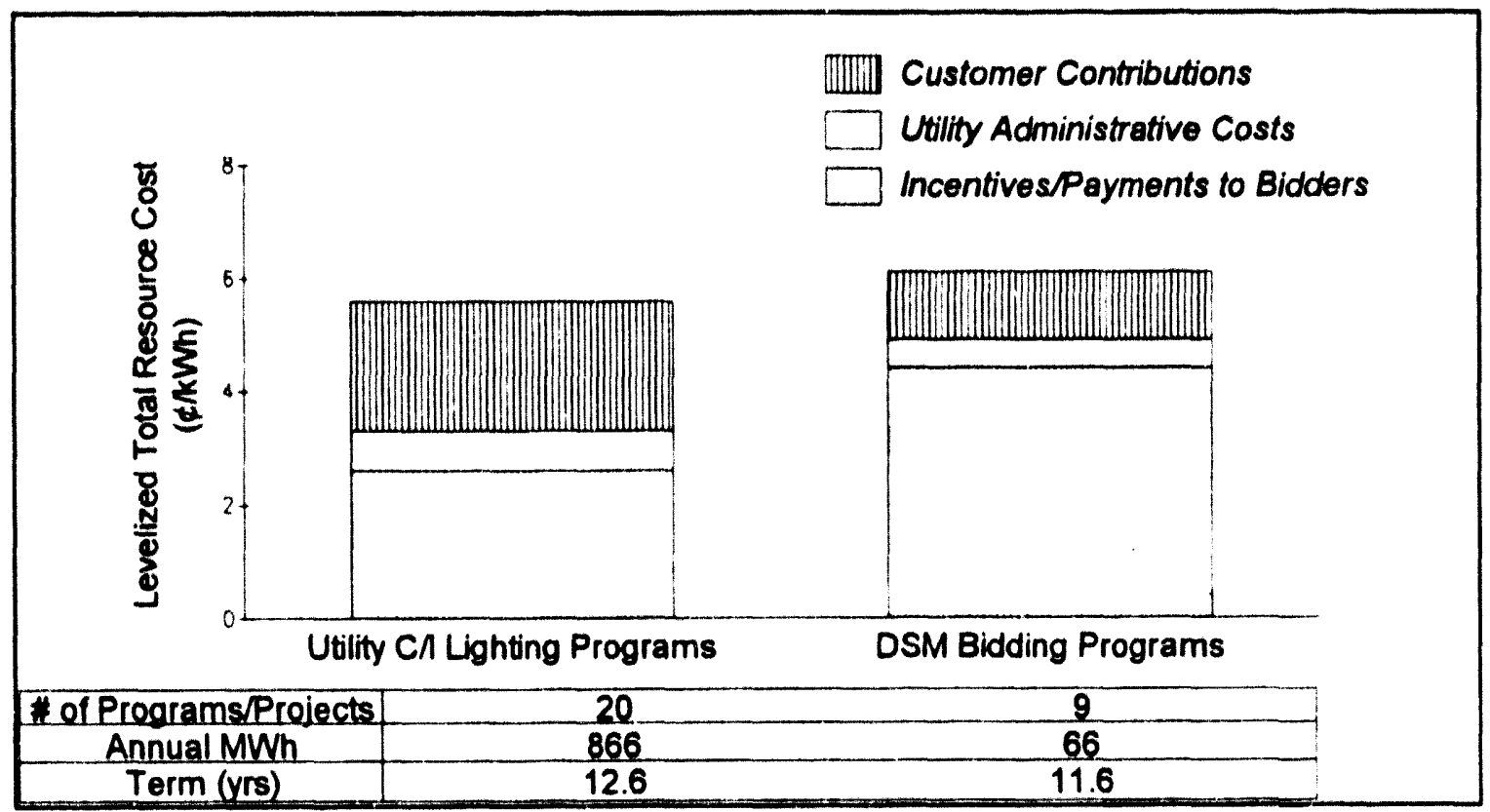

development and performance risks being borne by DSM developers. ${ }^{32}$ In addition to relative size, the most striking difference between the bidding projects and utility $\mathrm{C} / \mathrm{I}$ lighting programs is the relative distribution of costs paid for by the utility (incentives and administrative costs) and the end-use customer. Customers bear a larger portion of the direct costs in the utility $\mathrm{C} / \mathrm{I}$ lighting programs, whereas the utility bears most of the costs in the bidding programs. However, we believe that this phenomenon is primarily a result of poor design of bid scoring systems and auction type, rather than being an intrinsic feature of DSM bidding. ${ }^{33}$

The DSM bidding projects and utility $\mathrm{C} / \mathrm{I}$ lighting programs also differ with respect to resource risks and the relative uncertainty in the TRC estimates. Measure lifetime and persistence of savings are the major sources of uncertainty that affect the ultimate total

32 Some utilities would argue that ESCOs are able to target their efforts to particularly cost-effective market segments (e.g., buildings with high hours of operation), whereas most utility programs are open to all $\mathrm{C} / \mathrm{I}$ customers. Thus, a utility's costs to acquire DSM resources from these customers would be lower than their typical program average (Hamilton and Flaim 1992).

33 For example, in many integrated bidding programs, utilities relied solely on the equivalent of the Total Resource Cost (TRC) test in scoring the economic attributes of projects. The TRC test does not differentiate between costs paid for by the customer vs. costs paid by the utility because it focuses only on total costs. 
resource cost of the utility $\mathrm{C} / \mathrm{I}$ lighting programs. However, because DSM developers typically get paid only for what they deliver over a fixed contractual period, the persistence of savings has much less effect on the total resource costs of these contracts. In these bidding contracts, there is somewhat more uncertainty regarding ultimate market penetration because not all projects are on-line and there is some chance that developers may be unable to meet their contract demand reduction goal. In terms of data limitations, there are similar cost accounting issues (e.g., treatment of administrative costs and relatively poor information on customer costs) for both bidding projects and the $\mathrm{C} / \mathrm{I}$ lighting programs included in the DEEP report. This analysis should be viewed as exploratory, primarily because there is very limited overlap of utilities in both samples and because it is unclear that similar services (or products in some cases) are being offered by each type of program. Case studies of several utilities that compared the costs of different program delivery mechanisms could be quite useful. ${ }^{34}$

\subsection{Value of DSM Bidding Programs}

Ultimately, the merits of DSM bidding will be judged on whether the process yields projects that offer economic benefits to ratepayers compared to the relevant alternatives. In this regard, the costs of a "comparable" utility DSM program adjusted for additional risks and services provided by a DSM bidder provides a lower bound for comparing economic benefits to ratepayers of DSM projects, while the utility's avoided supply costs provides an upper bound. Detailed case studies of individual utilities would be required in order to define DSM programs that are "comparable" to DSM bids in terms of measures installed, services provided, performance risk, and customer satisfaction (Freeman Research Associates 1989).

In Table 3-3, we show each utility's avoided supply costs as published in its bidding RFP or used during bid evaluation and express DSM bidding program costs as a percent of these avoided costs. ${ }^{35}$ Total resource costs range from $42-104 \%$ of the utility's avoided supply costs in our sample of ten programs (see Table 3-3). However, given the uncertainties in customer and utility administrative costs and future avoided costs, several of these initial bidding programs appear to be only marginally cost-effective from this societal perspective. Moreover, estimates of future avoided costs have decreased

34 With case studies, it would be easier to collect detailed information on types of measures actually installed and other indicators of program success (e.g., customer satisfaction).

35 The avoided supply costs for individual projects typically vary among utilities because of differences in the load shape and load factor. We typically calculated project-specific, avoided costs, which were then aggregated to the utility program level using the same procedure used to calculate total resource costs (i.e., weighting avoided costs by $\mathrm{kWh}$ savings of individual contracts). 
significantly at many of these utilities since the early 1990s primarily because of lower forecasts of future gas prices and reduced need for new capacity. Thus, it is likely that some individual DSM contracts would not now pass a TRC test using each utility's current avoided cost forecast. ${ }^{36}$

36 Significant decreases in a utility's forecast of avoided costs can also have a similar effect on the economics of winning supply-side projects. 


\section{Risk Allocation in DSM Bidding Contracts}

\subsection{Overview}

One of the distinctive features of DSM bidding programs is their attempt to allocate the risks associated with DSM resources in an explicit fashion among ratepayers, DSM developers, and host customers through contracts signed between developers and utilities. ${ }^{37}$ In contrast, allocation of risks in more traditional utility DSM programs tends to be less defined, which often results in utility ratepayers implicitly bearing most of the risks. The objectives of this chapter are to identify the risks associated with DSM resources, to compare the allocation of risks in traditional utility DSM programs with bidding programs, and to examine the different approaches taken by utilities in their bidding programs.

We first categorize the risks associated with DSM resources and bidding programs into three broad categories (i.e., development, performance, and demand risk). We then compare and contrast the allocation of risks in a typical utility rebate program with bidjing programs. Based on our review of contracts signed in bidding programs, we then develop a general typology of provisions that attempt to allocate these risks and summarize provisions used by each utility. To illustrate the different approaches used by utilities, we create a prototypical ESCO project and model representative terms and conditions negotiated by each utility in their bidding program drawn from our survey of contracts. We then calculate payments to the developer under various performance scenarios. We find that most DSM bidding programs protect ratepayers in situations in which the project fails to develop or energy savings deteriorate over the term of the contract. However, DSM developers will seek a return on their investment that is commensurate with the development and performance risks that they are bearing. Our analysis suggests that the security deposits required by most utilities appear to have a fairly minimal impact on bid prices compared to the risks and payment provisions associated with "pay for performance" contracts.

Third-party DSM developers (i.e., ESCOs) also sign energy services agreements (ESAs) with host customers. It is not possible to systematically analyze the allocation of risks between ESCOs and host customers because these agreements are not publicly available. However, based on anecdotal evidence, ESCOS, in turn, typically attempt to pass on or to mitigate some performance risks (e.g., operation and maintenance of installed measures, provisions relating to minimum hours of operation) in these ESAs with host facilities. 


\subsection{Risks Associated With DSM Resources}

From the perspective of a utility and its ratepayers, the risks associated with DSM resources can be grouped into several broad categories:

- Development Risk - Risk that the expected demand and energy savings do not materialize. In the context of a DSM bidding program, the risk that a DSM developer is unable to develop projects successfully, which involves installation of DSM measures in customer facilities in accordance with schedules specified in the contract. In the context of a utility-run DSM program, risk that sufficient numbers of customers do not agree to install DSM measures being promoted by the utility.

- $\quad$ Performance Risk - Risk that demand reductions and energy savings that result from completed installations do not persist over the expected economic lifetime of the measures.

- Demand Risk - Risk that the utility's forecasted need for new capacity may diminish over the economic lifetime of measures. In effect, the value of the energy savings decreases, which potentially jeopardizes the cost-effectiveness of the DSM resource acquisition. ${ }^{38}$

\subsubsection{Allocation of Risks in Utility DSM Rebate Programs}

With the advent of large-scale DSM programs and the availability of incentives for utility shareholders to acquire these resources effectively, there has been increasing attention on the rewards and potential risks assumed by ratepayers in their financial support of utility DSM programs. Table 4-1 compares the allocation of risks among various groups (ratepayers, utility shareholders, DSM developers, and participating or host customers) in a prototypical utility rebate program and a DSM bidding program. In this stylized example, we assume that the utility is operating a large-scale DSM program that offers rebates to customers to purchase DSM measures. Program costs are expensed and the utility must achieve pre-specified performance goals in order to receive a financial incentive authorized by the PUC. Utility shareholders can also be penalized if the company fails to meet performance goals, which are typically specified in terms of minimum levels of market penetration, savings, or net benefits.

38 The utility's projections of its avoided supply costs may decrease because of lower than expected load growth (which may lower avoided capacity costs) or because of downward revisions in projected fuel prices (which would lower avoided energy costs). 
Table 4-1. Risk Allocation in Utility Rebate vs. DSM Bidding Program

\begin{tabular}{|lll|}
\hline & $\begin{array}{l}\text { Utility C/ Program Iwl } \\
\text { Incentives for Utility } \\
\text { Shareholders) }\end{array}$ & $\begin{array}{l}\text { DSM } \\
\text { Bidding }\end{array}$ \\
\hline $\begin{array}{l}\text { Development Risk } \\
\text { - Proper } \\
\text { Installation/Commissioning } \\
\text { Market Penetration Risk } \\
\text { laggregate) }\end{array}$ & Pharticipant & DSM Developer \\
$\begin{array}{l}\text { Performance Risk } \\
\text { - Energy Savings } \\
- \text { short-term } \\
- \text { long-term }\end{array}$ & Ratepayers/Shareholders & DSM Developer \\
$\begin{array}{l}\text { Demand Risk } \\
\text { Ratepayers }\end{array}$ & DSM Developer \\
& Ratepayers & DSM Developer \\
\hline
\end{tabular}

Who bears the major risks associated with DSM resources in a utility rebate program? Participating customers bear the development risks associated with installing the measures. Utility shareholders also bear some of the DSM development risk and performance risk, depending on hov' the incentive mechanism is structured. ${ }^{39}$ For example, utility shareholders are typically held accountable for achieving overall program market penetration goals (because of the shareholder incentives). Ratepayers implicitly bear the bulk of the performance risk if savings do not persist over the economic lifetime of the measures because a significant portion of the cost of the measures is paid upfront by ratepayers (i.e., the rebate) without strong contractual guarantees that the estimated savings will be maintained..$^{40}$ The utility also has some flexibility to manage demand risk. That is, if the program is no longer cost-effective for various reasons (e.g., avoided costs

39 With a few exceptions (e.g., California utilities), most utilities earn DSM incentives based on pre-specified engineering savings estimates per measure with some type of true-up based on near-term actual performance. The period over which savings are evaluated is typically much shorter than the expected economic life of the measures. The degree of development risk depends on the deadband range for acceptable performance and penalties for poor performance in the incentive mechanism. Typically, the utility will still receive cost recovery for expenses incurred, unless it is found to have acted imprudently.

40 The utility's performance is typically evaluated in terms of actual market penetration and an impact evaluation that measures near-term savings for a representative sample of participating and non-participating customers. 
have decreased, and/or savings estimates are revised downwards), then the utility can either cancel or alter the design of the program.

\subsubsection{Allocation of Risks in DSM Bidding Programs}

DSM developers are responsible for proper installation and commissioning of DSM measures at individual facilities and for achieving in aggregate their contract demand reduction goal in a bidding program (see Table 4-1). DSM developers also assume the risks associated with the near-term and long-term energy savings performance of installed measures. Ratepayers bear most of the demand risk in a bidding program because of the financial commitments involved in the long-term contract between the utility and DSM developer. Compared to a utility rebate program, demand risks may be more of an issue with DSM bidding programs.

Utilities use a variety of contractual mechanisms to mitigate the development, performance, and demand risks to ratepayers of DSM resources. These risk mitigation options include various types of security deposits, damage and penalty provisions, and "regulatory out" and "buyout" clauses (see Table 4-2). Conceptually, it is useful to separate contract provisions that focus on the ramp-up period (i.e., development) from those provisions that address the period in which the project is fully operational (i.e., performance). 
Table 4-2. DSM Risks and Contractual Risk Mitigation Options

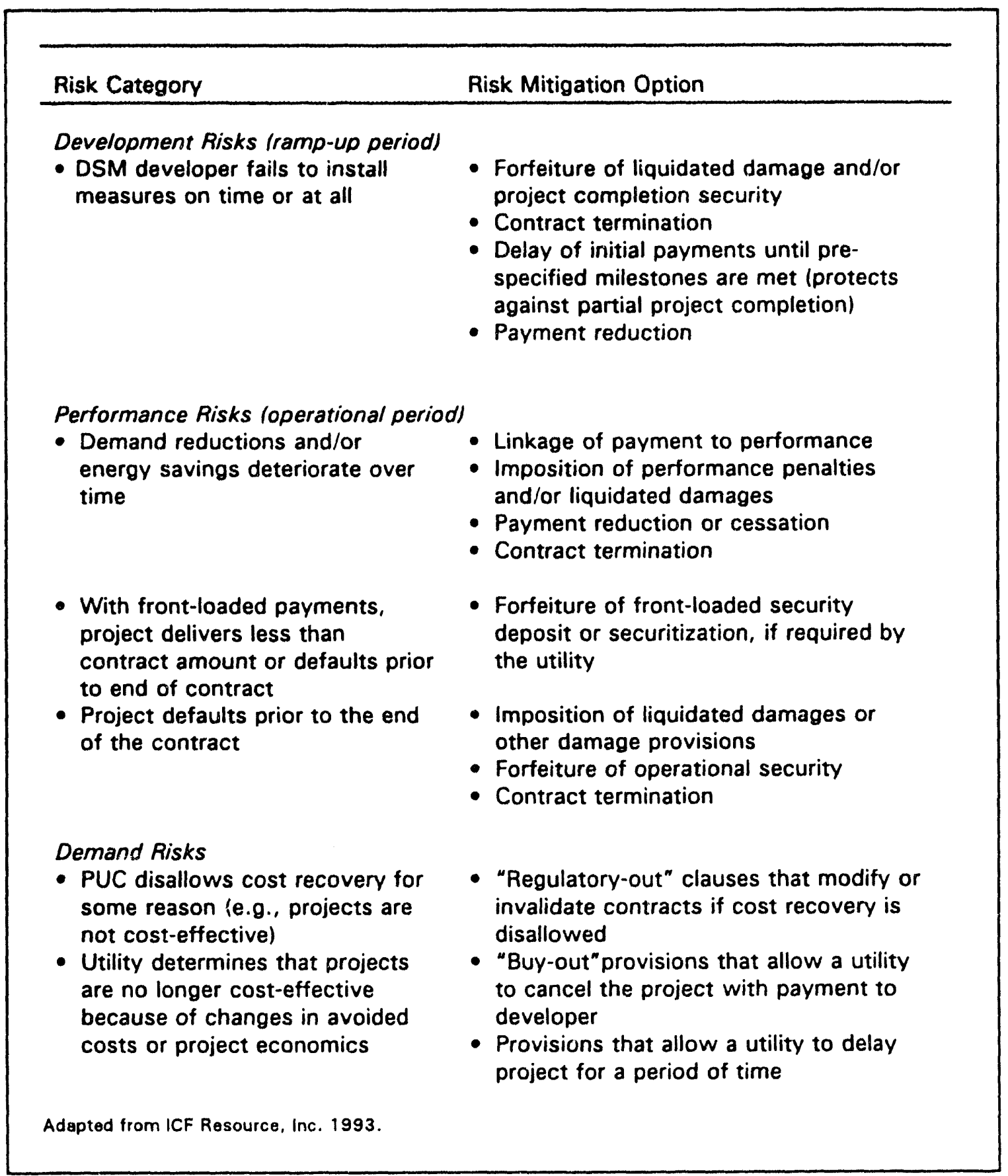




\section{Security Deposits}

Overall, development risks are borne almost entirely by the DSM developer during the ramp-up period of these programs, which typically extends for 2-3 years. ${ }^{41}$ During this period, ESCOs market their program to targeted groups of customers, negotiate energy service agreements with host customers, and then install measures at multiple sites in order to achieve a pre-specified contract demand reduction or energy savings goal. To mitigate the risk that DSM bid projects will not come on-line or will be delayed, utilities typically require some form of liquidated damage and/or project completion security deposits. Table 4-3 lists the deposit requirements for each utility's bidding program, the form of the deposit, as well as the conditions under which the deposit is returned to the developer. For most utilities, these deposits range between $\$ 15-22 / \mathrm{kW}$, or between $\$ 30,000-45,000$ for a two MW project (see Figure 4-1). The deposits are designed to compensate utility ratepayers for project failure which could, in theory, have adverse effects on system reliability and require utilities to turn to alternative and potentially more costly sources of capacity and energy.

It appears that the additional costs incurred by developers are influenced more by the form and duration of the deposit rather than by the actual amount. For example, two utilities (ORU and PSColo) required cash deposits, which are much more expensive for DSM developers than irrevocable letters of credit The opportunity cost of capital on cash deposits, which probably exceeds $11 \%$ per year, is much greater than the fees that DSM developers must pay to financial institutions for an irrevocable letter of credit (i.e., typically $1-5 \%$ of deposit requirement). Moreover, several utilities retain these types of deposits for the entire contract term (e.g., PSColo, PSE\&G, and CMP).

41 However, many contracts include provisions that delay imposition of damages and penalties for events reasonably beyond the control of the DSM bidder (i.e., "force majeure" clauses). 
Table 4-3. Deposit Requirements

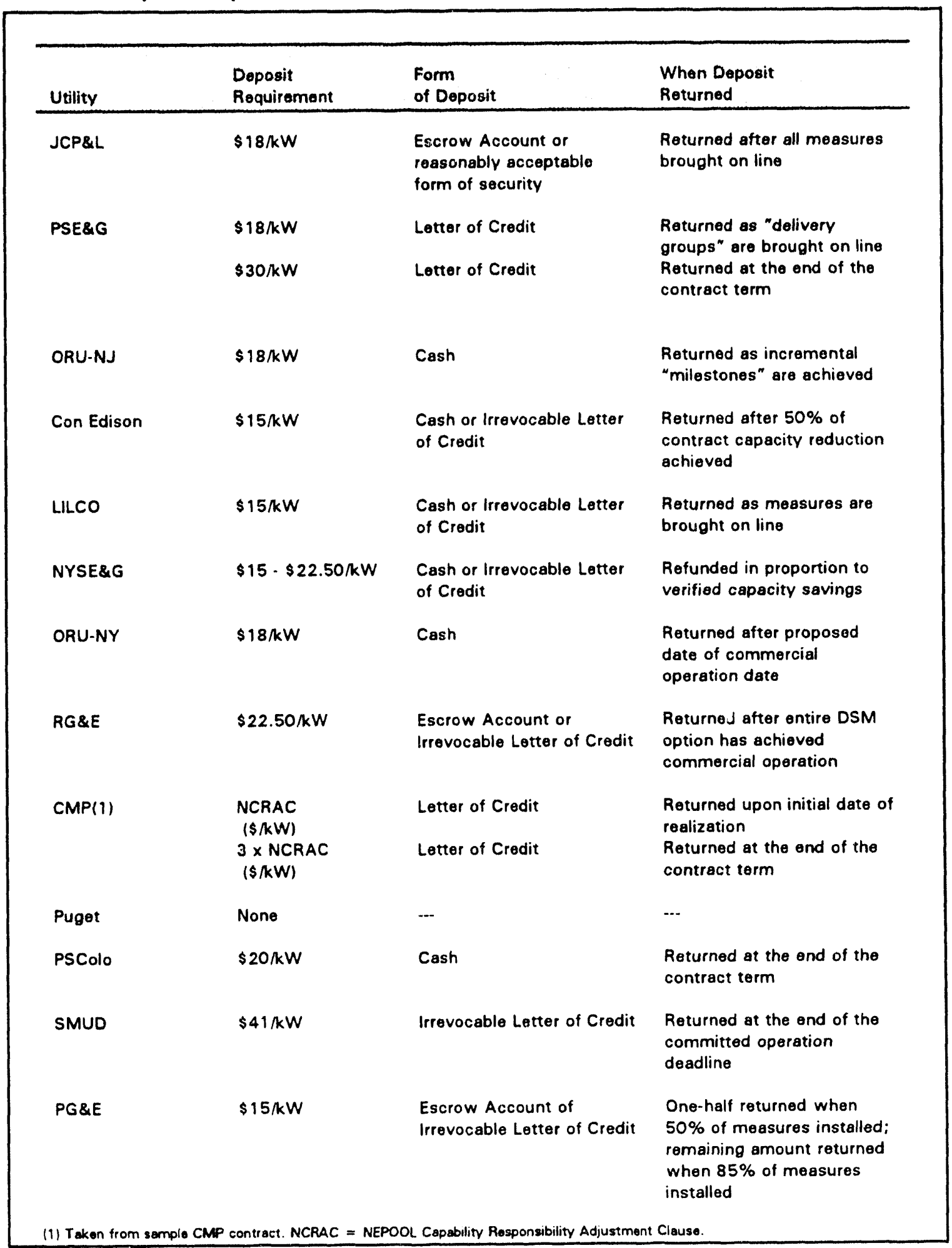


Figure 4-1. Deposit Requirements

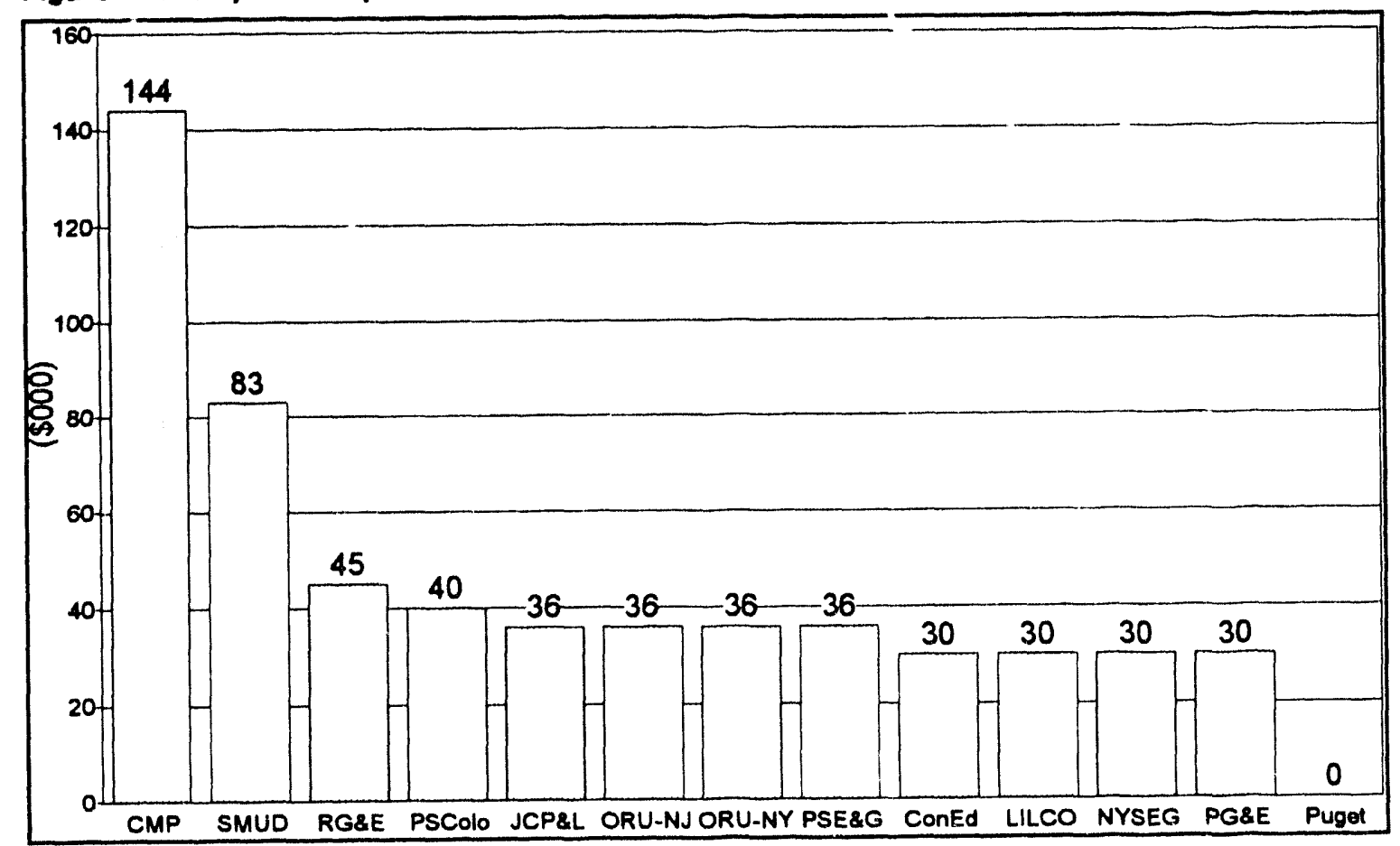

\section{Damage Provisions}

In about half of the bidding programs, developers are required to pay damages equal to the deposit amount times the capacity not installed in the event that the developer is only able to partially complete the contract demand goal (see Table 4-4). In the extreme cases, we found that Puget Power does not impose damages for project delay and failure in its 1989 RFP, while Con Edison, RG\&E, and PG\&E impose damages for partial project completion or project failure based on capacity deficiency charges or lost opportunities which may or may not be related to the amount deposited. 
Table 4-4. Damage Provisions for Partial Project Completion or Project Failure

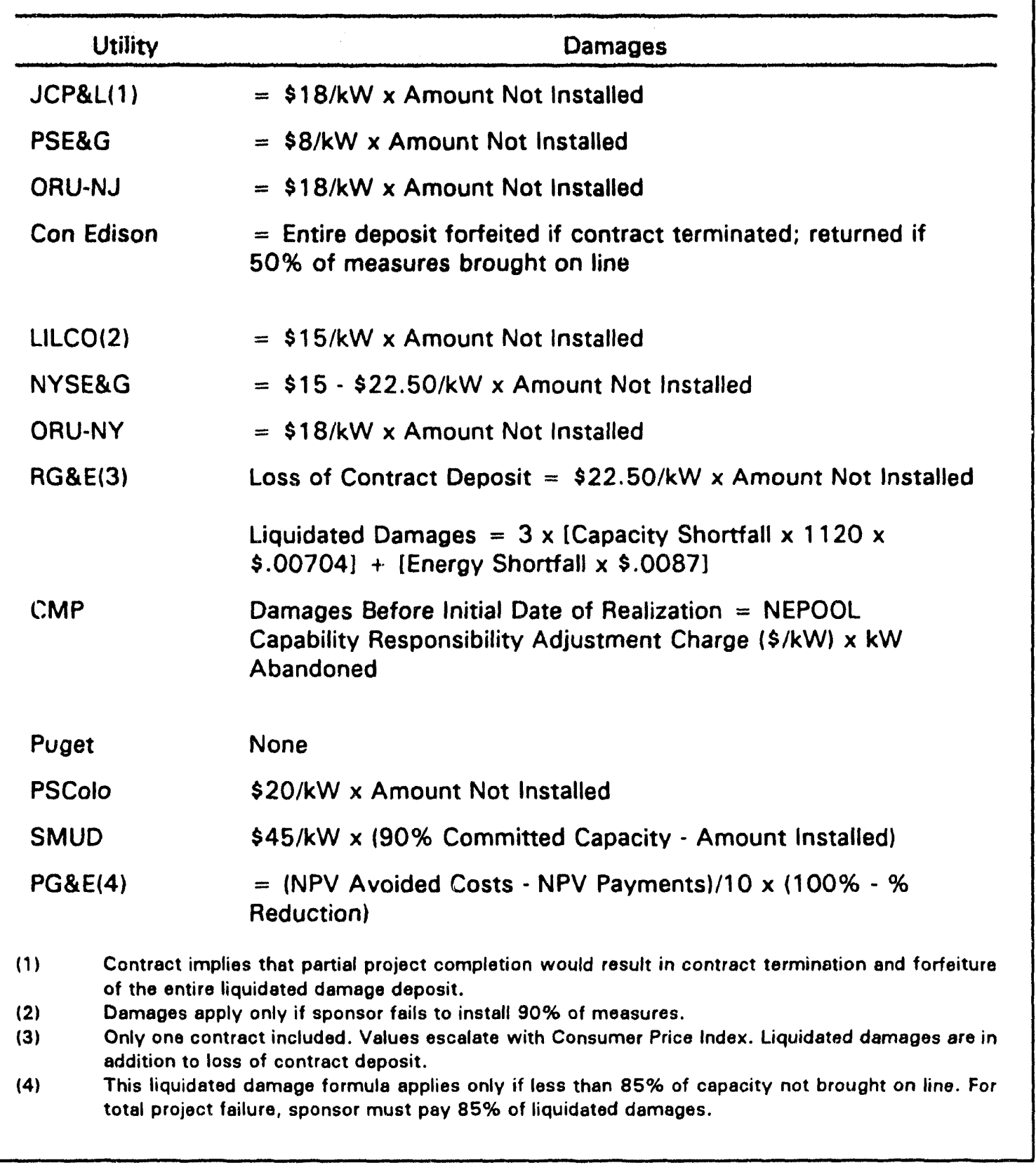




\section{Front-Loaded Security Requirements}

The operational stage occurs after the DSM developer has met its contract demand reduction or energy savings goals and then must maintain and verify savings from installed measures. During this period, the primary risks to utility ratepayers are that the energy savings will not persist over the contract term or that the project will default. To mitigate risks associated with project default, some utilities require additional security for payments that are "front-loaded. ${ }^{42}$ The deposit allows the utility to collect some portion of these overpayments in the event of contract termination or default. Our survey of contracts suggests that almost all utilities require front-loading security except those utilities that make upfront payments to developers based on peak demand reductions (LILCO, ORU-NY, and PSColo) (see Table 4-5). Actual "front-loading" security deposits will depend upon the avoided costs and payment schedules for individual utilities and projects. However, the direct financial impact on DSM developers is probably not that significant because fees to obtain letters of credit are a small percentage of the deposit amount (1-5\%).

Table 4-5. Front-Loaded Security Requirements

\begin{tabular}{|ll|}
\hline & Utilities \\
\hline $\begin{array}{l}\text { Front-Loaded Security Required } \\
\text { if Payments Exceed Avoided }\end{array}$ & $\begin{array}{l}\text { Central Maine Power } \\
\text { Costs }\end{array}$ \\
& $\begin{array}{l}\text { Pacific Gas \& Electric } \\
\text { Puget Sound Power }\end{array}$ \\
& Rochester Gas \& Electric \\
Front-Loaded Security Required & Jersey Central Power \& Light \\
if Payments Exceed Avoided & Orange \& Rockland Utilities-NJ \\
Costs by 35\% & Public Service Electric \& Gas \\
No Front-Loaded & Long Island Lighting Company \\
Security Requirements & New York State Electric \& Gas \\
& Orange \& Rockland-NY \\
& Public Service of Colorado \\
& Sacramento Municipal Utilities District \\
\hline
\end{tabular}

42 Bid payments are "front-loaded" if they exceed the avoided cost benefits of the energy and capacity savings in the initial years of the contract, see Stoft and Kahn, 1990. 


\section{"Pay-for-Performance" and Penalty Provisions}

To mitigate risks associated with persistence of savings, many utilities link payments to verified energy savings, impose performance penalties (or liquidated damages), and, in some cases, reduce or cease payments if demand reductions or energy savings fall below a certain pre-specified level. Table 4-6 summarizes the damage and penalty provisions that DSM developers must pay if savings deteriorate over the term of the contract based upon our survey of signed contracts in various DSM bidding programs. These provisions are often complex and tend to be quite project- and utility-specific. In some of the initial bidding programs in New Jersey and Maine that were integrated supply and DSM RFPs, utilities often linked damages to penalties that they would be obligated to pay to regional power pools in the event of capacity deficiency.

\section{"Regulatory-Out" and "Buyout" Clauses}

There is also a risk that a public utility commission (PUC) may disallow recovery of costs for a DSM bidding program, either during the ramp-up per it or operational stage. On the supply-side, disallowances have often been linked to witerminations that the anticipated need for the generation facility does not currently exist possibly because of a combination of construction delays and lower load growth ("demand risk") or that utilities did not adequately manage or contain construction costs. To mitigate against this risk, many utilities request that PUCs pre-approve contracts or attempt to include "regulatory-out" and "buyout" clauses (see Table 4-7).

"Regulatory-out" clauses allow utilities to terminate or modify a contract if a PUC disallows payments made to a DSM developer. ${ }^{43}$ Not surprisingly, utilities typically try to include these provisions in sample contracts and developers object. Regulators often settle the issue either through explicit Commission decisions or ratemaking policies (e.g., pre-approval of contracts). For example, the New York Public Service Commission (NYPSC) denied requests by most of the seven investor-owned utilities to include "regulatory-out" provisions in their contracts and reserved the right to review future payments for prudence. ${ }^{44}$ In contrast, utilities in New Jersey were allowed to include "regulatory-out" clauses. In the event that utilities are unable to obtain full and timely cost recovery for payments, the developer has the option of either renegotiating and

43 These clauses protect utility shareholders from the financial consequences of disallowances but result in additional financial risks to DSM developers because future cash flows are potentially jeopardized as contractually agreed upon payments are subject to continuing regulatory review.

44 Despite this ban, one utility still included a "regulatory-out" provision in several of their contracts (e.g., NYSEG's contracts with Planergy, HEC, and SESCO). 
Table 4-6. Damages and Penalty Provisions for Savings Deterioration or Parmanent Underdeliveries

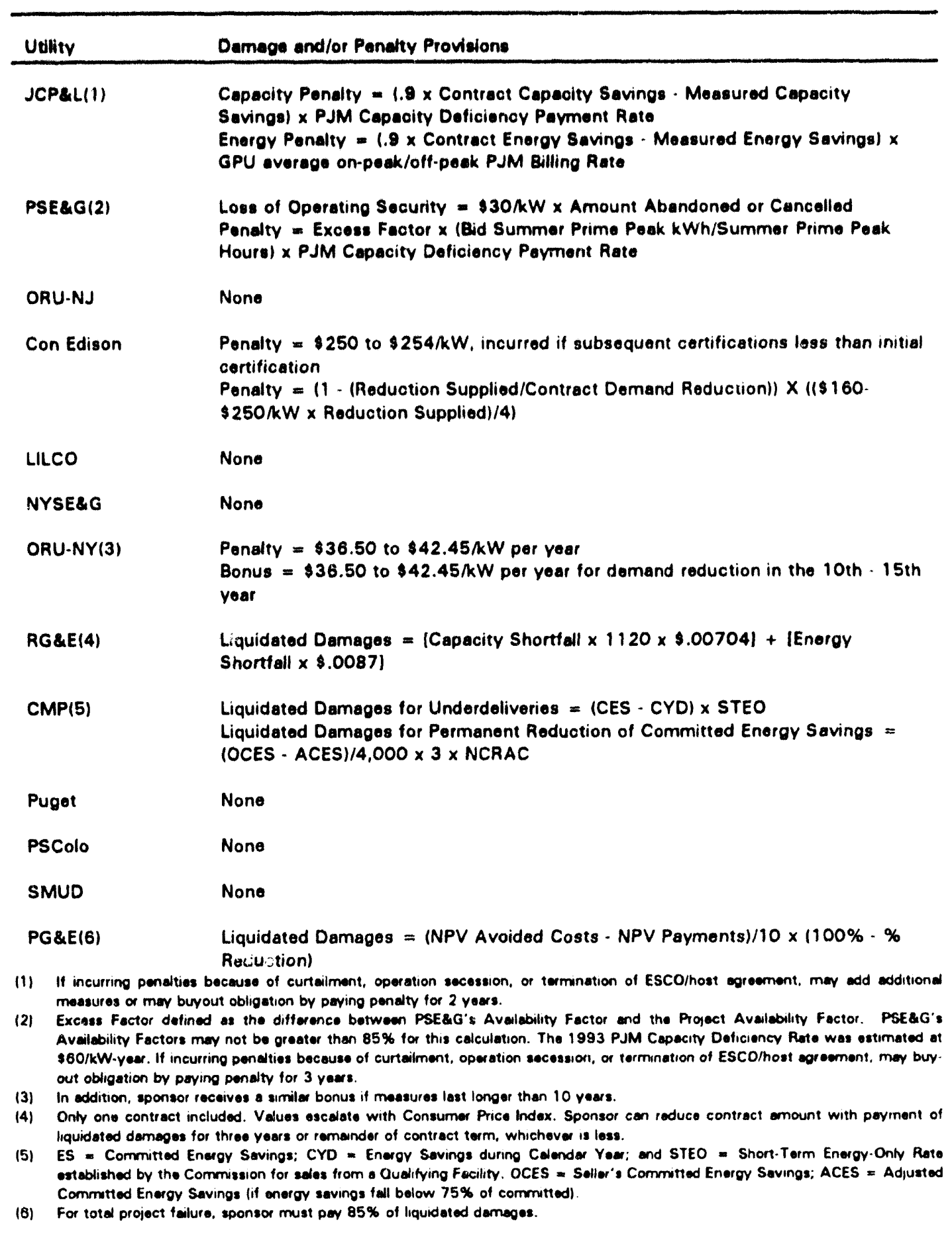


reducing contract rates to those allowed by the New Jersey Board of Regulatory Com missioners ( N J B R C ) or terminating the agreement. The effect of these clauses, howe ver, is substantially diminished because the NJBRC has prea p proved a 11 contracts. ${ }^{45}$ Although future commissioners are not bound by decisions of their predecessors, preapproval of long-term contracts makes it much less likely that future payments to DSM developers would be disallowed.
Table 4-7. Contract Pro-Approval and Regulatory Out Provisions

\begin{tabular}{|lcc|}
\hline Utility & $\begin{array}{c}\text { Pre-Approval } \\
\text { of Contracts }\end{array}$ & $\begin{array}{c}\text { Regulatory-Out } \\
\text { Provisions }\end{array}$ \\
\hline JCP\&L & Yes & Yes \\
PSE\&G & Yes & Yes \\
ORU-NJ & Yes & Yes \\
Con Edison & No & No \\
LILCO & No & No \\
NYSE\&G & No & No \\
ORU-NY & No & No \\
RG\&E & No & No \\
CMP & No & Yes \\
Puget & Yes & No \\
PSColo & Yes & No \\
SMUD & No & No \\
PG\&E & Yes & No \\
& & \\
\hline
\end{tabular}

A few utilities also include buyout and/or project delay clauses that provide options if the DSM project becomes uneconomic because the utility's estimated avoided costs decrease significantly. ${ }^{46}$ These provisions allow a utility to terminate or delay contracts without cause by compensating developers based on a pre-specified payment or formula. For example, one of NYSEG's contracts includes a "convenience termination fee," which is

4 The Board found "that a utility's competitive bid procurement process in its entirety and all power purchase contracts resulting therefrom shall be deemed reasonable and prudent upon and after approval by the Board" and that "all costs reasonably and prudently incurred by the utility including but not limited to purchased energy or energy and capacity costs which result from said contracts and costs associated with the APP's non-performance or termination...shall be flowed through to and/or fully and timely secovered from the utility's ratepayers..." Letter from Elizabeth Ard, JCP\&L, to Chrys Wilson, Board of Public Utilities, Nov. 20, 1990 quoting Board's September 28, 1988 Order entered in Docket No. 8010-687B.

4 Buyout clauses allow the utility to cancel the project with some payment to the developer. Delay clauses allow the utility to delay the project until it becomes economical. 
set at $\$ 57,000$ if the utility terminates the contract within 60 days after the agreement is signed and up to $\$ 159,000$ thereafter. It appears, however, that NYSEG must continue to pay for those measures already brought on-line. In contrast, SMUD's buyout provisions appear to fully compensate the developer for net revenues. ${ }^{47}$ Although buyout and delay features are attractive for the utility, it is difficult to establish an objective standard which would determine the appropriate value. Our survey of contracts suggests that, thus far, these provisions do not result in "stranded investment" for DSM developers.

\subsection{Comparative Analysis of Development and Performance Risks in DSM Bidding Programs}

We compare the relative impact of contract provisions that control development and performance risk in various DSM bidding programs by analyzing a prototypical ESCO project under various scenarios. We apply representative terms and conditions negotiated by each utility in their bidding contracts (see Tables 4-3 to 4-6) to a hypothetical ESCO project that is representative of a winning $\mathrm{C} / \mathrm{I}$ lighting project. Appendix $\mathrm{C}$ summarizes salient contract features that were modeled in our analysis of each utility. ${ }^{48}$ This stylized example provides a quantitative sense of some of the trade-offs involved in allocating these risks to varying degrees among developers.

In the base case, our prototypical project has a demand reduction goal of two MW and will deliver eight $\mathrm{GWh} /$ year over a ten-year period. Bid payments are fixed at $4.0 \mathrm{c} / \mathrm{kWh}$ per year for the term of the contract. Customers will contribute $0.5 \mathrm{c} / \mathrm{kWh}$, while the utility's administrative costs are estimated at $0.3 \mathrm{c} / \mathrm{kWh}$. In our example, avoided costs are assumed to be $3.0 \mathrm{c} / \mathrm{kWh}$ in the first two years, and increase at a rate of $1.0 \mathrm{c} / \mathrm{kWh}$ per year over the contract term. ${ }^{49}$ Over the contract term, the levelized avoided cost

47 SMUD's buyout provision pays the developer the net present value of the purchase price times the power savings less an estimate of costs that the seller will not incur for maintaining and verifying future savings, discounted at $12 \%$.

48 We relied on provisions of sample contracts included in the RFP for CMP where signed contracts were not publicly available. Thus, results for this utility are less representative than other utilities because actual terms and conditions negotiated by bidders may differ significantly from provisions in the sample contract.

49 This avoided cost escalation rate allows us to show the effects of front-loading security requirements. 
value is $5.8 \mathrm{c} / \mathrm{kWh}$, which is somewhat lower than avoided cost estimates published by most utilities in our sample at the time of their bidding RFPs. ${ }^{50}$

This quantitative analysis provides insights on several DSM policy issues: (1) the extent to which the contracts negotiated by each utility protect the financial interests of ratepayers in the event that the expected benefits of DSM projects do not materialize; and (2) the relative impact of damage provisions and the financial uncertainties associated with achieving satisfactory performance and avoiding performance penalties on the bid prices of DSM developers. The advantages of this approach are that it allows for systematic comparison of how DSM development and performance risks were allocated among ratepayers and developers by various utilities while addressing confidentiality concerns relating to individual contracts. The disadvantage is that findings are unique to our stylized ESCO bid.

\subsubsection{Scenario Development}

Starting with our base case (i.e., 100\% of savings achieved), we then develop a set of possible performance scenarios that include total project failure (i.e., $0 \%$ development), partial completion (i.e., 50\% and $75 \%$ installation of contract demand goal), and cases in which savings deteriorate to varying degrees in the last five years of the contract (see Table 4-8). Reasons that savings might not persist include degradation in the performance of installed equipment, changes in hours of operation at host customer facilities, or decisions by customers to remove equipment or go out of business.

For each scenario, we show initial projected payments to the developer and then subtract any damages and penalties that might be incurred for non-performance, which yields project revenues (see Appendix C; Table $\mathrm{C}-1$ ). We compute the societal net benefits and benefit/cost $(B / C)$ ratio by taking the difference between the NPV of the avoided supply costs and the total costs associated with the project. Benefits and costs are discounted at $11 \%$.

so While natural gas prices are not expected to increase at this rate, this schedule assumes that the utility initially has excess capacity foliowed by a capacity deficiency, which makes the avoided costs increase dramatically. 
Table 4-8. Performance Scenarios

\begin{tabular}{|c|c|}
\hline Scenario & Description \\
\hline Base Case & $\begin{array}{l}100 \% \text { of measures are installed; } 100 \% \text { of energy savings } \\
\text { delivered over the contract term }\end{array}$ \\
\hline \multicolumn{2}{|c|}{ Development Risk (due to incomplete installation) } \\
\hline $0 \%$ & $0 \%$ installed \\
\hline $50 \%$ & $\begin{array}{l}50 \% \text { installed, } 50 \% \text { delivery of energy savings over contract } \\
\text { term }\end{array}$ \\
\hline $75 \%$ & $\begin{array}{l}75 \% \text { installed, } 75 \% \text { delivery of energy savings over contract } \\
\text { term }\end{array}$ \\
\hline \multicolumn{2}{|c|}{ Performance Risk (due to savings deterioration) } \\
\hline $50 \%$ & $\begin{array}{l}100 \% \text { installed, } 100 \% \text { of energy savings, years } 1-5,50 \% \text {, } \\
\text { years } 6-10\end{array}$ \\
\hline $75 \%$ & $\begin{array}{l}100 \% \text { installed, } 100 \% \text { of energy savings, years } 1-5,75 \% \text {, } \\
\text { years } 6-10\end{array}$ \\
\hline $90 \%$ & $\begin{array}{l}100 \% \text { installed, } 100 \% \text { of energy savings, years } 1-5,90 \% \text {, } \\
\text { years } 6-10\end{array}$ \\
\hline
\end{tabular}

\subsubsection{Mitigating Development Risks to Utility Ratepayers}

In the base case, the NPV of utility payments and project revenues is about $\$ 1.9$ million, with net societal benefits of $\$ 0.4$ million, giving a $\mathrm{B} / \mathrm{C}$ ratio of 1.21 for our prototypical project.

In the three development risk scenarios, the developers' payments are always reduced in cases of total or partial project failure; project revenues vary among utilities depending on penalty and damage provisions. Figure 4-2 shows damages and penalties that could be imposed by each utility if our two MW project failed completely (i.e., 0\% installation), or was only partially successful (i.e., 50 and $75 \%$ installation of contract demand goal). Damage payments for project failure are $\$ 250,000$ for RG\&E, about $\$ 130,000$ for CMP, approximately $\$ 75,000$ for PG\&E and SMUD, and around $\$ 30,000$ 
Figure 4-2. Damage Payments for Project Failure and Partial Project Completion

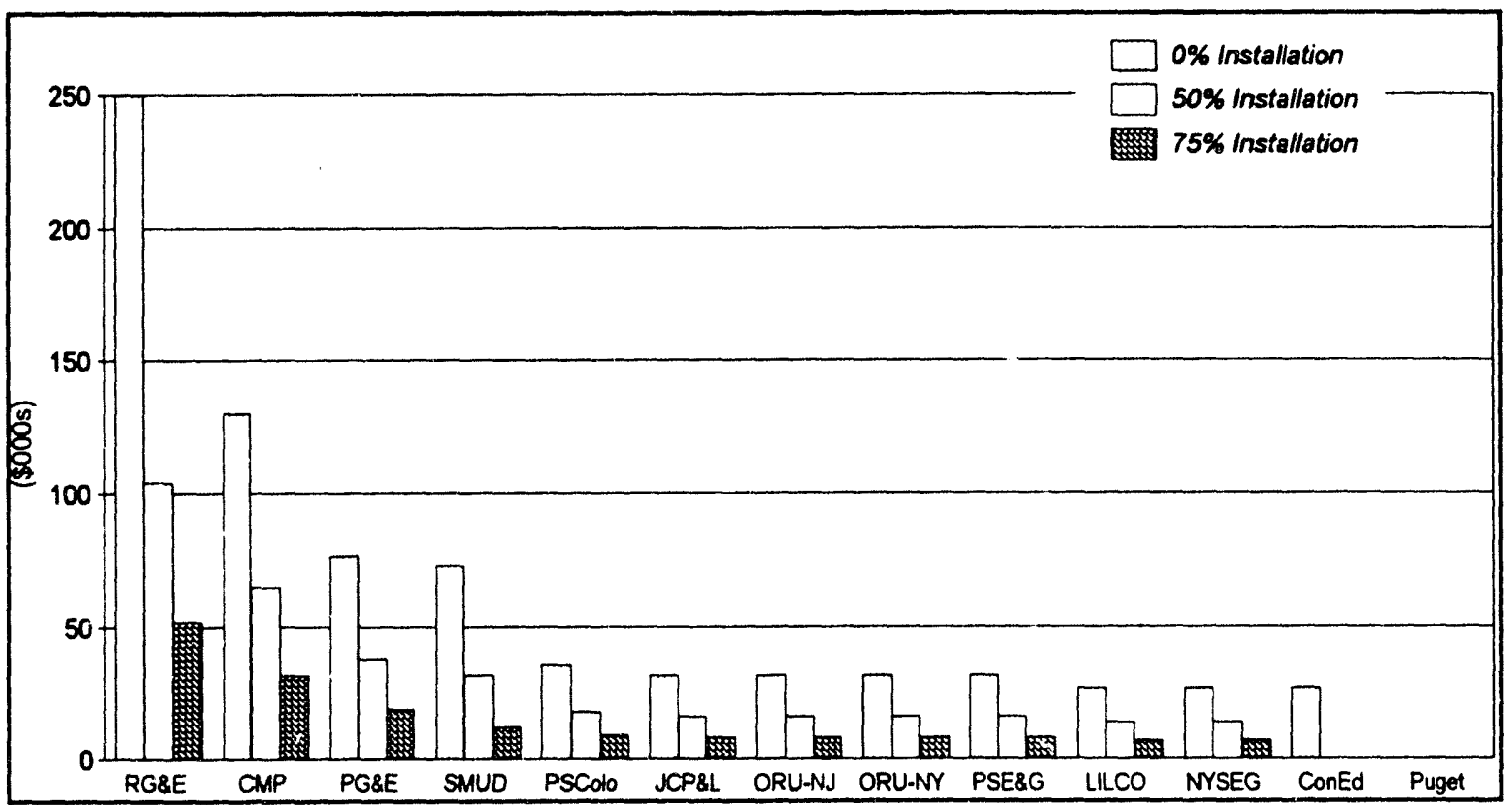

(or between $\$ 15-23 / \mathrm{kW}$ ) for the remaining utilities. ${ }^{51}$ For most utilities in our sample, damages and penalties range from about $2-10 \%$ of the lifecycle payments that our developer would receive in the basecase. Our prototypical project remains cost-effective from a societal perspective in cases where the developer is only partially successful in meeting the contract demand goal, primarily because payments are tied directly to successful installations. As Table 4-9 shows, B/C ratios would actually increase somewhat for several utilities compared to the base case value of 1.21 because of damages that could be imposed on developers if they achieved only $50 \%-75 \%$ of their contract demand goal.

s1 Note that values for CMP are based upon the sample contract and that actual values which were negotiated may be substantially lower. In addition, values for PG\&E are an artifact of our estimates of the avoided costs because PG\&E imposes liquidated damages based upon the program benefits (see Appendix C). 
Table 4-9. Benefit/Cost Ratios for Prototypical Project Under Various Scenarios

\begin{tabular}{|c|c|c|c|}
\hline \multirow[b]{2}{*}{ Utility } & \multicolumn{3}{|c|}{ Development Risk Scenarios } \\
\hline & $\begin{array}{l}50 \% \\
\text { Installed }\end{array}$ & $\begin{array}{l}75 \% \\
\text { Installed }\end{array}$ & $\begin{array}{l}100 \% \\
\text { Installed }\end{array}$ \\
\hline $\begin{array}{l}\text { Basecase Results } \\
\text { NYSEG } \\
\text { RG\&E } \\
\text { CMP } \\
\text { PG\&E } \\
\text { SMUD } \\
\text { OUR-NJ } \\
\text { ORU-NY } \\
\text { PSColo } \\
\text { LILCO } \\
\text { Puget } \\
\text { PSE\&G } \\
\text { Con Edison } \\
\text { JCP\&L }\end{array}$ & $\begin{array}{l}1.34 \\
1.33 \\
1.28 \\
1.25 \\
1.24 \\
1.23 \\
1.23 \\
1.23 \\
1.22 \\
1.21 \\
1.21 \\
1.21 \\
\mathrm{n} / \mathrm{a}\end{array}$ & $\begin{array}{l}1.21 \\
1.25 \\
1.23 \\
1.22 \\
1.22 \\
1.22 \\
1.22 \\
1.22 \\
1.21 \\
1.21 \\
1.21 \\
1.21 \\
\text { n/a }\end{array}$ & 1.21 \\
\hline Utility & $50 \%$ & $\begin{array}{l}\text { ormance Ri } \\
\text { Savings Per } \\
75 \%\end{array}$ & $\begin{array}{l}\text { rios } \\
90 \%\end{array}$ \\
\hline $\begin{array}{l}\text { Con Edison } \\
\text { JCP\&L } \\
\text { CMP } \\
\text { RG\&E } \\
\text { PG\&E } \\
\text { NYSEG } \\
\text { SMUD } \\
\text { ORU-NJ } \\
\text { PUget } \\
\text { PSE\&G } \\
\text { ORU-NY } \\
\text { PSColo } \\
\text { LILCO }\end{array}$ & $\begin{array}{l}1.25 \\
1.17 \\
1.14 \\
1.10 \\
1.09 \\
1.07 \\
1.07 \\
1.07 \\
1.07 \\
1.07 \\
0.90 \\
0.90 \\
0.90\end{array}$ & $\begin{array}{l}1.24 \\
1.18 \\
1.18 \\
1.16 \\
1.15 \\
1.15 \\
1.15 \\
1.15 \\
1.05 \\
1.15 \\
1.06 \\
1.06 \\
1.06\end{array}$ & $\begin{array}{l}1.21 \\
1.19 \\
1.20 \\
1.19 \\
1.19 \\
1.19 \\
1.19 \\
1.19 \\
1.19 \\
1.19 \\
1.15 \\
1.15 \\
1.15\end{array}$ \\
\hline
\end{tabular}

Notes: see Table 47 for a description of each scenario 


\subsubsection{Mitigating Performance Risks to Utility Ratepayers}

Table 4-9 also shows the benefit/cost ratios for each utility's bidding program if savings deteriorate in the last five years at our prototypical project. ${ }^{52}$ At most utilities, our project remains cost-effective from a total resource cost perspective and ratepayers are protected despite the fact that savings do not persist. However, LILCO, ORU-NY, and PSColo are notable exceptions in this area as these utilities make full payments to DSM developers after initial verification of peak demand reductions from installed measures. If savings deteriorated by $50 \%$ in the last five years at our prototypical project, the project would no longer be cost-effective at these three utilities given their contract provisions.

Figure 4-3 shows the risks to the DSM developer. We express payments to the developer as a percentage of the base case payments if energy savings deteriorate by $50 \%$ in years 6 through 10 . Payments are reduced by $30-35 \%$ at most utilities with differences due primarily to variation in penalties. If we assume that most of the developer's costs for

Figure 4-3. Payments with $50 \%$ Savings Deterioration in Years $6-10$ as a Percentage of Base Case Payments

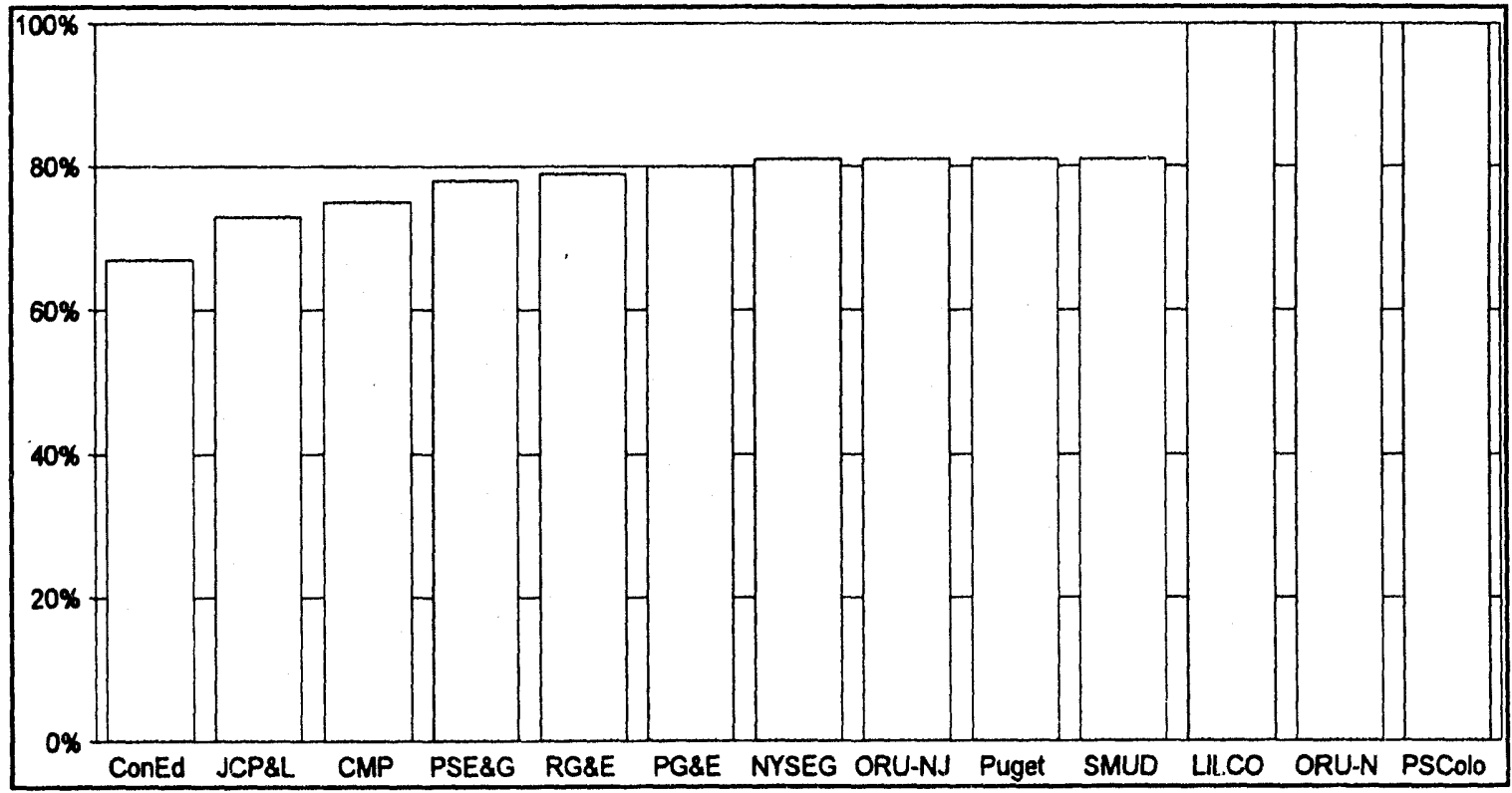

52 This assumes that the utility's forecast of avoided costs does not decrease significantly. 
the project are fixed (e.g., capital cost of installing measures), a $30-35 \%$ reduction in revenues will have a significant impact on the developer's return on investment. ${ }^{53}$

Among the bidding programs in our sample, Con Edison's provisions appear to be the most stringent. The utility can reduce payments by $\$ 250 / \mathrm{kW}$ if measures do not produce demand savings over the term of the contract. Con Edison also can impose penalties that vary from about $\$ 3-\$ 15 / \mathrm{kW}$ during the "summer peak period months" based upon a complex formula.

\subsection{4 "Downside" and "Upside" Risks for DSM Developers}

These contract features create substantial risks for DSM developers. Decreased payments from the utility are likely to reduce the expected return from projects and the utility can often terminate the contract in the event of partial project completion. Typically, utilities may terminate the contract for that portion not brought on-line, although JCP\&L's contracts apparently allowed the utility to terminate the contract and discontinue all payments. Figure 4-4 illustrates these two approaches. ${ }^{54}$ In this latter situation, contract termination for partial project completion results in the additional risk of "stranded investment" for the DSM developer because capital outlays have been made but the revenue stream discontinued. The Con Edison and RG\&E contracts also indicate that the agreement may be terminated if less than $50 \%$ of the measures were installed, but it is unclear whether payments for previously installed capacity would cease as well. Thus, damage provisions combined with the threat of contract termination impose substantial risks on the DSM developer. In the worst case, project viability may be threatened, unless the DSM developer can shift these performance risks to the host customer.

Some bidding contracts provide upside financial opportunities for DSM developers that exceed contract goals. This involves a recognition that it is difficult for an ESCO to install the specified contract demand goal (e.g., two MW) exactly given the "lumpiness" of savings from projects at individual facilities. For example, the JCP\&L and PSE\&G contracts explicitly indicate that the utilities will pay for up to $110 \%$ of the committed energy and capacity. In contrast, NYSEG's contract includes a provision that they are not obliged to pay for more than $100 \%$ of the committed capacity. Based on our contract review, many other utility bidding programs appear to be silent on this issue.

53 We have ignored the effect of contractual arrangement between the DSM developer and host customers, because these contracts are not publicly available.

JCP\&L did not enforce this provision due to an agreement reached among the interested parties. 
While contract quantity goals are most often specified in terms of p e a $k$ d e m a n d reductions, payments to the developer are often linked to energy (rather than demand) savings. Because hours of operation are difficult to predict accurately, many utilities are willing to pay for more than $100 \%$ of the energy savings over the contract term. For example, utilities in New Jersey agreed to pay up to $110 \%$ of the energy savings, whereas the potential upside for DSM developers ranges between $115 \%$ - 150\% of expected savings in contracts negotiated by $P G \& E$ i $n$ i $t s$ PowerSaving Partners program.

\subsection{Summary}

Figure 4-4. Termination for Partial Project Completion
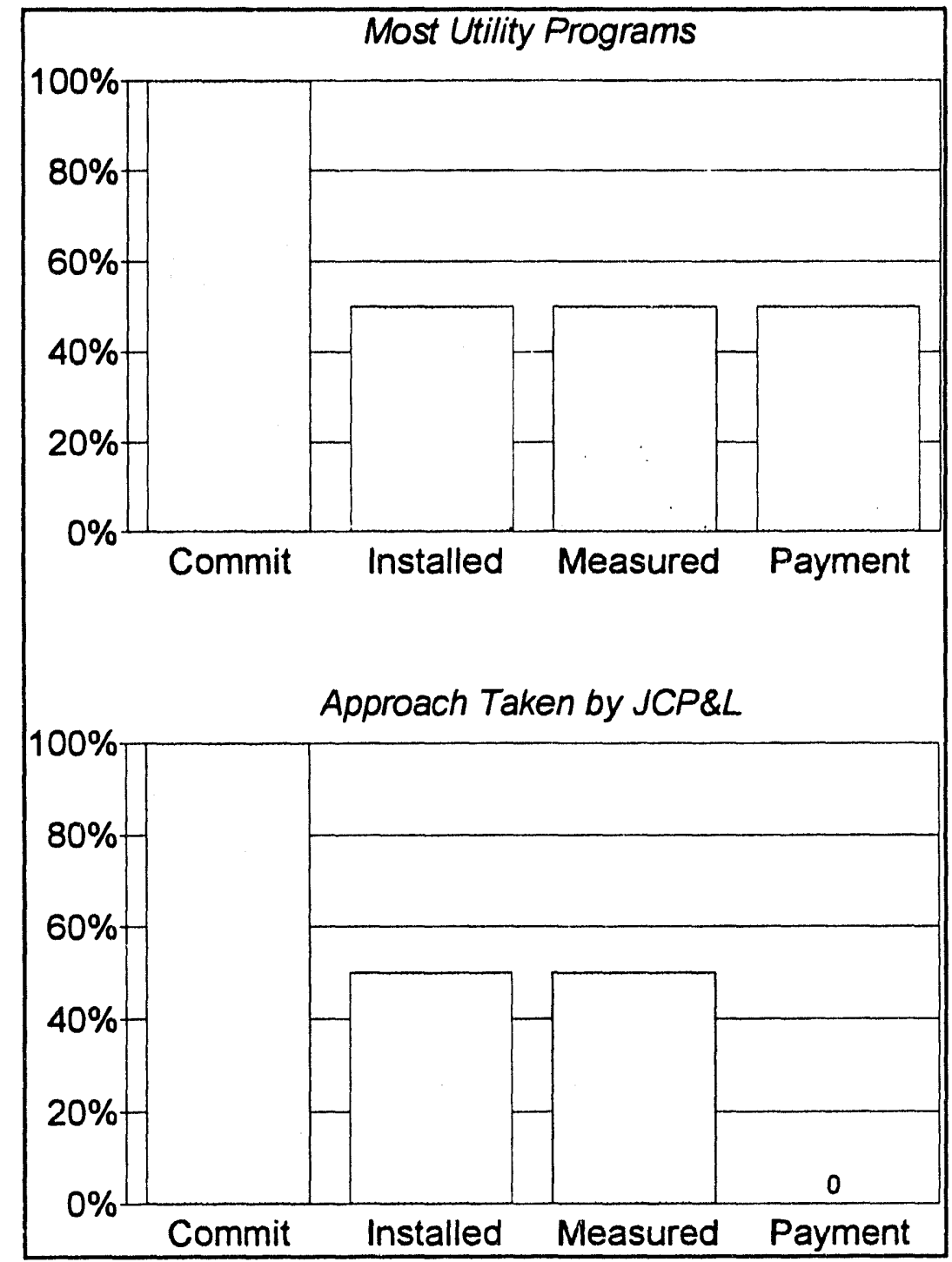

Allocation of the development and performance risks associated with DSM resources to DSM developers rather than ratepayers is a distinctive feature of DSM bidding programs compared to utility rebate programs. Our analysis also suggests that the risks associated with the "pay for performance" provisions that link payments over the contract term from the utility to verified savings are responsible for the bulk of the performance risk on DSM developers. Penalty and damage provisions and risks of potential stranded investment pose severe risks in a few bidding programs (e.g., Con Edison, RG\&E, and JCP\&L). For most utilities, the additional costs associated with damage deposits do not 
appear to be particularly onerous. The effect of these deposits on the bid prices of DSM developers is likely to be small compared to the potential risks and uncertainties related to "pay for performance," penalty, and project termination clauses. 


\section{Implications for DSM Policy and Bidding Program Design}

\subsection{Overview}

In this chapter, we suggest ways to improve the design and implementation of future DSM bidding programs in several areas:

- design strategies that are more likely to minimize the cost of acquired DSM resources;

- design strategies that encourage DSM bidders to obtain cost contributions from host customers;

- design strategies and contracting approaches that encourage DSM developers to install comprehensive packages of retrofits;

- contracting approaches that lead to a more efficient allocation of DSM development and performance risks among utility ratepayers, DSM developers, and host customers.

We then summarize key findings and discuss potential DSM policy implications based on our review of DSM bidding programs.

\subsection{Recommendations on the Design and Implementation of DSM Bidding Programs}

\subsubsection{Separate RFPs for DSM Resources are Preferable}

Choice of auction format (e.g., inclusion of supply-side and DSM resources) is the first major issue that utilities must confront in designing a bidding process. Our results suggest that bid payments were higher for those utilities that issued integrated supply-and DSM solicitations compared to those utilities that used either separate RFPs for DSM resources or parallel RFPs for supply and DSM (see section 3.4.3). Allowing DSM providers to participate in auctions that were often designed to procure generation resources increases the chance that utilities will pay more than is necessary to acquire DSM resources.

Moreover, several key differences between supply-side and DSM resources argue for procurement processes that are specifically tailored to evaluate the attributes and distinctive features of each resource. Supply-side and DSM resources differ significantly 
in terms of market structure, inherent characteristics, and level of development (see Table 5-1). On the supply-side, there is a more well-developed infrastructure of private power developers, whereas the energy services industry is relatively immature (although growing rapidly). Moreover, the provision of "saved energy" typically involves a complex relationship among customers, the ESCO, and utility, while supply-side power providers have a more straight-forward relationship with the utility only. Finally, the output of demand-side resources can never be measured with the same degree of certainty as supply-side resources.

Thus, for both theoretical and practical reasons, we prefer separate solicitations for supply-side and DSM resources or, at a minimum, the use of separate RFPs with distinctive scoring systems issued in parallel in an integrated bidding program. Use of separate solicitations for generation and DSM resources requires utilities to demonstrate that offers received can be effectively reconciled as part of an integrated resource planning process.

\subsubsection{Economic Valuation of DSM Bids}

The appropriate economic benchmark to use in valuing DSM bids is the next major design issue that utilities confront in DSM bidding programs. This issue is complicated by the fact that utilities are often trying to reconcile conflicting objectives with respect to DSM resources (e.g., maximize economic benefits to society, limit short-term rate impacts). The two most common approaches used by utilities to evaluate the economics of DSM bids involve (1) estimating total resource costs relative to the utility's avoided supply cost and (2) estimating utility payments to bidders relative to the utility's cost for delivering a "comparable" DSM program. This latter approach focuses on the utility's alternatives for acquiring DSM resources (i.e., DSM opportunity costs).

Specific program design and bid evaluation/scoring options include:

- $\quad$ Rank bids based on TRC test results ${ }^{55}$ - This approach has been mandated by a few PUCs and is theoretically appealing for many regulators, but often leads to perverse results in a DSM bidding context. In bidding programs that have used this approach, DSM bidders may maximize payments from the utility and not host customers. Minimal cost contributions from customers tends to exacerbate shortterm rate impacts.

ss In bidding, this is typically done either by ranking and scoring bids by benefit/cost ratios or total resource costs as a percent of avoided costs. 
Table 5-1. Comparability of Non-Utility Supply and DSM Options in Bidding

\begin{tabular}{|c|c|c|}
\hline & IPP/OF Project & ESCO Project \\
\hline $\begin{array}{l}\text { Market } \\
\text { Structure/Development } \\
\text { Setting }\end{array}$ & Wholesale & Retail \\
\hline Infrastructure Maturity & $\begin{array}{l}\text { Well-developed; over- } \\
\text { subscribed auctions }\end{array}$ & $\begin{array}{l}\text { "Infant" industry; new } \\
\text { players entering } \\
\text { market }\end{array}$ \\
\hline \multicolumn{3}{|l|}{ Resource Characteristics } \\
\hline Scale & $\begin{array}{l}\text { - order of magnitude larger } \\
\text { than DSM }\end{array}$ & - $2-15 \mathrm{MW}$ \\
\hline Economic Lifetime & - $20-30$ yrs & - $5.20 \mathrm{yrs}$ \\
\hline Proj. Lead Time & - $3-5$ yrs & $\begin{array}{l}\text { - } 0.5-4 \text { yrs; slow } \\
\text { ramp-up }\end{array}$ \\
\hline Dispatchability & $\begin{array}{l}\text { - utility control over output } \\
\text { subject to contract } \\
\text { provisions }\end{array}$ & $\begin{array}{l}\text { - utility control } \\
\text { limited compared } \\
\text { to supply }\end{array}$ \\
\hline $\begin{array}{l}\text { Principal } \\
\text { Uncertainties/Risks for } \\
\text { Ratepayers }\end{array}$ & $\begin{array}{l}\text { - Future fuel costs } \\
\text { - Envr. impacts }\end{array}$ & $\begin{array}{l}\text { Measurement of } \\
\text { output (i.e. } \\
\text { savings) } \\
\text { - Assessing societal } \\
\text { cost-effectiveness }\end{array}$ \\
\hline "Dispersity"/Diversity & - Much less diffuse & $\begin{array}{l}\text { - Highly diffuse and } \\
\text { diverse }\end{array}$ \\
\hline Ownership & - IPP/QF & $\begin{array}{l}\text { - Customer, not } \\
\text { ESCO }\end{array}$ \\
\hline \multicolumn{3}{|l|}{ Customer Involvement } \\
\hline Degree & - Little to none & - Significant \\
\hline $\begin{array}{l}\text { Cust. } \\
\text { service/satisfaction }\end{array}$ & - Not an issue & - Major concern \\
\hline
\end{tabular}


- Rank bids based on scoring metrics that focus on benefits and costs to the utility In this approach, the utility attempts to send a clear signal to DSM developers that they should maximize net resource benefits, while minimizing payments from the utility. The Utility Cost Test, and the so-called "Bang for the Buck" score used by several California utilities (e.g., SCE and SDG\&E) are examples of this approach. ${ }^{56}$

- $\quad$ Establish DSM ceiling prices using threshold requirements - This approach can be characterized as the "blunt" design approach. The utility constrains bid prices by listing maximum prices to be paid for DSM measures in the threshold requirements of its RFP. DSM ceiling prices are typically set relative to the utility's costs for similar utility-operated DSM programs. For example, several utilities have used their rebate levels plus an additional factor (e.g., $30-50 \%)$ to account for additional marketing costs and performance risks to bidders. Utilities that have used this approach (e.g., LILCO, ORU-NY) also have less stringent "pay-for-performance" provisions in their contracts, which means that ratepayers bear most of the performance risk. Another problem with this approach is that the underlying rationale for rebate levels for particular DSM measures is often not well articulated by utilities and some utilities change their rebate levels relatively frequently.

- $\quad$ Rank bids based on other measures of value to the utility - This approach relies more heavily on the utility's subjective judgment in contrast to the other approaches where DSM bids are typically scored on some pre-established objective criteria score. In its RFP, the utility provides bidders with qualitative guidance on desirable attributes (e.g., bids that are attractive compared to current utility programs, minimize utility cost contribution, demonstrate societal benefits) and then evaluates bids based on their value. Aside from the analytic challenges (which are substantial), the basic issue in this approach comes down to trust. The challenge for the utility is to convince the regulatory agency and other interested parties that it can evaluate bids fairly, which is easier if the utility does not have perceived conflicts of interest. This approach is theoretically appealing because it is often quite difficult for an objective scoring system to fully reflect and capture the economic value of bidder's projects. However, objective scoring of a project's economic attributes does have the important advantage that the results are transparent (and easily auditable).

so The "Bang for the Buck" score is calculated by the following formula: total resource net benefits/utility program costs. It reflects an implicit weighting of a total resource and utility perspective. 
In a DSM-only bidding program, we would recommend against relying solely on the TRC test to evaluate the economics of bids, and would suggest using the TRC test as a threshold requirement. ${ }^{57}$ Bid scoring metrics that focus on costs to the utility, either objective or subjective, will tend to encourage DSM developers to obtain maximum cost contributions from host customers. We expect this to become an even more prominent design feature of DSM programs as utilities respond to increasing competitive pressures by attempting to structure DSM programs so as to minimize rate impacts.

\subsubsection{Strategies that Encourage DSM Developers to Propose and Install Comprehensive Packages of Measures}

Some proponents of DSM bidding initially argued that these programs would provide a good opportunity for ESCOs to offer innovative services and comprehensive packages of measures to customers. In part, they were critical of DSM rebate programs, which they claimed often resulted in "cream-skimming" because a limited number of end uses (e.g., lighting) or measures were targeted. "Cream-skimming" is a problem for DSM resource acquisition to the extent that other cost-effective measures are unlikely to be installed at a given site after the initial installation has been made.

For some utilities, the degree of comprehensiveness of services and measures offered by DSM developers was an important element in their assessment of bid quality. However, our results suggest that utilities frequently had difficulty crafting enforceable contract provisions to ensure that DSM bidders install comprehensive packages of measures in the commercial sector as indicated in their bid proposals (see section 3.4.3). This issue is important because utilities typically agree to pay more to bidders that offer customers a comprehensive set of measures and services than bidders offering more limited services or measures.

Based on results to date, ESCOs have not been particularly successful in convincing customers to install comprehensive retrofits, defined as multiple measures in several end uses. We documented a number of instances in which DSM developers proposed the installation of comprehensive packages of measures, but ultimately installed only lighting measures. ESCOs and utilities report a number of barriers that make it difficult to install comprehensive retrofit packages, including small benefits to customers (in terms of bill savings) from some motor retrofits and difficulties specifying appropriate measurement and verification protocols for certain HVAC measures (particularly controls).

57 More emphasis should be placed on TRC test results to select among supply and DSM projects if utilities are required to conduct integrated bidding. 
These problems - encouraging DSM developers to propose comprehensive measures and then getting developers to install what they proposed - have been recognized for some time. A number of utilities have tried to address this issue explicitly either in the design of their bidding RFPs, through specific contractual mechanisms, or during program implementation.

\section{Design of Bidding RFPs}

Utilities have used several strategies to encourage the installation of comprehensive retrofits in their RFP designs:

- Specifying as a threshold requirement the maximum amount or percent of savings/demand reductions that can be obtained from a particular end use (e.g., LILCO stated that no more than $70 \%$ of the savings could come from lighting measures);

- Specifying as a threshold requirement that a logical grouping of measures (ECM packages) that include all cost-effective measures be considered to avoid creamskimming or creating lost opportunities;

- $\quad$ Establishing a comprehensiveness attribute in scoring systems and assigning a significant weight (e.g., Commonwealth Electric and PG\&E assigned 10\% and $7 \%$ respectively for comprehensiveness); and

- Specifying different ceiling prices for individual measures, rather than a bundled price for the installation of a mix of measures. This approach may limit the problem of potentially "overpaying" for certain DSM measures. Conversely, utilities could use this strategy to encourage DSM developers to promote certain technologies that either have higher resource value to the utility or higher perceived market barriers.

\section{Contract Provisions}

Utilities typically attempt to reflect the representations made by DSM bidders in proposals in specific contract provisions. Examples include:

- Provisions that limit the utility's obligation to make payments - For example, contracts in SMUD's bidding program indicate that the utility does not have to 

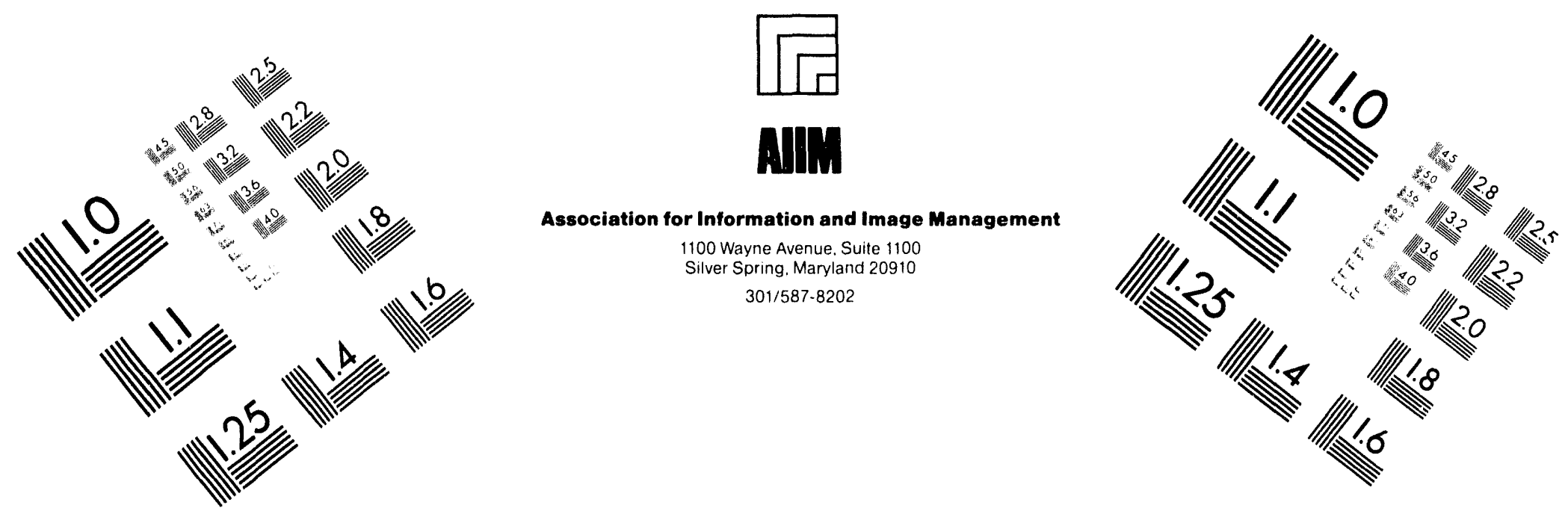

\section{Centimeter}

(12) | Inches
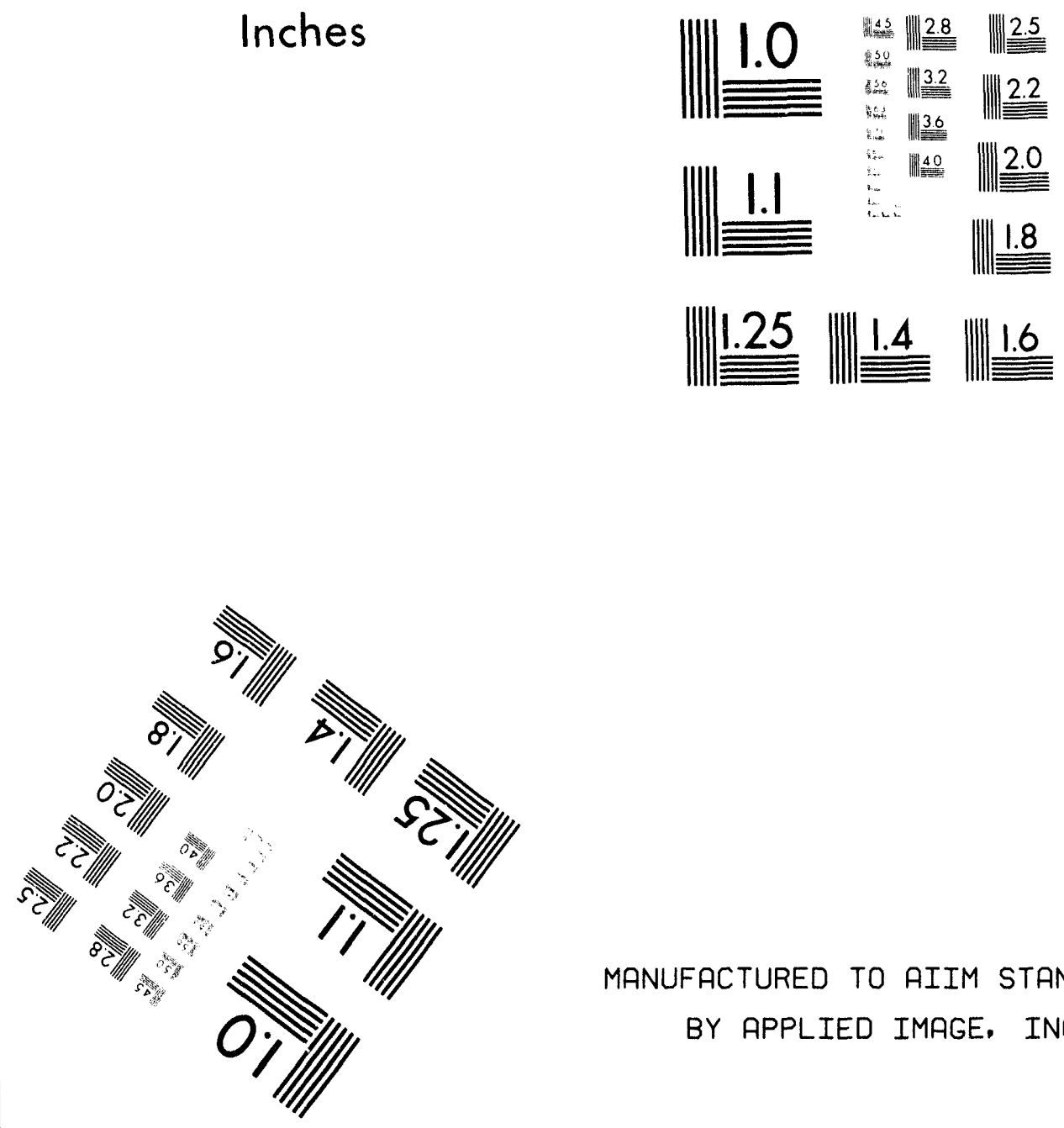

MANUFACTURED TO AIIM STANDARDS BY APPLIED IMAGE, INC.

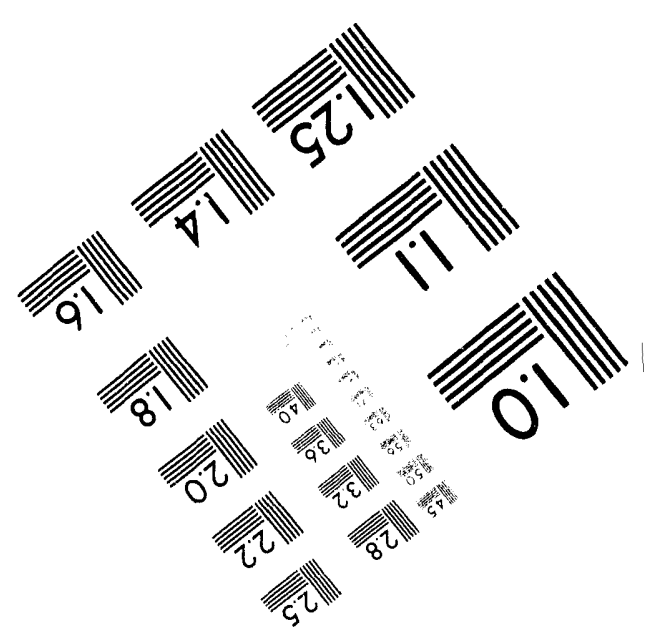



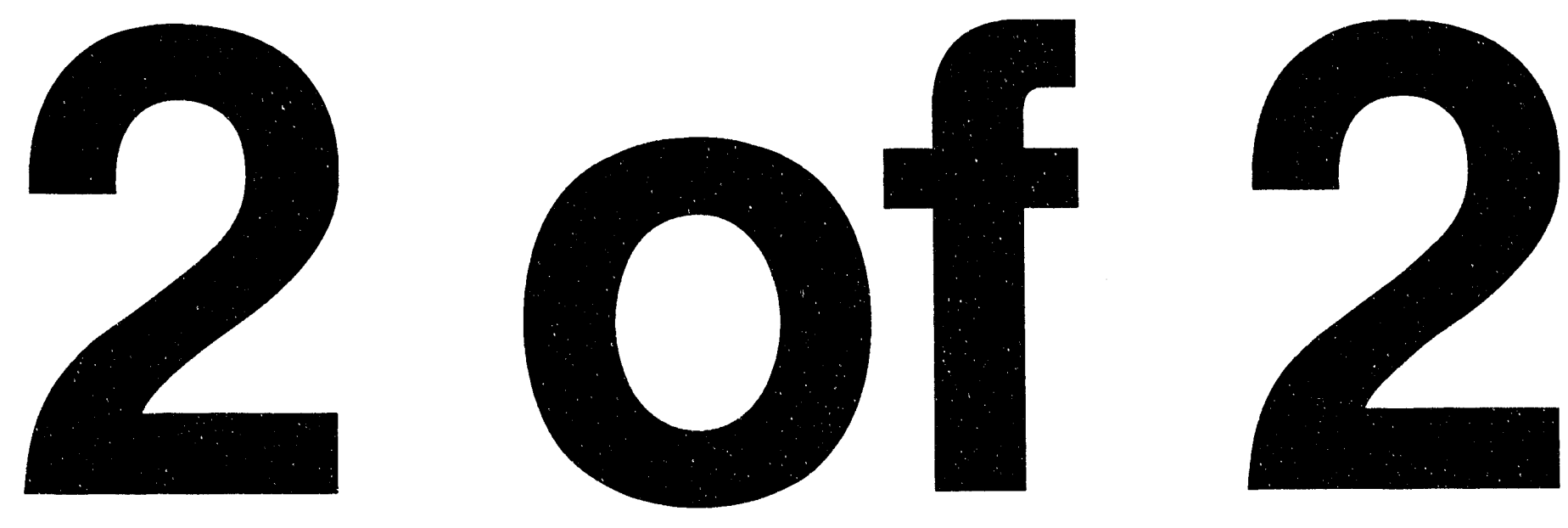
pay for capacity savings that result from lighting technologies if these savings represent in excess of $70 \%$ of the total contract capacity.

- "Tiered pricing" provisions - Conversely, a utility could negotiate various types of tiered pricing schemes in which a DSM developer would receive a higher bid payment if they achieve savings reductions that exceeded a pre-specified amount (either at end use or whole-building level). The level of bid payments could also be linked to the mix of measures achieved.

- $\quad$ Measurement and verification (M\&V) protocols - Many M\&V protocols included in contracts require DSM developers to submit descriptions of individual projects, which generally include a list of all cost-effective measures, the types of measures that will ultimately be installed, and a proposed M\&V plan for the facility. The contracts often specify that utilities must approve the M\&V plan for individual facilities. At this time, utility program managers have an opportunity to monitor the type and mix of measures being installed.

\subsection{Efficient Allocation of Performance and Development Risks}

In this section, we offer suggestions on several contract provisions that affect the allocation of development and performance risks among utility ratepayers, DSM developers, and host customers.

Economic theory suggests that it is more efficient if risks are borne by those parties that are best able to control and manage them. In the context of DSM bidding programs, we suggest that DSM developers should bear the development and performance risks associated with potential installation cost overruns and savings deterioration, but perhaps not be fully responsible for risks, such as hours of operation, over which they may have relatively little control.

- Impose "liquidated damages" based upon an assessment of the damages actually incurred by the utility for DSM project failure - At least three utilities have tried to quantify the damages (or costs) to a utility of DSM project failure. Two utilities based damages upon their estimates of the costs of replacement capacity, while PG\&E linked damages to the amount of money that utility ratepayers would lose because the project failed to produce expected benefits. PG\&E assumes that a DSM project san be replaced in one year and assesses damages roughly based upon the project benefits foregone during that one year period. The remaining utilities concede t'iat damages are too difficult for them to quantify and rely on damage assessments primarily drawn from supply-side contracts, which generally 
vary from $\$ 15-\$ 30 / \mathrm{kW}$, although a few utilities have established much higher levels. ${ }^{58}$ The advantage of the "supply-side" approach is that it is simple and straightforward and provides DSM bidders with comparable incentives to fulfill their contractual obligations in different regions of the country. ${ }^{59}$ Conceptually, it would be preferable to base damages upon actual losses or additional costs incurred by the utility. PG\&E's approach is innovative in this sense in that it explicitly considers the characteristics of DSM resources. ${ }^{60}$

- $\quad$ For factors outside the control of DSM developers, there should be some sharing of risks and rewards between DSM developers, ratepayers, and host customers Over time, utilities have increased the acceptable range in energy savings deliveries that DSM developers are allowed in fulfilling contract demand reduction goals. In part, this reflects a recognition that changes in hours of operation often depend upon host customer use patterns, weather, and other factors largely beyond the control of third-party DSM developers. In some of the early bidding programs, utilities commonly agreed to pay for energy savings ranging from $90 \%$ to $110 \%$ of the contract goal, and imposed penalties for failure to meet the lower target. This "performance band" has expanded considerably in more recent bidding programs. For example, SCE has agreed to pay for energy savings ranging from $85 \%-115 \%$ of the contract goal and PG\&E has individually negotiated contracts which in some cases pay up to $150 \%$ of the energy savings goal, but only if savings are attributable to increased hours of operation. Hours of operation risk is difficult for DSM bidders to cortrol unless they craft enforceable contract provisions with host customers. However, most host customers will be reluctant to sign contracts that commit them to operate their facilities or building for a pre-specified number of hours to ensure that estimated savings are realized. In part, this occurs because hours of operation are

S8 The economic consequences associated with the failure of a large supply-side project to develop include potentially higher costs for replacement power and adverse effects on utility system reliability. Initially, replacement costs can be quite high for large-scale projects, although these costs may diminish with time as the utility finds cost-effective sources of replacement power (e.g., builds or contracts for additional capacity and energy). If a supply-side project fails long before the projected on-line date, there may be little or no costs associated with project failure because the utility can build this need into its resource planning (ICF Resources, Inc. 1993).

59 An ESCO would have a strong incentive to focus their limited resources on meeting contract demand reduction goals where damages associated with failure to develop were high, and place less emphasis on meeting contractual goals in utility bidding programs that did not require liquidated damage deposits.

60 In practice, if an ESCO fails to achieve a contract demand reduction goal, the DSM market potential may still be available to be captured by another third party or utility DSM program within a relatively short time period. 
often affected by exogenous factors outside of their control (e.g., the economy). Thus, it might be more appropriate to use relatively wide "performance bands," which implicitly means that ratepayers bear some of these risks.

- Allow for the use of arbitration to resolve disputes over claimed energy savings Several utilities (e.g., Puget Power) have included provisions in their contracts that provide for binding arbitration in the event that the parties can not reach agreement on the annual electricity savings based on the verification and analysis plan. Given that standardized procedures to measure savings are still evolving for certain applications and types of DSM measures, this type of dispute resolution procedure may be useful.

\subsection{Summary and Policy Implications}

Utility DSM bidding programs can be viewed as a set of large-scale experiments to acquire "DSM savings" through competitive processes. Program designs varied significantly among utilities. We would characterize a "successful" program as one in which a utility performed well compared to clearly articulated goals and design objectives, the utility's bid selection and evaluation processes was perceived to be fair and reasonable, and the outcome produced significant benefits to ratepayers. By this standard, the results of the first generation of DSM bidding programs are quite mixed. For example:

With DSM bidding, ratepayers are protected financially against the major risks associated with DSM resources, although the costs of DSM bidding programs were typically higher than expected.

- The cost of "negawatts" in our sample of DSM bidding programs ranged between 5.4 - 8 cents/kWh, which is higher than values typically cited by DSM proponents for measures that primarily target commercial and industrial (C\&I) customers. ${ }^{61}$

- Factors that contributed to relatively high program costs include: poor program design (see section 5.2.1), the relative immaturity of the ESCO industry, allocation of performance and development risks to DSM developers, and a more complete accounting of resource costs. In early DSM bidding programs, developers' bid prices reflected the fact that bidding was untested and imposed

61 For example, a 1990 study of achievable DSM potential in New York estimated that levelized total resource costs could range between $2-4 \mathrm{c} / \mathrm{kWh}$ for aggressive DSM programs targeted at C/I customers. 
unprecedented performance and development risks on DSM developers. Some DSM develcpers were initially able to take advantage of certain program designs, combined with the relative immaturity of the ESCO industry, to extract "excess" economic rent from utilities. ${ }^{62}$ However, the "learning curve" for both utilities (in terms of program design) and the energy service industry (in terms of entry by new competitors) is steep, thus "excess" profits should not be a significant factor over the long term.

- One of the innovative features of DSM bidding programs, compared to typical utility rebate programs, is that DSM developers bear significant performance and development risks.

- DSM developers also typically include measuring and monitoring costs, expected operation and maintenance expenses, and equipment replacement costs over the contract term in their bid prices. ${ }^{63}$ ESCOs claim that measuring, monitoring, and reporting costs account for about $3-5 \%$ of total project costs.

- In DSM bidding, there is often a more explicit accounting of some of the socalled "hidden costs" of DSM (e.g., transaction, marketing, and financing costs). For example, DSM developers must recover all expected marketing costs in their bid price. Many DSM developers finance the initial cost of a project at a customer's facility and make a return on their investment from payments from the utility and a portion of the customer's bill savings. Financing costs can represent a significant fraction of total project costs and partially reflect the costs of overcoming market barriers of customers to DSM.

A number of utilities have encountered significant difficulties in implementing DSM bidding programs.

- With respect to the implementation process, the record is also quite mixed as outcomes have been frustrating for both utilities and DSM developers. DSM bidding programs have been quite contentious and difficult for some utilities to

62 DSM developers were paid based on the value of their savings, rather than their costs; their ability to obtain "excess" economic rents is related to the immaturity of the energy services market and their relative competitive against private power producers in integrated bidding programs.

63 Bid prices often include all anticipated operations and maintenance costs rather than only those that are incremental. In contrast, many DSM potential studies assume that incremental annual O\&M costs are either unchanged or decrease for certain DSM measures compared to currently installed technologies (e.g., reflectors). 
implement. For example, bidders have filed formal complaints with PUCs on issues related to the utility's selection process in several states (e.g., New York and Washington). Based on results of process evaluations, there is some dissatisfaction among ESCOs and customer bidders with many of the current bidding programs (Goldman et al. 1992; Goldman et al. 1993; Peters et al. 1991; Peters et al. 1992a; Peters et al. 1992b; ERCE 1991; Barakat \& Chamberlin Inc. 1992; Barakat \& Chamberlin Inc. 1993). In some cases, DSM developers have expressed concerns over protracted or failed contract negotiations and lack of cooperation by some utility staff during field implementation.

- One indication of the degree of dissatisfaction arnong ESCOs with DSM bidding is that the National Association of Energy Service Companies (NAESCO) proposed that utilities test an alternative approach called the "competitive conservation contract" or DSM Standard Offer (NAESCO 1992). Under this approach, a utility would establish a price for a measured unit of energy savings over various time periods (e.g., 5, 10, 15 years) for a particular resource block size, and then develop a standard contract (including a protocol for measuring and verifying savings for various measures). Under a standard offer, ESCOs can present demand reductions from specific host customer facilities to the utility after conducting a comprehensive audit, which reduces the ESCOs uncertainty and bid preparation and marketing costs compared to a DSM bidding program.

DSM bidding has contributed to increased interest and support for performance contracting.

- DSM bidding programs have resulted in broader acceptance for acquiring DSM resources based on pay-for-performance contracting. DSM bidding programs (and the long-term contracts between utilities and DSM developers) have also led to advances in the protocols and techniques for measuring, monitoring, and verifying savings. In particular, industry organizations that represent participants in these programs (e.g., NAESCO) and some utilities have begun developing standardized M\&V protocols.

Almost all DSM bidding programs have cost less than the utility's supply-side alternatives (at the time of the RFP). Yet, substantial disagreements remain regarding the value of these programs to ratepayers, driven in part by differences over the appropriate figure of merit and disappointing implementation experiences. 
- Several of the initial bidding programs appear to be only marginally cost-effective from a total resource cost perspective, given the uncertainties in customer and administrative costs and future avoided costs. Many utilities would also argue that the costs of a "comparable" utility DSM program provides a better measure of the true value of a DSM bidding program to ratepayers. However, properly valuing performance and development risks and the costs of additional services compared to a utility DSM program alternative is challenging analytically and difficult for utility managers because of the perception of conflicting objectives. The fact that utilities have relatively little experience assessing DSM performance risk in their own programs over long time periods contributes to the uncertainty in valuing DSM bidding contracts that provide payments only for verified demand or energy reductions.

- Our review of DSM bidding does suggest however that DSM developers at most utilities have not been particularly successful in installing comprehensive packages of measures, which is an important attribute of bid quality and value. In section 5.2.3, we suggested various program design and contractual options to improve in this area in future bidding programs. Initially, at the urging of many PUCs, utilities issued DSM bidding RFPs that tended to be quite broad and "openended" in the sense that they included few restrictions on market segments, eligible measures, and had minimal threshold requirements (Wolcott and Goldman 1992). The underlying motivation was to encourage innovation among energy service providers, but this approach increased the difficulties involved in bid evaluation given the diversity of market segments and technologies. As utilities gain experience with DSM bidding, they tend to favor more targeted, focused RFPs (e.g., Puget Power, NEES, JCP\&L). In the future, utilities that are particularly concerned about assuring comprehensiveness should consider developing more targeted and well-specified RFPs (e.g., types of services desired, targeted market segments). This will typically result in the use of more extensive threshold requirements that specify the major attributes affecting bid quality (e.g., M\&V protocol; measure and product mix; qualifications, experience, and technical risk) in order to facilitate price (and value) comparisons among DSM bids. 


\section{References}

American Council for an Energy Efficient Economy (ACEEE) 1990. "The Achievable Conservation Potential in New York State From Utility Demand-Side Management Programs.” Final Report. Washington, DC: ACEEE. Report 90-18. 1064-EEED-AEP-88. November.

Applied Energy Group Inc. 1992. "Impact Evaluation of LILCO's 1992 Electric Conservation and Load Management Plan: DSM Competitive Bidding." Chapter 13. Project G-5.

Barakat \& Chamberlin Inc. 1992. "Process Evaluation of Public Service of Colorado's 50-MW Bidding Program.” April.

Barakat \& Chamberlin Inc. 1993. "Evaluation of the Orange and Rockland Utilities Competitive Bidding Program for Demand-Side Resources." Portland, OR: Barakat \& Chamberlin Inc. Energy Authority Report 93-15. February.

Bonneville Power Administration (BPA) 1991. "Request for Proposals: Competitive Acquisition of Firm Electric Energy, Conservation Resources.” January.

Boston Edison Company (BECo) 1993a. "Conservation \& Load Management Filing For Year Ending December 31, 1992.” Boston, MA: Commonwealth of Massachusetts, Department of Public Utilities. July.

Boston Edison Company (BECo) 1993b. "Second Annual 1991 \& 1992 DSM Program Reconciliation Report." June.

Boston Edison Company (BECo) 1989. "Energy Conservation Retrofit Program: Status Report." March.

California Public Utilities Commission (CPUC) "Public Utilities Code, section 747(b)."

California Public Utilities Commission (CPUC) 1992a. "Interim Opinion on Demand-Side Management Bidding Pilots.” Decision 92-09-080. September 16.

California Public Utilities Commission (CPUC) 1992b. "Interim Opinion on Pacific Gas and Electric Company's Bidding Pilot.” Decision 92-03-038. March 11.

Central Maine Power (CMP) 1987. "Power Partners Program: Energy Management Request for Proposals." December. 
Central Maine Power (CMP) 1989. "Power Partners Program: Energy Management Request for Proposals." May.

Chilton, R.S., and M. Ambrosio 1992. "The New Jersey Electric Utility Capacity Planning Process: The Need for Restructuring and Opportunities for Enhanced Efficiency." Division of Electric, New Jersey Board of Regulatory Commissioners. May 27.

City of Anaheim 1991a. "Request for Proposals for Demand-Side Management Projects by the Anaheim Public Utilities Department." April.

City of Anaheim 1991b. "Request for Proposals for Demand-Side Management Projects from Customers of the Anaheim Public Utilities Department." February.

Colorado Public Utilities Commission 1990. "Stipulation and Settlement Agreement. In the Matter of the Application of Public Service Company of Colorado to Place into Effect a Demand-Side Management Cost Adjustment Clause.” Docket No. 90A-147E. October.

Demand-Side Report 1993a. "EUA Cogenex Eyes Acquisition of Two Energy Services Firms in NY, Maine." September 2.

Demand-Side Report 1993b. "PS Colorado Picks 45 Proposals Totaling $51 \mathrm{MW}$ for Negotiations." July 8.

Demand-Side Report 1993c. "PSE\&G: Response to Standard Offer Contract Has Been 'Overwhelming'." July 8.

Duke Power Company (Duke) 1992. "Energy Services Partnership: Request for Proposals." September.

Electric Power Research Institute (EPRI) 1991. "Acquisition of Third-Party Demand-Side Management Resources." Boston, MA: Charles River Associates, Inc. EPRI CU-7362. June.

ERC Environmental \& Energy Services Co. (ERCE) 1991. “Evaluation of Central Maine Power's Pilot Power Partners Program (T\&C 19.15), Pilot Efficiency Buy-Back Program (T\&C 19.13), and Pilot Commercial and Industrial Shared Savings Program (T\&C 19.12)." 
Eto, J., E. Vine, L. Shown, R. Sonnenblick, and C. Payne 1993. "The Cost and Performance of Utility Commercial Lighting Programs." Draft Report from the Database on Energy Efficiency Programs (DEEP) Project. Berkeley, CA: Lawrence Berkeley Laboratory. December.

Finleon, J.L., K.A. Triplett, and B.C. Peterson 1992. "Incorporating Lessons Learned into Demand-Side Bidding." Proceedings. 1992 ACEEE Summer Study on Energy Efficiency in Buildings. Washington, DC: ACEEE. 8:8.51.

Freeman Research Associates 1989. "Comparative Evaluation of the Customer Conservation Program and the Performance Contracting Program." Final Report Prepared for New England Power Service. NY: Freeman Research Associates. May.

Goldman, C.A. 1992. "Integrated Resource Bidding Options Paper.” Docket No. DSM OIR (R.91-003/I.91-08-002). San Francisco, CA: CPUC. December.

Goldman, C.A., and J.F. Busch 1992. "DSM Bidding - The Next Generation." The Electricity Journal. 5:4:34-43. May.

Goldman, C.A., J.F. Busch, E.P. Kahn, R. Baldick, and A. Milne 1993. "Review of Consolidated Edison's Integrated Resource Bidding Program.” Berkeley, CA: Lawrence Berkeley Laboratory. LBL-33599. July.

Goldman, C.A., J.F. Busch, E.P. Kahn, S.S. Stoft, and S. Cohen 1992. "Review of Integrated Resource Bidding at Niagara Mohawk." Berkeley: Lawrence Berkeley Laboratory. LBL-31667. May.

Goldman, C.A., and D.R. Wolcott 1990. "Demand-Side Bidding: Assessing Current Experience." Proceedings. ACEEE 1990 Summer Study on Energy Efficiency in Buildings. Volume 8. Washington, DC: F CEEE. pp.8.53-8.68. June.

Hamilton, W.E., and T.A. Flaim 1992. "Acquiring DSM Resources Through All-Source Bidding: Lessons Learned.” Proceedings. DSM Bidding: Status and Results. Bala Cynwyd: Synergic Resources Corporation. pp.27-29. April.

ICF Resources Inc. 1993. "Preparing Bid and Evaluating Response to Competitive Solicitation: A Hands-On Approach." March 5.

Jersey Central Power and Light (JCPL) 1989. “1989 Solicitation, Demand-Side RFP Overview and Instructions." Volume 5. August. 
Joskow, P.L., and D.B. Marron 1992. "What Does a Negawatt Really Cost? Evidence from Utility Conservation Programs.” The Energy Journal. 13:4:41-74.

Kahn, E.P., C.A. Goldman, S. Stoft, and D. Berman 1989. "Evaluation Methods in Competitive Bidding for Electric Power." Berkeley, CA: Lawrence Berkeley Laboratory. LBL-26924. June.

Kahn, E.P., S. Stoft, C. Marnay, and D. Berman 1990. "Contracts for Dispatchable Power: Economic Implications for the Competitive Bidding Market." Berkeley, CA: Lawrence Berkeley Laboratory. LBL-29447. October.

Leung, P., and R.F. Durning 1978. "Power System Economics: On Selection of Engineering Alternatives." Journal of Engineering for Power. 100:333-346. April.

Linn, J.J. 1992. "Once Bidding is Over, the Hard Work Begins." DSM Bidding: Status and Results. Albany, NY: SRC. April.

Michaels, H. 1988. "Bulk Purchase of Conservation by Competitive Bid." Proceedings. ACEEE Summer Study on Energy Efficiency in Buildings. Volume 6. 6.141-6.152. August.

Mills, W. 1989. "An Overview of Demand-Side Management Bidding Programs in New York State.” Proceedings. ECNE National Conference on Utility DSM Programs. Bedford, MA: EPRI.

National Association of Energy Service Companies (NAESCO) 1992. "NAESCO Standard for Measurement of Energy Savings for Electric Utility Demand-Side Management (DSM) Projects, Revision 1.1." Washington, DC: NAESCO. October 27.

National Independent Energy Producers (NIEP) 1991. "Competing for Power: A Survey on Competitive Procurement Systems and Blueprint for the Future." July.

New England Electrical System (NEES) 1987. "Request for Proposals in New England Electric's Performance Contracting Program." October.

New Jersey Board of Regulatory Commissioners (NJBRC) 1988. "Stipulation of Settlement." Docket No. 8010-687B. Trenton, NJ: July 1. 
New York Department of Public Service (NYDPS) 1990. "Summary of Utility DSM Bidding Programs in New York." NY: Office of Energy Efficiency and Environment. November.

New York Public Service Commission (NYPSC) 1988. "Opinion and Order Concerning Bidding, Avoided-Cost Pricing, and Wheeling Issues.” Opinion No. 88-15. June.

Niagara Mohawk Power Corporation 1993. "Annual Evaluation Report: 1992 Demand-Side Management Program.” July.

Northern California Power Agency (NCPA) 1991. "1992 Requests for Proposals: Demand-Side Management Resource.” August.

Orange \& Rockland Utilities (ORU) 1989. "Request for Proposals to Supply Capacity and Energy and/or Provide for the Installation of Demand Reduction Measures." Volume III: Demand-Side Bid Solicitation New Jersey. June.

Pacific Gas \& Electric, San Diego Gas \& Electric, Southern Califormia Edison, Southern California Gas, California Energy Commission et al. 1992. "Joint Testimony Report on Ex Post Measurement for Demand-Side Management Programs." Docket No. 91-08-003/I.01-08-002. San Francisco, CA: PG\&E. October 29.

Pacific Gas \& Electric Company (PG\&E) 1992. "PowerSaving Partners: Request for Demand-Side Management Proposals." October.

Pacific Gas \& Electric Company (PG\&E) 1993a. "Annual Summary Report on Demand Side Management Programs in 1992 and 1993." March.

Pacific Gas \& Electric Company (PG\&E) 1993b. "PG\&E Announces Short List of 'Powersaving Partners' (news release)." April.

PacificCurp Electric Operations (PacifiCorp) 1991. "Request for Proposals, Long-Term Supply of Electricity Resources from Conservation Measures and Generating Facilities." October.

Peters, J., D. Barry, M. Horowitz, and D. Wolcott 1991. "A Dual State Bidding Program: Effects of Different Guidelines." Proceedings. International Energy Program Evaluation Conference. July. 
Peters, J.S., M. McRae, and P. Seratt 1992a. "Resource Acquisition by Bonneville Power Administration: An Assessment of Current Experience." Oakland, CA: Barakat \& Chamberlin Inc. May.

Peters, J.S., M.R. McRae, and K. Seiden 1992b. "Process Evaluation of Public Service of Colorado's 50-MW Bidding Program." Oakland: Barakat \& Chamberlin, Inc. April 15.

Public Service Electric and Gas Company (PSE\&G) 1989. "Request for Proposals for Large Scale Conservation Investments." August.

Public Service of Colorado (PSColo) 1990. "50 MW Bidding Program -- Request for Proposals." December.

Public Service of Colorado (PSColo) 1992. "Second DSM Competitive Bid Program -Request for Proposals." August.

Public Service of Indiana 1989. "Resource Bidding Program: Demand-Side Management." December.

Puget Sound Power \& Light Company (Puget) 1989. “Request for Proposals: Long-Term Purchase of Resources from Commercial and Industrial Conservation and Generating Facilities." June.

Puget Sound Power \& Light Company (Puget) 1991. "Request for Proposals: Long-Term Purchase of Resources from Conservation and Generation Facilities.” September.

Robertson, H.E. 1993a. "DSM Perspectives: Differing Views, Impressive Results." Current Competition. 4:3:15. August.

Robertson, H.E. 1993b. "Ownership Types--Winning Bids." Current Competition. 4:3:13. August.

Stoft, S., and E. Kahn 1990. "Evaluation of Front Loading In Auctions for Wholesale Power." Utilities Policy. 28-35. October.

Vine, E., O. DeBuen, and C. Goldman 1990. "Stimulating Utilities to Promote Energy Efficiency: Process Evaluation of Madison Gas and Electric's Competition Pilot Program." Berkeley, CA: Lawrence Berkeley Laboratory. LBL-29642. December. 
Washington Utilities and Transportation Commission (WUTC) 1989. "Proposed Washington Utilities and Transportation Commission Regulations, Chapter 480-107." June.

Wolcott, D.R., and C.A. Goldman 1992. "Moving Beyond Demand-Side Bidding: A More Constructive Role for Energy Service Companies." Proceedings. ACEEE 1992 Summer Study on Energy Efficiency in Buildings. Volume 8. Integrated Resource Planning. Washington, DC: American Council for an Energy-Efficient Economy (ACEEE). August. 


\section{Summary of Utility DSM Bidding Programs}

\section{A.1 Overview}

DSM bidding programs have been shaped to a great extent by the state regulatory environment as well as the prior experience of utilities in contracting with private power producers and energy service companies. Table A-1 summarizes the roles of regulators and utilities in the development process of DSM bidding programs in various states. One fundamental distinction among states is the degree of discretion that utilities had or took in developing their bidding process. Several public utility commissions (PUCs) developed explicit guidelines prior to the utilities issuing competitive bidding solicitations (e.g., New York, New Jersey, Washington, and California), while, in other states, utilities issued RFPs on their own initiative without prior approval from state regulators (e.g., Indiana, Colorado, Montana). In these latter situations, utilities usually retained more flexibility in the design and implementation of their bidding programs. In states such as New York and New Jersey, the main focus was on developing competitive acquisition procedures for supply-side resources and DSM resources were considered relatively late in the process.

Table A-2 (see end of Appendix A) summarizes key design features of the bidding programs of individual utilities. Information is provided on the following features and characteristics: amount of capacity or energy requested by the utility, type of auction, overall bid evaluation philosophy, eligibility and threshold requirements with respect to measures, types of entilies, and customer classes, minimum bid size, minimum security deposit, basis for determining ceiling prices, and the form of and basis for payments. In the next sections, these features are described in more detail.

\section{A.2 Resource Block Size}

The amount of capacity or energy solicited by a utility is determined by the utility's resource need and influenced by the type of auction (i.e., integrated RFP where supply and DSM options compete for a common resource block or separate RFP for DSM) and maturity of the program (pilot vs. full-scale). DSM-only RFPs have ranged in size from 3 - 50 MWs, while the resource block s'ze of integrated RFPs has ranged betweeri 100 $550 \mathrm{MW}$. 
Table A-1. Regulatory Oversight In Developing Bidding Programs

\begin{tabular}{|c|c|c|c|c|c|}
\hline & $\begin{array}{l}\text { PUC Rulos/ } \\
\text { Guidelines } \\
\text { Adopted in } \\
\text { Advench of DSM } \\
\text { Bidding RFPy }\end{array}$ & $\begin{array}{l}\text { Proceis Used to } \\
\text { Developl } \\
\text { Approve PUC } \\
\text { Rute }\end{array}$ & $\begin{array}{l}\text { Rooulatory } \\
\text { Roview of } \\
\text { Proposed Uitity } \\
\text { Bidding RFPs }\end{array}$ & $\begin{array}{l}\text { Utility Discretion } \\
\text { in Conducting } \\
\text { Progrem }\end{array}$ & $\begin{array}{l}\text { Ovorall Loval } \\
\text { of puC } \\
\text { involvernont }\end{array}$ \\
\hline CA & Yes & $\begin{array}{l}\text { Informal } \\
\text { working } \\
\text { groups; formal } \\
\text { PUC decision }\end{array}$ & $\begin{array}{l}\text { Utility } \\
\text { developed } \\
\text { RFP; formal } \\
\text { PUC approval }\end{array}$ & Moderate & Extensive \\
\hline co & No & N/A & Utility-initiated & Extensive & Minor \\
\hline IN & No & $N / A$ & Utility-initiated & Extensive & $\begin{array}{l}\text { Minor } \\
\text { (prudency } \\
\text { only) }\end{array}$ \\
\hline ME & No & N/A & Utility-initiated & Extensive & $\begin{array}{l}\text { Minor } \\
\text { (prudency } \\
\text { only) }\end{array}$ \\
\hline MA & Yes & $\begin{array}{l}\text { Technical } \\
\text { workshops; } \\
\text { DPU decision }\end{array}$ & $\begin{array}{l}\text { Single-stage } \\
\text { utility RFP; } \\
\text { formal review } \\
\text { stage }\end{array}$ & Significant & Extensive \\
\hline NY & Yes & $\begin{array}{l}\text { Informal } \\
\text { working } \\
\text { groups and } \\
\text { workshops; } \\
\text { formal PSC } \\
\text { decision }\end{array}$ & $\begin{array}{l}\text { Utility } \\
\text { developed } \\
\text { RFPs; formal } \\
\text { PSC app;oval }\end{array}$ & Moderate & Significant \\
\hline NJ & Yes & $\begin{array}{l}\text { Negotiated } \\
\text { settlement } \\
\text { agreement; } \\
\text { reviewed and } \\
\text { modified by } \\
\text { BPU }\end{array}$ & $\begin{array}{l}\text { Review only, } \\
\text { not approval }\end{array}$ & Limited & Significant \\
\hline NC & No & N/A & Utility-initiated & Extensive & $\begin{array}{l}\text { Minor } \\
\text { (prudency } \\
\text { only) }\end{array}$ \\
\hline WA & Yes & $\begin{array}{l}\text { Informal } \\
\text { technical } \\
\text { negotiations; } \\
\text { issuance of } \\
\text { final rules }\end{array}$ & $\begin{array}{l}\text { Review only, } \\
\text { not approval }\end{array}$ & Extensive & Minor \\
\hline
\end{tabular}




\section{A.3 Type of Solicitation}

There are three major types of solicitations that utilities have used to acquire DSM resources: an integrated supply and DSM RFP, DSM and supply RFPs issued in parallel to meet a common resource block (parallel common block RFP), and separate RFP for DSM. It is most useful to think about alternative solicitation types as a continuum of approaches, rather than a set of distinct options (see Figure A-1) (Goldman 1992).

In an integrated, "all-source" RFP, DSM projects compete directly with generation projects and the utility defines similar bid evaluation criteria and scoring for supply and DSM resources (see Figure A-2). In a parallel common block RFP, there are separate RFPs for supply and demand-side resources which compete to fill a common resource block. General bid evaluation categories might be similar between the supply and DSM RFPs, although there will typically be significant differences in the individual component attributes or weights for a particular category (see Figure A-3). For example, project viability and success might be a general factor, but the utility may place more weight on site control for generation resources, while emphasizing developer experience for DSM projects. Finally, in separate block bidding, the utility determines the timing, block size and evaluation criteria for supply and DSM resources separately, consistent with its IRP plan (see Figure A-4). Integration and comparison of supply and DSM resources occurs

Figure A-1. Types of Solicitations

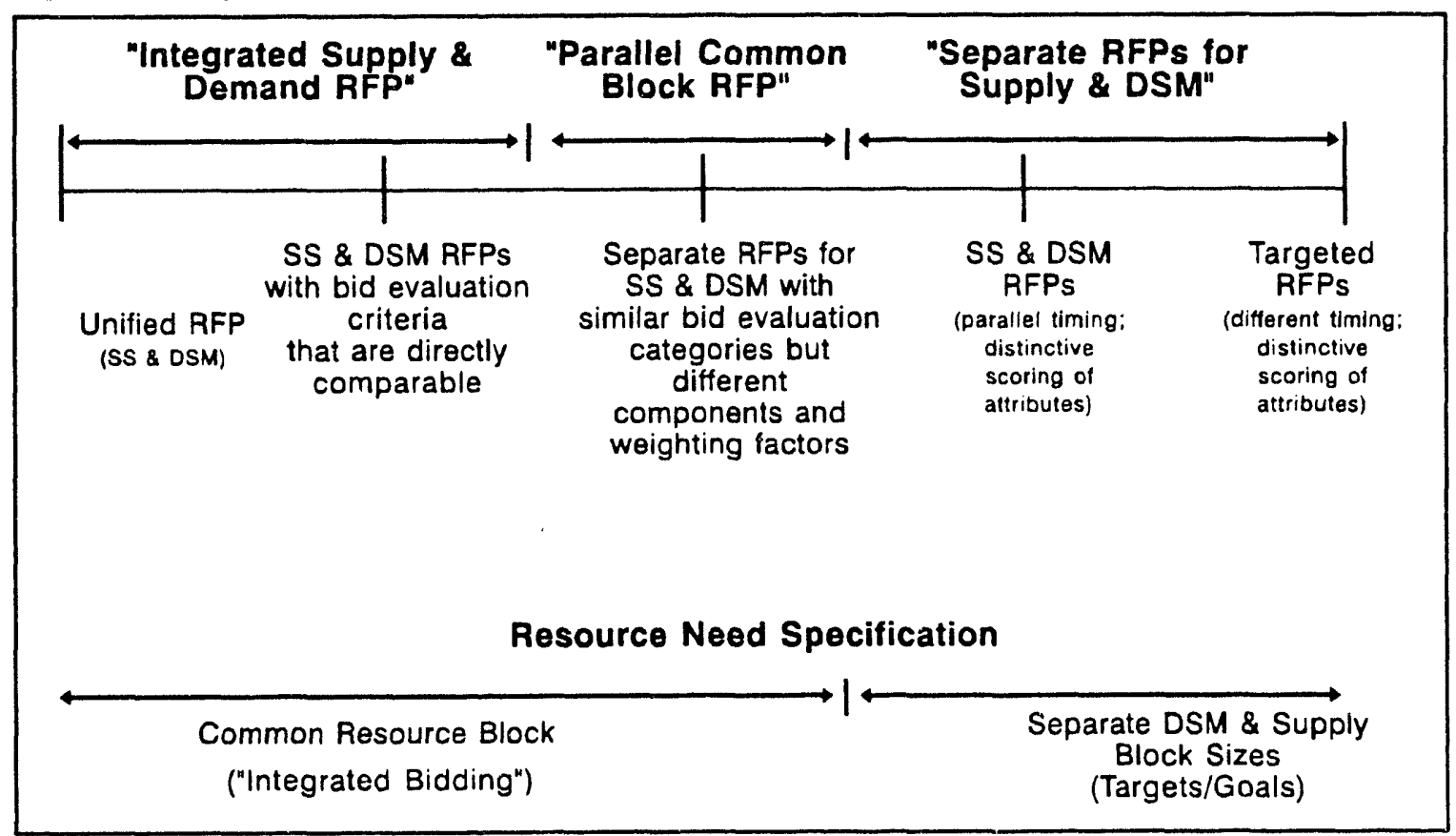


Figure A-2. Integrated Supply and DSM RFP

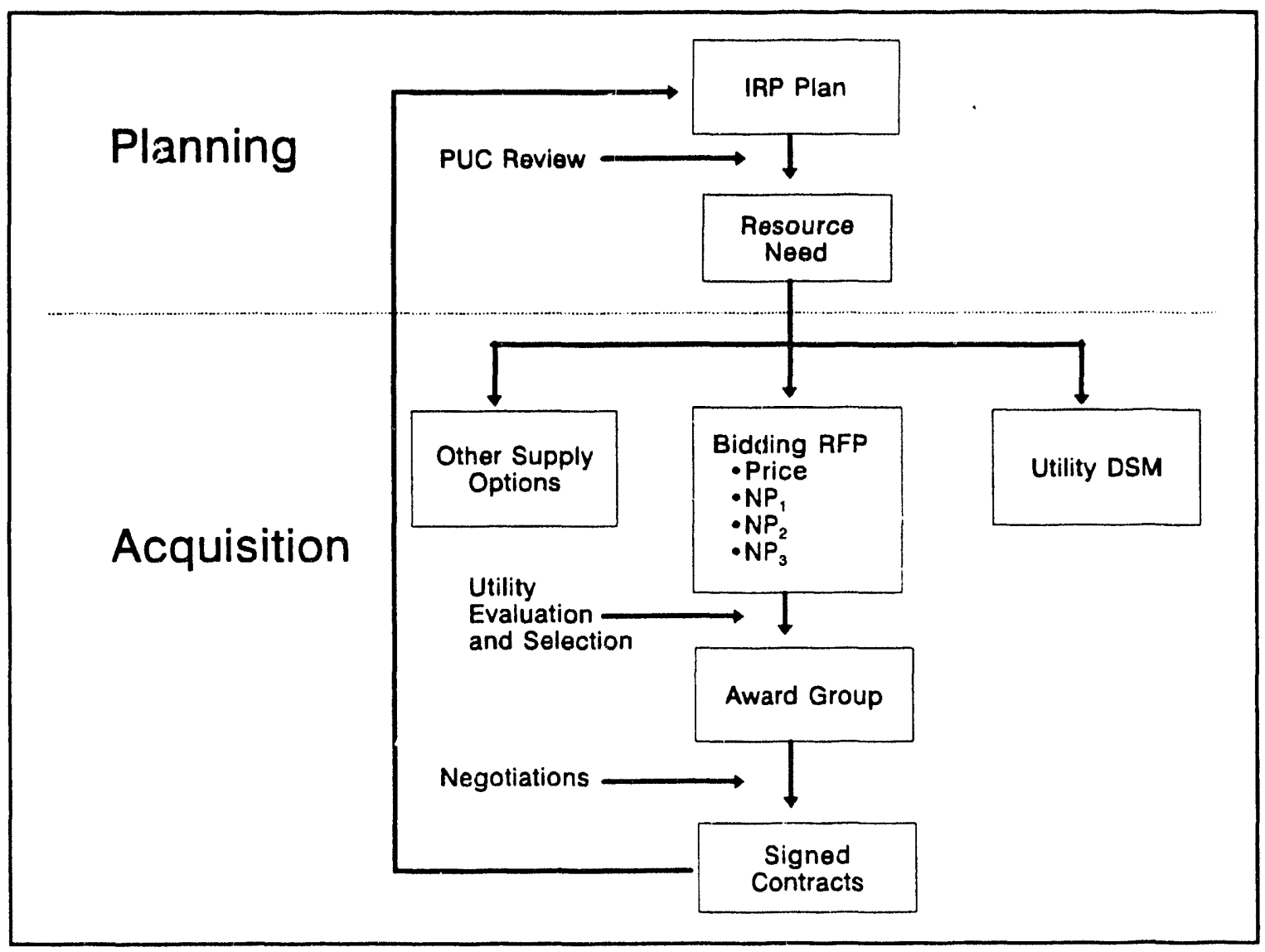


Figuie A-3. Parallel Common Block RFP

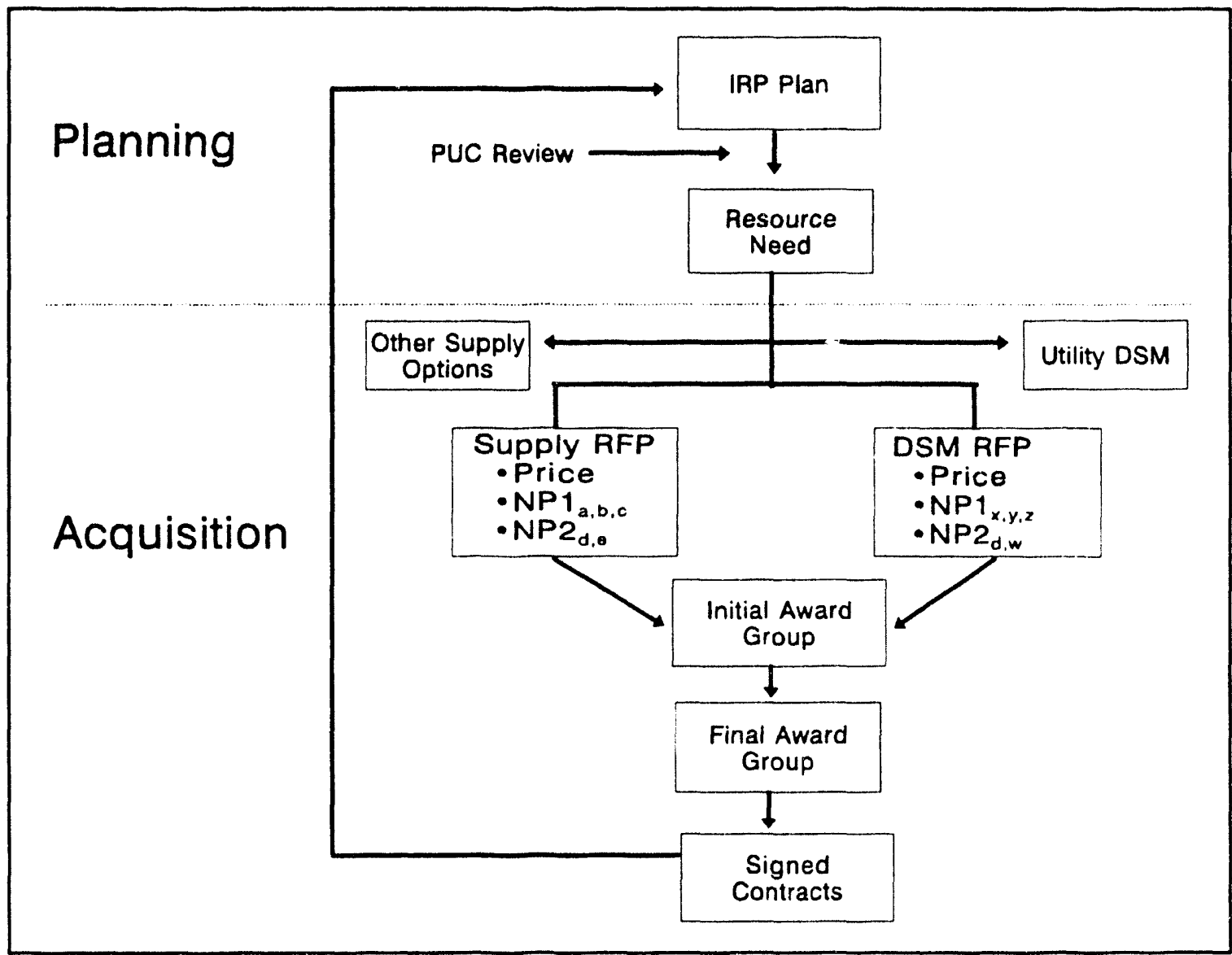


Figure A-4. Separate RFPs for Supply and DSM

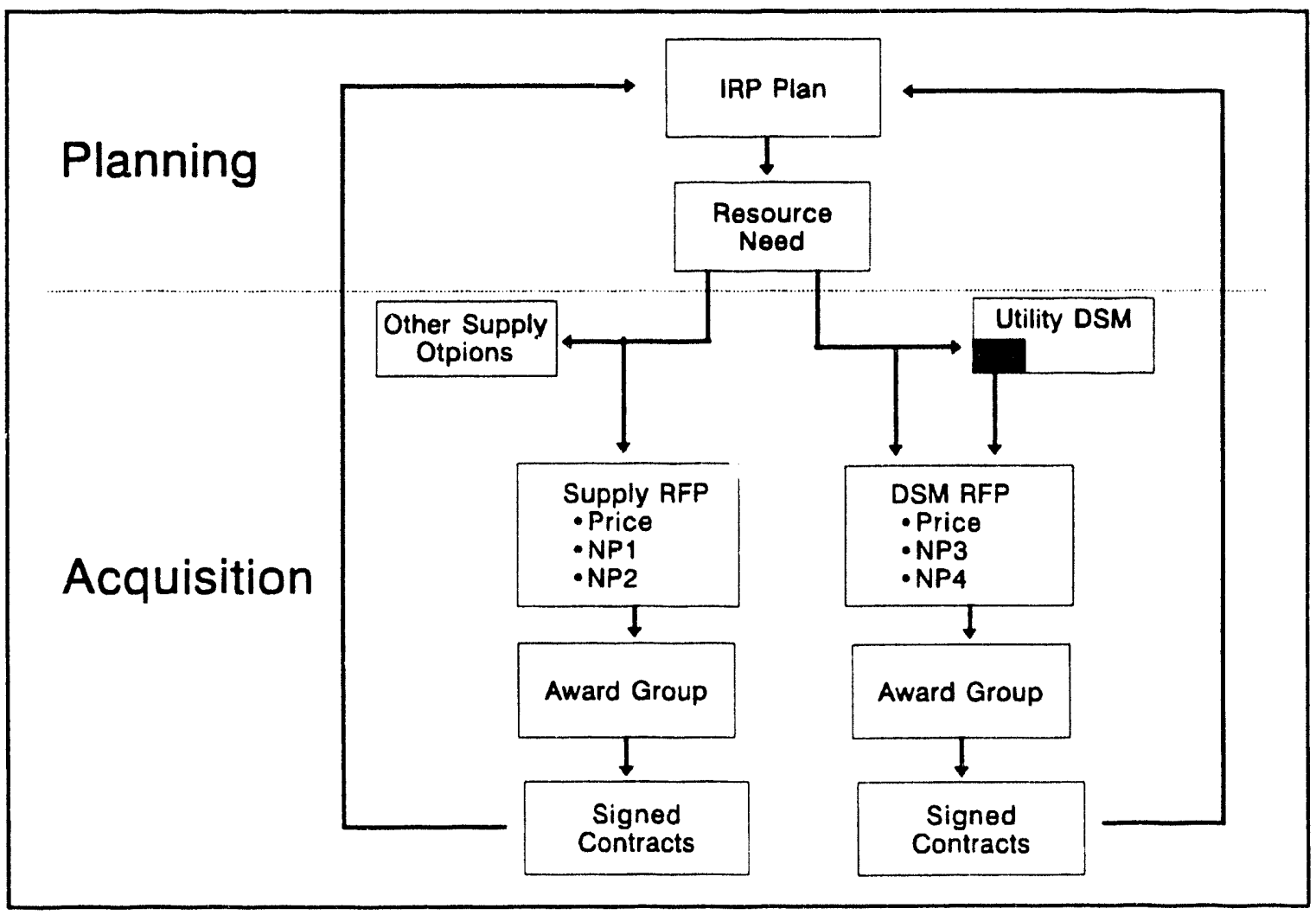

primarily in the utility's IRP process and subsequent regulatory review of an IRP plan. The utility might decide to procure some portion of its own DSM programs through competitive solicitations asking third parties to provide saved energy or specified services (shown as shaded box in Figure A-4).

Differences regarding the most preferable type of solicitation are rooted in differing views of the proper relationship between planning and competitive resource acquisition processes in defining market opportunities as well as the advisability and value of direct comparisons of supply and DSM options in bidding processes. While no consensus has emerged regarding the appropriate auction format, most utilities indicate that they would prefer to acquire supply and DSM resources using either separate acquisition processes or parallel common block approaches (EPRI 1991; Hamilton and Flaim 1992). For example, in those states where utilities have initiated bidding programs without or prior to formally-established PUC bidding guidelines, utilities have chosen separate RFPs to acquire supply and DSM resources. Utilities cite inherent differences between supply and DSM resource options and the difficulties of making direct comparisons as the primary reasons for this preference (EPRI 1991). 


\section{A.4 Bid Evaluation Design Philosophy}

The various approaches that utilities have taken in designing bid evaluation and scoring systems can be grouped into four general design philosophies:

"Open" bid evaluation system - In this approach, the utility's RFP includes an explicit scoring system with points and relative weights for various attributes. Bidders then selfscore their projects and the utility verifies bidders' scores by examining the detailed project proposals and then ranks bids. This approach can be characterized as "open" because the utility's bid evaluation and selection process is transparent to bidders, prior to their submission of bids.

"Closed" bid evaluation system - In this approach, the utility's RFP describes its preferences by indicating desirable features for various attributes and the methods that will be used to evaluate individual projects. DSM and supply projects are ranked based on a combination of quantitative factors and subjective evaluation. The distinctive feature of this approach is that the utility possesses information about the bid evaluation process that is not available to bidders and bidders do not self-score their own projects. The utility retains substantial discretion to select among competing projects and determine the optimal mix of projects. There is a strong emphasis on negotiations between the utility and the most viable bidders to obtain desirable features that increase the value of projects for both parties (Kahn et al. 1989).

"Hybrid" bid evaluation system - This system combines elements of both "open" and "closed" approaches. The utility's RFP indicates that bid evaluation will be conducted in several phases. In the first stage, the utility typically uses a self-scoring system to rank projects and select an Initial Award Group (IAG). During phase 2, the utility performs a more detailed analysis and may consider additional selection criteria and factors in evaluating projects, interactive effects among projects, and interactions between DSM bids and the utility's other DSM programs. The utility will then select the best mix of projects for its Final Award Group winners for contract negotiations based on the results of its phase 2 analysis.

"Hybrid" bid scoring system - In this option, the utility's RFP indicates that certain attributes will be evaluated based on objective criteria, while others will be evaluated subjectively based on qualitative criteria. For example, the utility's RFP might state that 
price would account for $60 \%$ of the total score and would be self-scored by bidders, while the utility would score non-price factors that were worth $40 \%$ of the total points. ${ }^{64}$

These three approaches differ along several critical dimensions:

- amount of information provided to bidder regarding selection criteria and process prior to bid preparation;

- degree of reliance on objective scoring systems to rank projects; and

- degree of emphasis and allowed scope of negotiations between utilities and bidders.

As utilities and non-utility parties have gained experience with bidding, there has been a general trend away from "open" bid evaluation approaches towards "hybrid" and "closed" approaches (Kahn et al. 1990; National Independent Energy Producers 1991). Many utilities that have used self-scoring systems believe that they tend to encourage bidders to "game" their proposals to obtain the highest points, rather than focusing on developing good projects. All parties note that scoring and valuation of non-price factors is the most significant problem area for "open" bid evaluation. systems.

\section{A.5 Eligibility Requirements}

Typically, utilities use a multi-stage process to evaluate proposals submitted by customers or ESCOs in response to RFPs. These include: (1) initial screening to determine if projects meet minimum eligibility and threshold requirements, (2) ranking of projects and selection of an Award Group of winning bidders, and (3) negotiations and signing of contracts with winning bidders. Minimum threshold requirements employed by various utilities for DSM options include:

64 The principal difference with "hybrid" bid evaluation system is that winning bidders are selected based on a single-stage evaluation that includes both objective and subjective elements, rather than a two-stage approach (which allows the utility to account explicitly for interactive effects among projects in its analysis of portfolios). 


\section{A.5.1 Eligible Bidders}

ESCOs and customers have typically both been allowed to bid in DSM bidding RFPs. Early perfor mance contracting programs (e.g., NEES, BECo) tended to be restricted only to ESCOs. Bidding programs sponsored by wholesale power marketing authorities (e.g., BPA) have also allowed retail utilities to propose energy savings.

\section{A.5.2 Market Sectors}

Most RFPs have been open to all market sectors (i.e. residential, commercial, and industrial sectors) with a few exceptions (e.g., Puget Power, LILCO, NEES, SCE). These utilities have limited their DSM auctions to the commercial and industrial sectors.

\section{A.5.3 Eligible Measures}

For most utilities, eligible measures typically include energy efficient end use devices, ${ }^{65}$ load-shifting measures, ${ }^{66}$ and load management devices or systems. Ineligible measures often include measures that reduce use through the curtailment or cessation of end-use consumption (e.g., relocation outside the service area), self-generation, cogeneration, fuel switching, and new construction projects. However, PSColo allowed bidders to propose fuel-switching and new construction projects. At the other extreme, Con Edison and LILCO limited eligible measures to end-use efficiency measures specified in the RFP. The following are the abbreviations used for the measures in Table A-2:
$\mathrm{EE} \quad=$ Energy efficient end use devices
LS = Load shifting measures
$\mathrm{LM}=$ Load management devices or systems
$\mathrm{CC}=$ Cessation of consumption
$\mathrm{CG}=$ Cogeneration
FS = Fuel switching
$\mathrm{NC}=$ New construction projects

6s Such measures typically include energy efficient lighting systems, motors, and heating and cooling equipment.

6o Load-shifting measures shift energy use from on-peak to off-peak periods. 


\section{A.5.4 Minimum Bid Size}

Minimum bid size typically range from $100-500 \mathrm{~kW}$ or $100,000-250,000 \mathrm{kWh}$, with two notable exceptions. Public Service of Indiana required ESCO and customer bids to be at least $5 \mathrm{MWs}$ and Central Hudson required ESCOs bids to be at least $2.5 \mathrm{MW}$ (although customer bids could be as small as $100 \mathrm{~kW}$ ). These high minimum bid sizes appear to have dampened market response.

\section{A.5.5 Minimum Security Deposit}

Many utilities require winning bidders to post security deposits to be maintained during the construction period and sometimes throughout the full term of the contract. These security deposits are meant to secure the bidders obligation to pay "liquidated damages" if the project fails to come on line on time or at all, or fails during the operational period. While not the intended purpose, the security deposits also encourage customers and contractors to install the measures on time. Minimum security deposits typically range between $\$ 15-\$ 18 / \mathrm{kW}$ for those utilities that specify security deposits. Some utilities indicate that a deposit will be required in their RFP, but do not specify the minimum amount or form of the deposit.

\section{A.5.6 Security Deposits for Front-Loaded Payments}

DSM bidders often propose front-loaded payment streams. For example, a bidder might propose payments of $7 \mathrm{c} / \mathrm{kWh}$ during the first year of the contract and $2 \mathrm{c} / \mathrm{kWh}$ over the remainder of the contract term, whereas the long-run avoided cost might be only 4 $\mathrm{c} / \mathrm{kWh}$ during the first year, but ramp-up thereafter. In cases where payments to bidders are higher than the utility's long-run avoided costs, the utility and its ratepayers may be harmed financially if a project failed during this time period. To mitigate this risk, a few utilities require DSM bidders to provide front-loaded security deposits to cover some portion of the payments that exceed avoided cost. For example, ORU requires frontloaded security if contract payments exceed payment based upon avoided cost prices by 35 percent. Other utilities such as LILCO and PSColo have not been overly concerned about the front-loading issue and allow upfront one-time payments after measure installation. 


\section{A.5.7 Minimizing "Free Riders"}

Several utilities have tried to address concerns regarding potential "free riders" in the design of their bidding program. ${ }^{67}$ Often this issue is addressed by the utility specifying minimum payback periods for DSM measures. For example, CMP and Con Edison required that all measures have payback periods that exceed one and two years, respectively. DSM bidders are required to show that the total costs for each individual measure exceed the customer's expected bill savings for the time period specified (e.g., one to two years).

\section{A.6 Ceiling Prices}

Two major issues related to bid ceiling prices are: (1) the desirability of posting a ceiling price in an RFP, and (2) the appropriate basis. Many utilities have established ceiling prices based on the long-run avoided cost of supply, which is the estimated cost to the utility of meeting its future capacity and energy needs. ${ }^{68}$ The justification for the use of avoided costs is that it represents a good proxy for the value of the DSM resource and ensures that the DSM resources are cost-effective from a total resource perspective. ${ }^{69}$

Other utilities prefer to specify DSM ceiling prices which are less than avoided supply costs or are set in relation to the utility's own costs for delivering comparable planned or existing DSM programs. For example, LILCO designed its bidding program based upon its own "Dollars and Sense" rebate program and set the ceiling prices at 30 percent above the rebate and administrative costs associated with its own program. The ceiling prices for seven separate measures ranged from $\$ 250 / \mathrm{kW}$ for low-cost lighting equipment to $\$ 700 / \mathrm{kW}$ for thermal energy storage and non-electric cooling equipment. Con Edison increased its estimated program costs by 50 percent in setting ceiling prices for individual measures. Ceiling prices ranged between $\$ 725-\$ 2,700 / \mathrm{kW}$ for commercial and industrial sector measures. Puget Power set the ceiling price for conservation resources equal to the net present value of the utility's avoided cost of supply minus the net present

67 It is assumed that customers have sufficient incentives to install measures with short simple payback periods on their own, thus, utilities should have little reason to pay for installation of such measures.

6 The avoided cost has two basic components. The capacity component includes the fixed costs required to build additional power plants and the energy component includes the variable costs such as fuel and operation and maintenance expenses. Some utilities also include avoided transmission and distribution costs and avoided environmental externalities.

69 To be cost-effective from the total resource perspective, the sum of utility costs plus direct participant costs can not exceed the utility's long-term avoided cost of supplying electricity. 
value of the anticipated savings from the installed measures during the first two years of operation (Puget 1989).

The primary argument in favor of lower ceiling prices is that DSM resources cost substantially less than supply resources and that use of the avoided cost allows DSM developers to extract considerable economic rent. ${ }^{70}$ The underlying design philosophy in this case is that ceiling prices should be set at levels which are adequate to induce a sufficient market response. Scme utilities argue that ceiling prices that are set at less than avoided supply costs also indirectly encourage third-party contractors to extract higher customer contributions to cover the cost of the energy efficiency measures. One approach that addresses the balance between the appropriate price signal for DSM in terms of societal value as well as equity impacts is to require projects to pass the TRC test as a threshold criteria and establish ceiling prices at levels that are adequate to induce the desired market response.

\section{A.7 Form of Bid Payment (Basis)}

Utilities typically allow ESCOs to receive either one-time upfront payments for demand reductions or periodic payments over the term of the contract (e.g., quarterly, annually). The basis for payments to DSM bidders can be either peak demand reductions $(\mathrm{kW})$, annual electricity savings $(\mathrm{kWh})$, or a combination of both. Utilities whose primary load shape objectives are peak-shaving or load management will tend to make payments based on $\mathrm{kW}$ demand reductions. Some utilities maintain that it is easier to implement bidding programs that base payments on $\mathrm{kW}$ demand reductions, because administrative costs associated with measurement and verification tend to be lower.

o In a perfectly competitive market, the economic rent should diminish as new entrants lower the prices paid to DSM developers, but it is commonly acknowledged that the energy service industry is still in its infancy. 
Table A-2: Summary of Utility Demand-Side Management Bidding Solicitations

\begin{tabular}{|c|c|c|c|c|}
\hline & $\begin{array}{l}\text { New England } \\
\text { Electrical System(1) } \\
(10 / 87)\end{array}$ & $\begin{array}{c}\text { Boston Edison Co.(2) } \\
(5 / 88)\end{array}$ & $\begin{array}{c}\text { Central Maine } \\
\text { Power \#1(3) } \\
(12 / 87)\end{array}$ & $\begin{array}{c}\text { Central Maine } \\
\text { Power \#2(4) } \\
\text { (5/89) }\end{array}$ \\
\hline Capacity Block & $35 \mathrm{MW}$ & $35 \mathrm{MW}$ & $100 \mathrm{MW}$ & $150-300 \mathrm{MW}$ \\
\hline Type of Solicitation & NA & NA & Integrated RFP & Integrated RFP \\
\hline $\begin{array}{l}\text { Bid Evaluation Design } \\
\text { Philosophy }\end{array}$ & Closed & Hybrid & Closed & Closed \\
\hline Eligible Bidders & ESCOs only & ESCOs and Customers & ESCOs and Customers & ESCOs and Customers \\
\hline Market Sectors & C\&I & C\&I & All sectors & All sectors \\
\hline \multirow[t]{2}{*}{ Eligible Measures } & $\begin{array}{l}\text { Not Eligible: } \\
\text { CG, FS, CC }\end{array}$ & Eligible: $\mathrm{EE}, \mathrm{LM}$ & $\begin{array}{l}\text { Eligible: EE, LS, FS for } \\
\text { "alternative fuels" } \\
\text { Not Eligible: CC, CG }\end{array}$ & Eligible: $\mathrm{EE}$ \\
\hline & & 10 minimum contract life & $\begin{array}{l}\text { Must have payback } \\
\text { period of at least } 1 \text { year }\end{array}$ & $\begin{array}{l}\text { Must have a payback } \\
\text { period of at least } 1 \text { year }\end{array}$ \\
\hline Minimum Bid & $>500 \mathrm{~kW}$ & $>150 \mathrm{~kW}$ & $\underset{k W h}{>} 100 \mathrm{~kW}$ or 100,000 & $\begin{array}{l}>100 \mathrm{~kW} \text { or } 100,000 \\
\mathrm{kWh}\end{array}$ \\
\hline Minimum Deposit & $1 / 2$ contract amount & None & $\$ 54$ (or $\$ 108$ ) $/ \mathrm{kW}$ & $\$ 54$ (or $\$ 108 / \mathrm{kW}$ ) \\
\hline Front-Loaded Security & No & Yes & $\begin{array}{l}\text { No, but discourages } \\
\text { front-loading through } \\
\text { evaluation system }\end{array}$ & Yes \\
\hline Ceiling Prices & $\$ 0.07 \mathrm{c} / \mathrm{kWh}$ & Avoided costs & Avoided costs & Not stated in the RFP \\
\hline Form of Bid Payment & One-time (adjusted $\mathrm{kW}$ ) & Installments (kWh) & Installments (kWh) & Installments (kWh) \\
\hline
\end{tabular}


Table A-2: Summary of Utility Demand-Side Management Bidding Solicitations

\begin{tabular}{|c|c|c|c|c|}
\hline & $\begin{array}{c}\text { Orange \& Pockland -. } \\
\text { NY(5) } \\
(6 / 89)\end{array}$ & $\begin{array}{c}\text { Orange \& Rockland -- } \\
N J(6) \\
(6 / 89)\end{array}$ & $\begin{array}{l}\text { Puget Sound } \\
\text { Power \#1(7) } \\
(6 / 89)\end{array}$ & $\begin{array}{c}\text { Jersey Central } \\
\text { Power \& Light(8) } \\
(\mathbf{8} / 89)\end{array}$ \\
\hline Capacity Block & $\begin{array}{l}150 \mathrm{MW} \text { in New York \& } \\
\text { New Jersey combined }\end{array}$ & $\begin{array}{l}150 \mathrm{MV} \text { in New York \& } \\
\text { New Jersey combined }\end{array}$ & 100 "average" MW & $270 \mathrm{MW}$ \\
\hline Type of Solicitation & Parallel RFP & Parallel RFP & Integrated RFP & Integrated RFP \\
\hline $\begin{array}{l}\text { Bid Evaluation Design } \\
\text { Philosophy }\end{array}$ & Open & Open & Closed & Open \\
\hline Eligible Bidders & ESCOs and Customers & ESCOs and Customers & ESCOs and Customers & ESCOs and Customers \\
\hline Market Seciors & All sectors & All sectors & C\&I & All sectors \\
\hline \multirow[t]{2}{*}{ Eligible Measures } & $\begin{array}{l}\text { Eligible measures: EE, } \\
\text { LS, LM, and shifting } \\
\text { peak load to thermal } \\
\text { load, e.g., absorption } \\
\text { cooling }\end{array}$ & $\begin{array}{l}\text { Eligible measures: EE, } \\
\text { LS, LM, and shifting } \\
\text { peak load to thermal } \\
\text { load, e.g., absorption } \\
\text { cooling }\end{array}$ & $\begin{array}{l}\text { Eligible measures: EE } \\
\text { lighting systems, } \\
\text { insulation, space heating } \\
\text { and cooling systems, } \\
\text { water heating systems }\end{array}$ & $\begin{array}{l}\text { Eligible measures: EE, } \\
\text { LS, and measures which } \\
\text { allow JCP\&L to control } \\
\text { end-uses for purpose of } \\
\text { reducing customer } \\
\text { demand }\end{array}$ \\
\hline & & 5-year contract term & 10 -year term & $\begin{array}{l}\text { Not eligible: } C G \\
10-20 \text { year terms }\end{array}$ \\
\hline Minimum Bid & $100 \mathrm{~kW}$ & $100 \mathrm{~kW}$ & $100,000 \mathrm{kWh}$ & $400 \mathrm{~kW}$ \\
\hline Minimum Deposit & $\$ 18 / \mathrm{kW}$ & $\$ 18 / \mathrm{kW}$ & none & $\$ 18 / \mathrm{kW}$ \\
\hline Front-Loaded Security & No & $\begin{array}{l}\text { Yes, if contract } \\
\text { payments exceed } \\
\text { payments based upon } \\
\text { avoided cost prices by } \\
35 \%\end{array}$ & $\begin{array}{l}\text { Yes, if payments exceed } \\
\text { avoided costs }\end{array}$ & $\begin{array}{l}\text { Yes, if payments exceed } \\
\text { levelized avoided costs } \\
\text { by } 35 \%\end{array}$ \\
\hline Ceiling Prices & $\begin{array}{l}\$ 550 / \mathrm{kW} \text { for } 10 \text {-year } \\
\text { measures (NY) } \\
\$ 800 / \mathrm{kW} \text { for } 15 \text {-year } \\
\text { plus measures (NY) }\end{array}$ & Avoided costs & $\begin{array}{l}\text { Net present value (NPV) } \\
\text { of bid price < NPV } \\
\text { avoided costs - NPV of } \\
\text { savings during years } 1 \& \\
2\end{array}$ & Avoided costs \\
\hline Form of Payment (Basis) & One-time $(\mathrm{kW})$ & Installments (kWh) & Installments $(\mathrm{kWh})$ & Installments (kWh) \\
\hline
\end{tabular}


Table A-2: Summary of Utility Demand-Side Management Bidding Solicitations

\begin{tabular}{|c|c|c|c|c|}
\hline & $\begin{array}{c}\text { Public Service } \\
\text { Electric \& Gas(9) } \\
(8 / 89)\end{array}$ & $\begin{array}{c}\text { Niagara Mohawk(5) } \\
(11 / 89)\end{array}$ & $\begin{array}{c}\text { Long Island } \\
\text { Lighting Company (5) } \\
(11 / 89)\end{array}$ & $\begin{array}{c}\text { Public Service of } \\
\text { Indiana Energy(10) } \\
(12 / 89)\end{array}$ \\
\hline Resource Block Size & $200 \mathrm{MW}$ & $\begin{array}{l}350 \mathrm{MW} \text { with } 50 \mathrm{MW} \\
\text { DSM goal }\end{array}$ & $15-20 \mathrm{MW}, \mathrm{DSM}$ only & $550 \mathrm{MW}$ \\
\hline Type of Solicitation & Integrated RFP & Parallel RFP & Separate RFP & Parallel RFP \\
\hline $\begin{array}{l}\text { Bid Evaluation Design } \\
\text { Philosophy }\end{array}$ & Open & Hybrid & Closed & $\begin{array}{l}\text { Closed } \\
\text { Eligible Bidders }\end{array}$ \\
\hline ESCOs and customers & EsCOS and Customers & ESCOs and Customers & ESCOs and Customers & Eligible Bidders \\
\hline Eligible Measures & $\begin{array}{l}\text { Eligible: EE le.g., } \\
\text { lighting, cooling, } \\
\text { heating) } \\
\text { Not eligible: FS }\end{array}$ & $\begin{array}{l}\text { Not eligible: } C C, C G \text {, } \\
\text { FS, and new rate } \\
\text { designs }\end{array}$ & $\begin{array}{l}\text { Eligible: } 7 \text { types of } \\
\text { commercial energy } \\
\text { efficiency measures that } \\
\text { are also offered under } \\
\text { LILCO's "Dollars \& } \\
\text { Sense" program } \\
\text { Lighting measures may } \\
\text { comprise no more than } \\
75 \% \text { of total demand } \\
\text { reduction awarded to bid } \\
\text { contracts }\end{array}$ & $\begin{array}{l}\text { Eligible: EE, LS, LM } \\
\text { (e.g., energy } \\
\text { management systems or } \\
\text { remote load control), or } \\
\text { measures which } \\
\text { otherwise improve PSI's } \\
\text { load factor } \\
\text { Must have a service life } \\
\text { at least } 10 \text { years }\end{array}$ \\
\hline Market Sectors & All sectors & All sectors & $\mathrm{C} / \mathrm{l}$ sectors & All sectors \\
\hline Minimum Bid & $400 \mathrm{~kW}$ & $100 \mathrm{~kW}$ & Not specified in RFP & $5 \mathrm{MW}$ \\
\hline Minimum Deposit & $\$ 18 / \mathrm{kW}$ & $\$ 15 / \mathrm{kW}$ & $\$ 15 / \mathrm{kW}$ & $\$ 20 / \mathrm{kW}$ \\
\hline Front-Loaded Security & $\begin{array}{l}\text { Yes, if payments exceed } \\
135 \% \text { of avoided costs }\end{array}$ & No & No & Not specified in RFP \\
\hline Ceiling Prices & Avoided costs & $\begin{array}{l}\text { None: Company supply } \\
\text { alternative will be scored } \\
\text { by bid scoring system to } \\
\text { determine minimum } \\
\text { qualifying proposal score }\end{array}$ & & Avoided costs \\
\hline $\begin{array}{l}\text { Form of Bid Payment } \\
\text { (Basis) }\end{array}$ & Installments $(\mathrm{kWh})$ & Installments (kW?) & One-time (kW) & Installments (kW) \\
\hline
\end{tabular}


Table A-2: Summary of Utility Demand-Side Management Bidding Solicitations

\begin{tabular}{|c|c|c|c|c|}
\hline & $\begin{array}{c}\text { Consolidated Edison(5) } \\
\qquad(2 / 90)\end{array}$ & $\begin{array}{c}\text { New York State } \\
\text { Electric \& Gas(5) } \\
\text { (7/90) }\end{array}$ & $\begin{array}{c}\text { Rochester Gas } \\
\text { \& Electric(5) } \\
(9 / 90)\end{array}$ & $\begin{array}{c}\text { Central Hudson (5) } \\
(11 / 90)\end{array}$ \\
\hline Resource Block Size & $200 \mathrm{MW}$ & $\begin{array}{l}130 \mathrm{MW} \text {, with } 30 \mathrm{MW} \\
\text { goal for DSM }\end{array}$ & $\begin{array}{l}20 \mathrm{MW} \text { in a separate but } \\
\text { parallel auction }\end{array}$ & $20 \mathrm{MW}$ \\
\hline Type of Solicitation & Integrated RFP & Separate RFP & Separate RFP & Separate RFP \\
\hline $\begin{array}{l}\text { Bid Evaluation Design } \\
\text { Philosophy }\end{array}$ & Open & Open & Open & Not available \\
\hline Eligible Bidders & ESCOs and Customers & ESCOs and Customers & ESCOs and Customers & ESCOs and Customers \\
\hline Market Sectors & All sectors & All sectors & All sectors & All sectors \\
\hline Eligible Measures & $\begin{array}{l}\text { Eligible: Commercial and } \\
\text { residential measures } \\
\text { specified in the RFP } \\
\text { Payback period for each } \\
\text { measures must be at } \\
\text { least } 2 \text { years }\end{array}$ & $\begin{array}{l}\text { Eligible: Measures that } \\
\text { are "technically proven } \\
\text { and commercially } \\
\text { available" } \\
\text { Not Eligible: Measures } \\
\text { that "rely on continuing } \\
\text { customer behavior" such } \\
\text { as lowering thermostats } \\
\text { are disallowed }\end{array}$ & $\begin{array}{l}\text { Not Eligible: CC, CG, } \\
\text { FS, and new rate } \\
\text { designs }\end{array}$ & $\begin{array}{l}\text { Eligible: A range of } \\
\text { commercial and } \\
\text { residential measures that } \\
\text { reduce summer or winter } \\
\text { peak loads or average } \\
\text { demand } \\
\text { All must have minimum } \\
10 \text { year lifetime }\end{array}$ \\
\hline Minimum Bid & $100 \mathrm{~kW}$ & $100 \mathrm{~kW}$ & $100 \mathrm{~kW}$ & $\begin{array}{l}2.5 \mathrm{MWs} \text { for ESCOs } \\
100 \mathrm{~kW} \text { for customers }\end{array}$ \\
\hline $\begin{array}{l}\text { Minimum Security } \\
\text { Deposit }\end{array}$ & $\$ 15 / \mathrm{kW}$ & $\$ 15 / \mathrm{kW}$ & $\$ 15 / \mathrm{kW}$ & $\$ 15 / \mathrm{kW}$ \\
\hline Front-Loaded Security & Yes & Yes & Yes & Not available. \\
\hline Ceiling Prices & $\begin{array}{l}50 \% \text { above avoided } \\
\text { rebate and administrative } \\
\text { cost to deliver same } \\
\text { measures under Con } \\
\text { Edison's own DSM } \\
\text { program } \\
\text { Range from } \$ 325 \text { to } \\
\$ 3,100 / \mathrm{kW}\end{array}$ & $\begin{array}{l}\text { None: Company } \\
\text { alternative will be scored } \\
\text { to set minimum } \\
\text { qualifying score } \\
\text { Integrated resource plan } \\
\text { used to determine MW } \\
\text { awarded to DSM \& } \\
\text { supply contracts }\end{array}$ & $\begin{array}{l}\text { None: Non-bid capacity } \\
\text { alternative will be scored } \\
\text { by bid scoring system to } \\
\text { compare with bids } \\
\text { received }\end{array}$ & $\begin{array}{l}\text { Bid price in } \$ / \mathrm{kW} \text { of } \\
\text { highest-cost winning bid } \\
\text { in company's supply } \\
\text { auction }\end{array}$ \\
\hline Form of Bid Payment & Installments (kW) & Installments (kWh) & Installments (kWh) & Not available \\
\hline
\end{tabular}


Table A-2: Summary of Utility Demand-Side Management Bidding Solicitations

\begin{tabular}{|c|c|c|c|c|}
\hline & $\begin{array}{c}\text { Public Service of } \\
\text { Colorado \#1(11) } \\
\text { (12/90) }\end{array}$ & $\begin{array}{c}\text { Bonneville Power } \\
\text { Administration(12) } \\
\text { (1/91) }\end{array}$ & $\begin{array}{l}\text { City of Anaheim \#1 (13) } \\
\text { (2/91) }\end{array}$ & $\begin{array}{l}\text { City of Anaheim \#2 (14) } \\
\qquad(4 / 91)\end{array}$ \\
\hline Resource Block Size & $50 \mathrm{MW}$ & 300 "average" MW & $100 \mathrm{MW}$ & $100 \mathrm{MW}$ \\
\hline Type of Solicitation & Separate RFP & Parallel RFP & Separate RFP & Separate RFP \\
\hline $\begin{array}{l}\text { Bid Evaluation Design } \\
\text { Philosophy }\end{array}$ & Hybrid & Closed & Closed & Closed \\
\hline Eligible Bidders & ESCOs and Customers & $\begin{array}{l}\text { Customer utilities, } \\
\text { ESCOs, and government } \\
\text { entities }\end{array}$ & Customers & ESCOs \\
\hline Market Sectors & All sectors & All sectors & $\mathrm{C} / \mathrm{l}$ & $\mathrm{C} / \mathrm{I}$ \\
\hline Eligible Measures & $\begin{array}{l}\text { Eligible: EE, LS, FS, NC, } \\
\text { and demand reduction } \\
\text { measures } \\
\text { Not eligible: CC, CG, } \\
\text { and changes in operating } \\
\text { hours } \\
10 \text {-year minimum }\end{array}$ & $\begin{array}{l}\text { Eligible: } E E \\
\text { Minimum contract term } \\
\text { of } 10 \text { years }\end{array}$ & $\begin{array}{l}\text { Eligible: Any measure } \\
\text { that reduces on-peak } \\
\text { demand, chiller } \\
\text { reple :ements, } \\
\text { interruptible load } \\
\text { programs, thermal } \\
\text { storage, and C/l lighting }\end{array}$ & $\begin{array}{l}\text { Eligible: All conservation } \\
\text { programs will be } \\
\text { considered }\end{array}$ \\
\hline Minimum Bid & $\begin{array}{l}\text { ESCOs } 300 \mathrm{~kW} \\
\text { Customers } 100 \mathrm{~kW}\end{array}$ & $\begin{array}{l}2,190,000 \mathrm{kWh} \text { or } .25 \text { a } \\
\mathrm{MW}\end{array}$ & None & None \\
\hline Minimum Deposit & $\$ 20 / \mathrm{kW}$ & $\$ 5 / \mathrm{a} \mathrm{kW}$ for $>5 \mathrm{MW}$ & Not specified in RFP & Not specified in RFP \\
\hline Front-Loaded Security & Not applicable & Not specified in RFP & Not specified in RFP & Not specified in RFP \\
\hline Ceiling Prices & $\begin{array}{l}\$ 240 / \mathrm{kW} \text { (points added } \\
\text { for projects above } \\
\text { reference price, points } \\
\text { subtracted from those } \\
\text { below) }\end{array}$ & Not specified in RFP & $\begin{array}{l}\text { Southern California } \\
\text { Edison's capacity and } \\
\text { energy rates }\end{array}$ & $\begin{array}{l}\text { Southern California } \\
\text { Edison's capacity and } \\
\text { energy rates }\end{array}$ \\
\hline $\begin{array}{l}\text { Form of Bid Payment } \\
\text { (Basis) }\end{array}$ & One-time payments (kW) & Installments (kWh) & Not specified in RFP & Not specified in RFP \\
\hline
\end{tabular}


Table A-2: Summary of Utility Demand-Side Management Bidding Solicitations

\begin{tabular}{|c|c|c|c|}
\hline & $\begin{array}{l}\text { Northem California } \\
\text { Power Agency (15) } \\
\text { (8/91) }\end{array}$ & $\begin{array}{l}\text { Puget Sound Power \& } \\
\text { Light Company \#2(16) } \\
\text { (9/91) }\end{array}$ & $\begin{array}{c}\text { Pachic Power } \\
\text { \& Light(17) } \\
(10 / 91)\end{array}$ \\
\hline Resource Block Size & $200 \mathrm{MW}$ & $100-200 \mathrm{MW}$ & $50 \mathrm{MW}$ \\
\hline Type of Solicitation & Parallel RFP & Integrated/Parallel RFP & Parallel RFP \\
\hline $\begin{array}{l}\text { Bid Evaluation Design } \\
\text { Philosophy }\end{array}$ & Closed & Closed & Closed \\
\hline Eligible Bidders & ESCOs and customers & ESCOs and customers & ESCOs and customers \\
\hline Market Sectors & All sectors & All sectors & All sectors \\
\hline \multirow[t]{3}{*}{ Eligible Measures } & \multirow[t]{3}{*}{$\begin{array}{l}\text { Eligible: EE lighting, } \\
\text { heating, ventilation, air } \\
\text { conditioning, and } \\
\text { refrigeration, and motors } \\
\text { and controls, and NC }\end{array}$} & $\begin{array}{l}\text { Eligible: Measures } \\
\text { specified in the RFP and } \\
\text { other measures that } \\
\text { offer "verifiable } \\
\text { electricity savings based } \\
\text { on proven technologies" }\end{array}$ & $\begin{array}{l}\text { Eligible: EE } \\
\text { Must provide energy } \\
\text { savings for } 10-20 \\
\text { years }\end{array}$ \\
\hline & & Not eligible: FS, CC & \\
\hline & & $\begin{array}{l}\text { Measures must have a } \\
\text { useful life of } 10 \text { years }\end{array}$ & \\
\hline Minimum Bid & $10 \mathrm{~kW}$ or $10,000 \mathrm{kWh}$ & $100,000 \mathrm{kWh}$ & $250,000 \mathrm{kWh}$ \\
\hline Minimum Deposit & Not specified in RFP & $\$ .00375 / k W h$ & $20 \%$ of purchase price \\
\hline Front-Loaded Security & No & Yes & Yes \\
\hline Ceiling Prices & None & Avoided costs & Avoided costs \\
\hline $\begin{array}{l}\text { Form of Bid Payment } \\
\text { (Basis) }\end{array}$ & Not specified in RFP & Instaliments (kWh) & Installments (kWh) \\
\hline
\end{tabular}


Table A-2: Summary of Utility Demand-Side Management Bidding Solicitations

\begin{tabular}{|c|c|c|c|}
\hline & $\begin{array}{c}\text { Public Service of } \\
\text { Colorado } \# 2(18) \\
(8 / 92)\end{array}$ & $\begin{array}{c}\text { Duke Power } \\
\text { Company }(29) \\
(9 / 92)\end{array}$ & $\begin{array}{c}\text { Pacific Gas \& } \\
\text { Electric(20) (10/92) }\end{array}$ \\
\hline Resource Block Size & $50 \mathrm{MW}$ & $25 \mathrm{MW}$ & $20 \mathrm{MW}$ \\
\hline Type of Solicitation & Separate RFP & Separate RFP & Separate RFP \\
\hline $\begin{array}{l}\text { Bid Evaluation Design } \\
\text { Philosophy }\end{array}$ & Hybrid & Closed & Closed \\
\hline Eligible Bidders & ESCOs and Customers & ESCOs and Customers & ESCOs and Customers \\
\hline Market Sectors & All sectors & All sectors & All sectors \\
\hline Eligible Measures & $\begin{array}{l}\text { Eligible: EE, LS, FS, NC, } \\
\text { and demand reduction } \\
\text { measures } \\
\text { Not eligible: CC, CG, } \\
\text { and changes in operating } \\
\text { hours }\end{array}$ & $\begin{array}{l}\text { Eligible: EE, LS } \\
\text { Not Eligible: CG, FS, CC }\end{array}$ & $\begin{array}{l}\text { Eligible: Electric and gas } \\
\text { energy efficiency } \\
\text { proposals, including } \\
\text { load-management } \\
\text { proposals that reduce } \\
\text { the consumption of } \\
\text { electricity or gas }\end{array}$ \\
\hline & 10-vear minimum & & Not eligible: NC, CG, FS \\
\hline Minimum Bid & $\begin{array}{l}\text { ESCOs } 300 \mathrm{~kW} \\
\text { Customers } 100 \mathrm{~kW}\end{array}$ & $\begin{array}{l}100 \mathrm{~kW}, \text { but }<5,000 \\
\mathrm{~kW}\end{array}$ & $\begin{array}{l}100 \mathrm{~kW} \text { or } 100,000 \\
\mathrm{kWh}\end{array}$ \\
\hline Minimum Deposit & $\$ 20 / \mathrm{kW}$ & $\$ 22-34 / \mathrm{kW}$ & $\$ 15 / \mathrm{kW}$ \\
\hline Front-Loaded Security & Not applicable & Yes & $\begin{array}{l}\text { Yes, if payments exceed } \\
\text { avoided costs in any } \\
\text { calendar year }\end{array}$ \\
\hline Ceiling Prices & $\begin{array}{l}\$ 240 / \mathrm{kW} \text { (points added } \\
\text { for projects above } \\
\text { reference price, points } \\
\text { subtracted from those } \\
\text { below) }\end{array}$ & Avoided costs & Avoided costs \\
\hline $\begin{array}{l}\text { Form of Bid Payment } \\
\text { (Basis) }\end{array}$ & One-time $(\mathrm{kW})$ & Not specified in RFP & Installments (kWh) \\
\hline
\end{tabular}


Table A-2: Summary of Utility Demand-Side Management Bidding Solicitations

Sources:

(1) NEES, 1987.

(2) BECo, 1989.

(3) CMP, 1987.

(4) CMP, 1989.

(5) New York Department of Public Service, 1990.

(6) ORU, 1989.

(7) Puget, 1989

(8) JCPL, 1989.

(9) PSE\&G, 1989.

(10) Public Service of indiana, 1989.

(11) PSColo, 1990.

(12) BPA, 1991.

(13) City of Anaheim, 1991b.

(14) City of Anaheim, 1991a.

(15) NCPA, 1991

(116) Puget, 1991.

(17) PacifiCorp, 1991.

(18) PSColo, 1992

(19) Duke Power Company, 1992.

(20) PG\&E, 1992. 


\section{Calculating Levelized Bid Prices}

Levelized bid prices (in $\mathrm{c} / \mathrm{kWh}$ ) were calculated using a method proposed by Leung and Durning (1978), which divides levelized bid payments by levelized $\mathrm{kWh}$ saved. Leung and Durning's method is equivalent to dividing the net present value (NPV) of the annual bid payments by the NPV of the annual $\mathrm{kWh}$. The rationale for their approach, which was developed in the context of evaluating utility financial operations, is that "[s]ince the sales of energy produced is the only source for revenues, the levelizing of revenues (as the numerator) dictates the annual generation be levelized (as the denominator) in order to be mathematically correct."

We use this levelization technique primarily because DSM projects often do not provide comparable levels of savings in each year of the contract. For many DSM bids, energy and peak demand savings ramp up over a two to three year period as ESCOs develop projects at host customer facilities in order to achieve their specified contract demand goal. In some cases, savings also ramp-down at the end of the contract if measure life is less than contract term. The Leung and Durning method allows us to reflect the timing and occurrence of bid payments and the corresponding energy savings.

A simple example illustrates the rationale for this approach. Assume that a DSM bidder receives payments of $5 \mathrm{c} / \mathrm{kWh}$ for every unit of energy saved and that the bidder delivers $100 \mathrm{kWh}$ in years 1 and 2 , and $500 \mathrm{kWh}$ in years 3 through 5 . The NPV of the payment stream is $\$ 58.15$ with a levelized cost of $\$ 15.73$ (see Table B-1). On a per kWh basis, the levelized bid price would be $3.15 \mathrm{c} / \mathrm{kWh}$ using peak annual energy savings $(\$ 15.73 / 500)$ or $4.63 \mathrm{c} / \mathrm{kWh}$ using average energy savings $(\$ 15.73 / 340)$. If we divide the levelized payments by the levelized energy savings (i.e., $\$ 15.73 / 315$ ), we obtain the actual bid price of $5 \mathrm{c} / \mathrm{kWh}$. It would be possible to avoid this potential ambiguity in levelized bid prices by simply taking the NPV of the bid prices in each year (i.e., 5 $\mathrm{c} / \mathrm{kWh}$ ) and levelizing this term over the 5 year contract period.

However, this simple, straightforward method does not work for payments that increase (or vary in any manner) over the contract. Assume that a DSM bidder receives payments of $3 \mathrm{c} / \mathrm{kWh}$ in the first year, which increase by $1 \mathrm{c} / \mathrm{kWh}$ in each year of a five year contract. The energy savings remain the same as in the previous example. In this situation, if we simply levelized the NPV of bid prices, we obtain a figure of $5 \mathrm{c} / \mathrm{kWh}$. This would be correct figure only if we received equal energy savings in each year of the contract. However, the bidder delivers most of the energy savings in the last three years of the contract when bid prices are higher. Consequently, the levelized bid price should also be slightly higher. The Leung and Durning method results in levelized bid 
prices which are slightly higher $(5.57 \mathrm{c} / \mathrm{kWh}=\$ 17.52 / 315)$, which better reflects the actual occurrence of the savings.

Table B-1. Illustrative Examples of Levelized Bid Price Calculations

\begin{tabular}{|c|c|c|c|c|c|c|}
\hline \multirow[b]{2}{*}{ Year } & \multicolumn{3}{|c|}{$\begin{array}{l}\text { Example } \\
\# 1\end{array}$} & \multicolumn{3}{|c|}{$\begin{array}{l}\text { Example } \\
\# 2\end{array}$} \\
\hline & $\begin{array}{l}\text { Bid Price } \\
\text { (c/kWh) }\end{array}$ & $\begin{array}{l}\text { Savings } \\
\text { (kWh) }\end{array}$ & $\begin{array}{l}\text { Payment } \\
\text { (\$) }\end{array}$ & $\begin{array}{l}\text { Bid Price } \\
\text { (c/kWh) }\end{array}$ & $\begin{array}{l}\text { Savings } \\
\text { (kWh) }\end{array}$ & $\begin{array}{l}\text { Payment } \\
\text { (\$) }\end{array}$ \\
\hline 1 & 5 & 100 & 5 & 3 & 100 & 3 \\
\hline 2 & 5 & 100 & 5 & 4 & 100 & 4 \\
\hline 3 & 5 & 500 & 25 & 5 & 500 & 25 \\
\hline 4 & 5 & 500 & 25 & 6 & 500 & 30 \\
\hline 5 & 5 & 500 & 25 & 7 & 500 & 35 \\
\hline Total & 25 & 1700 & 85 & 25 & 1700 & 97 \\
\hline NPV & 18 & 1,163 & $\$ 58.15$ & 18 & 1,163 & $\$ 64.76$ \\
\hline Levelized (\$) & & & $\$ 15.73$ & & & $\$ 17.52$ \\
\hline Average (kWh) & & 340 & & & 340 & \\
\hline Levelized (kWh) & & 315 & & & 315 & \\
\hline Levelized ( $\mathrm{c} / \mathrm{kWh}$ ) & 5 & & & 5 & & \\
\hline
\end{tabular}




\section{Review and Analysis of Bidding Contracts}

This appendix summarizes salient contract features that were modeled in our analysis of each utility. Where possible, signed contracts between utilities and DSM developers form the basis for our characterization of prototypical contract features. However, we relied on provisions of sample contracts included in the RFP for utilities (e.g., Central Maine Power) where signed contracts were not publicly available.

- Central Maine Power (CMP) - Our analysis is based on the sample contract that accompanies the second RFP. In the sample contract, DSM developers must deposit about $\$ 72 / \mathrm{kW}$ during the ramp-up period, and three times that amount during the contract term. The entire contract may be terminated for partial project completion and liquidated damages will be incurred if energy savings fall below $100 \%$. In our example, we assume that the underdeliveries of energy savings are permanent, which means that liquidated damages are based upon the New England Power Pool Capability Responsibility Adjustment Charge (i.e., $\$ 72 / \mathrm{kW}$ in 1992). ${ }^{71}$ The contract capacity is also reduced after payment of these damages. However, several developers indicated that these features were modified during contract negotiations with CMP. ${ }^{72}$

- $\quad$ Orange and Rockland Utilities (New York) - ORU-NY signed four agreements with two ESCOs that provide for full payment upon installation and verification of the measures. ORU-NY will also pay for more than $100 \%$ of contracted capacity savings. The utility can impose liquidated damages for failure to install all of the measures and can terminate the contract for failure to install $90 \%$ of the measures. However, the utility will pay for those measures already on-line. In these contracts, no penalties are imposed if $\mathrm{kWh}$ savings deteriorate over time.

- $\quad$ Orange and Rockland Utilities (New Jersey) - ORU-NJ executed four contracts with ESCOs. ORU-NJ imposes liquidated damages for failure to install measures, prorating the damages to the amount brought on-line. Unlike most other utilities, some developers are required to make cash deposits to secure their potential liability. ORU-NJ does not appear to impose penalties for subsequent

7 Liquidated damages for short-term underdeliveries are based upon a short-term energy-only (STEO) rate set for qualifying facilities.

12 For example, several developers indicated that lower security deposits were negotiated and that their contract terminates (and liquidated damages apply) only for that portion not brought on line. Developers also indicated that payments were capped at $110 \%$ of the committed savings. 
underperformance over the term of the contracts. Front-loaded security is required, but only if payments exceed avoided cost by more than $35 \%$.

- $\quad$ Puget Power - Our analysis relies primarily on one executed contract that was obtained from a DSM developer. In its first DSM bidding RFP, Puget Power did not require contract or security deposits and appears to impose no penalties for partial project failure or savings deterioration. ${ }^{73}$ The sample contract, however, does contain provisions that allow the utility to terminate the contract if the developer fails to bring the project on-line by a pre-specified date or if, after the initial operation date, the developer delivers less than $50 \%$ of the committed energy savings for longer than three months. Finally, it is unclear whether the utility would pay for energy savings in excess of $100 \%$ of the contracted amount.

- Jersey Central Power \& Light (JCP\&L) - The four DSM contracts signed by JCP\&L impose liquidated damages and contract termination for failure to install the committed contract capacity and include penalties if savings deteriorate over the term of the contract. The termination provision applies to the entire contract, even if the developer brings a portion of the committed capacity on-line. However, contract provisions do allow for a three-year project delay, but require damage payments of $\$ 1 / \mathrm{kW}$ per month during this period. ${ }^{74}$

Penalties are based upon the replacement capacity costs for the lost energy and capacity savings, which we have estimated to be $3.0 \mathrm{c} / \mathrm{kWh}$ and $\$ 72 / \mathrm{kW}$ in 1998 , respectively. The contracts indicate that ESCOs can replace lost savings in order to mitigate these penalties. However, we assumed a "worst case scenario" in our example in which ESCOs were unable to replace the savings and, thus, were obligated to pay an amount equal to the penalty associated with a two year deficiency. This two-year buy-out clause only applies if the deficiencies result from the curtailment or cessation of operation at a host customer facilities. Presumably, the developer would be responsible for penalties over the entire contract term if the deficiencies resulted from equipment failure or deterioration.

73 However, in its second DSM bidding RFP, Puget's sample contract includes provisions that impose liquidated damages for partial project completion and a front-loaded security deposit to be retained as long as necessary during project operation.

74 While these termination provisions are onerous compared to other utilities, enforcement of these provisions was preempted because of an agreement worked out among the utility, DSM developers, and regulatory agency staff as part of a broader settlement on incentive ratemaking and cost recovery for utility DSM programs. In our example, however, we modeled the impact of the contract provisions. 
- $\quad$ Public Service Electric \& Gas (PSE\&G) - The eight contracts signed by PSE\&G impose liquidated damages for failure to install necessary measures and penalties if savings deteriorate over the contract term. We assumed that DSM developers would simply pay liquidated damages for measures not installed. However, in these contracts, they also have the option of delaying the delivery date by paying $\$ 1 / \mathrm{kW}$ per month for up to a two year period. If the developers opt for this delay provision and then still fail to install the measure, the liquidated damage payments could reach $\$ 64,000$ (in NPV terms) or $\$ 36 / \mathrm{kW}$.

Penalties are based upon the replacement capacity costs for the lost energy and capacity savings, which we estimate at $\$ 70 / \mathrm{kW}$ in 1998 . DSM developers are allowed to replace lost savings in order to mitigate these penalties. However, we assumed a "worst case scenario" in which ESCOs were unable to replace the savings and, thus, were obligated to pay an amount equal to the penalty associated with a three-year deficiency.

- Consolidated Edison (Con Edison) - Payments to DSM developers are based on $\mathrm{kW}$ demand reductions rather than energy savings. Payments occur over a fouryear period for one contract and over the entire term for the other. Penalty provisions are quite severe if the committed contract capacity is not fully installed or if the demand reductions deteriorate over time (due, for example, to equipment failure or removal). In addition, Con Edison may terminate the contract if the developer fails to install $50 \%$ of the committed contract capacity. In modeling the "worst case" performance risk scenario, we assumed that peak demand reductions could deteriorate by up to $50 \%$. In contrast to LILCO and PSColo, we assume that these reductions could be detected by Con Edison's verification procedures that include inspections each year of the contract. ${ }^{75}$

- $\quad$ Long Island Lighting Company (LILCO) - The three contracts signed by LILCO pay DSM developers based on savings from reducing peak demand. LILCO provides full payment upon installation and verification of the measures and will pay for more than $100 \%$ of the contracted capacity savings. The utility will impose liquidated damages for failure to install all measures, but penalties are not imposed if $\mathrm{kWh}$ savings deteriorate over the contract term.

- New York State Electric and Gas (NYSEG) - The DSM contracts negotiated by NYSEG include liquidated damages for failure to install all of the committed capacity and energy savings. However, there are no performance penalties if

is We assume that annual energy savings may potentially deteriorate more than peak demand reductions because of changes in hours of operation. 
savings deteriorate over time, other than reduced payments and the contracts do not appear to require front-loaded security deposits. One unusual contract features allows the utility to reduce payments by $10 \%$ if all measures are not brought online.

- Rochester Gas \& Electric (RG\&E) - We reviewed two of the three contracts that RG\&E has signed with ESCOs. These agreements require contractors to post a contract deposit of $\$ 22.50 / \mathrm{kW}$, which must be forfeited if the developer fails to install $50 \%$ of the measures. In addition, RG\&E will impose liquidated damages for partial project completion and failure. Unlike other contracts we reviewed, RG\&E has the right to terminate the contract if the ESCO does not install $50 \%$ of the measures by the contract completion date. "Liquidated damages" are also imposed if a contractor fails to deliver the full energy savings after projects are completed. The utility will impose liquidated damages for falling below the $100 \%$ mark, but will pay for energy or capacity savings up to $110 \%$ of the contracted amount. Moreover, these damages appear to be incurred on an annual, rather than a one-time basis.

- $\quad$ Public Service Colorado (PSColo) - PSColo pays DSM developers the full contract amount after the installation and verification of DSM measures. Developers are responsible for ensuring that peak demand reductions (but not energy savings) persist over the contract term. The contracts contain no specific performance guarantees, although developers are required to repair or replace any equipment that fails to provide the agreed upon $\mathrm{kW}$ demand savings. Because of this provision, we assume that developers will provide the full demand savings over the contract term, but that annual energy savings may fluctuate as a result of changes in hours of use or other factors. These fluctuations will not result in any payment reductions (because payments are made upfront), penalties, or liquidated danı.ages (because of our assumption that peak demand savings remain unchanged). ${ }^{76}$ However, project economics are affected because the avoided cost benefits will change as the energy savings vary.

- Pacific Gas \& Electric (PG\&E) - Based on our review of ten signed contracts, it appears that PG\&E was quite willing to individually negotiate and adapt

76 Liquidated damages are $\$ 20 / \mathrm{kW}$ if the contractually agreed upon demand reductions are not maintained over the contract term; inclusion of these damages would not have a large effect on total payments or the benefit/cost ratios. 
contract concitions to the specific circumstances of developers. ${ }^{7}$ Compared to other utilities where terms and conditions tended to be more standardized, it is more difficult to develop a generic characterization of PG\&E's bidding contracts because there is more variation in terms and conditions among contracts. We modeled one contract that shows PG\&E's general approach to allocating risk between the utility and DSM developers. PG\&E will pay developers the full bid price for energy savings if actual savings are within a certain deadband (85\% to $115 \%$ of estimated energy savings). This feature was modified in several contracts that had tiered pricing schemes and the contracts differ as to what occurs if actual savings fall outside of the deadband range. ${ }^{78}$ Liquidated damages can be imposed both for failure to bring measures on-line (defined as $85 \%$ of the contracted savings) and for deterioration in savings over time. Liquidated damages are calculated based upon the premise that a DSM project could be replaced by an alternative resource within one year. ${ }^{79}$

- Sacramento Municipal Utility District (SMUD) - Two of the three contracts that SMUD negotiated with ESCOs are pay for performance. In the third contract, the ESCO will receive an annual management fee and subcontractors will receive reimbursement for $50 \%$ of direct costs for services provided. ${ }^{80}$ All three contracts impose liquidated damages for failure to bring measures on line, but penalties are not imposed for performance failure after the projects are fully operational. SMUD imposes damages for failure to bring $80 \%$ to $90 \%$ of the committed capacity savings on line, but will pay for the installation of more than $100 \%$ of the measures.

We then compared the impact of contract provisions that control development and performance risk in each utility's bidding program by analyzing a prototypical ESCO contract that is representative of a lighting contract under various scenarios. Table $\mathrm{C}-1$ presents the results of this analysis for each utility, including projected payments to the

7 In part, this might be attributable to the increasing maturity of the industry (as the PG\&E program is the most recent) or the result of the utility's explicit attempt to create a "partnership" with DSM developers, which translated into more flexibility during negotiations.

78 Two contracts receive no payment below $85 \%$ of the contracted power savings; the other eight adopt a reduced payment below this threshold. Six contracts also pay for power in excess of $115 \%$, up to $150 \%$ for one contract.

79 Damages are calculated by taking one-tenth of the difference between the NPVs of avoided costs and total payments, which is equivalent to a one year assessment of the value of replacing the resource should a project fail.

80 Presumably, customers will be responsible for paying the remaining $50 \%$ of direct costs. 
DSM developer under each scenario, damages and penalties that might be incurred for non-performance, which yields project revenues. We then computed the net benefits and benefit/cost ratio from a total resource perspective after including estimates of administrative costs $(0.3 \mathrm{c} / \mathrm{kWh})$ and customer cost contributions $(0.5 \mathrm{c} / \mathrm{kWh})$ for our prototypical ESCO contract. 
Table C-1. Payments, Damages, and Penalties for Various Performance Scenarios

\begin{tabular}{|c|c|c|c|c|c|c|c|c|c|c|}
\hline & \multirow{2}{*}{$\begin{array}{c}\text { Program } \\
\text { Completion/ } \\
\text { Liquidated } \\
\text { Damage } \\
\text { Deposit } \\
\end{array}$} & \multirow[b]{2}{*}{$\begin{array}{c}\text { Form } \\
\text { of } \\
\text { Security }\end{array}$} & \multirow[b]{2}{*}{$\begin{array}{c}\text { Front-Loaded } \\
\text { Security } \\
\text { Deposit } \\
\end{array}$} & \multirow{2}{*}{$\begin{array}{c}\text { Base } \\
\text { Case } \\
100 \% \\
(\$ 1000 \mathrm{~s}) \\
\end{array}$} & \multicolumn{3}{|c|}{ Development Rlsk } & \multicolumn{3}{|c|}{ Performance Rlsk } \\
\hline & & & & & $\begin{array}{c}0 \% \\
\text { Installed }\end{array}$ & $\begin{array}{c}50 \% \\
\text { Installed }\end{array}$ & $\begin{array}{c}75 \% \\
\text { Installed }\end{array}$ & $50 \%$ & $75 \%$ & $90 \%$ \\
\hline CMP (sample contract, 1989 RFP) & & & $\$ 16$ & & & & & & & \\
\hline Payment & & & & $\mathbf{s 1 , 8 8 5}$ & so & $\$ 942$ & $\$ 1,413$ & $\$ 1.533$ & $\$ 1,709$ & $\$ 1,814$ \\
\hline Liquidated Damages & $\$ 144$ & LOC & & & (\$130) & $(\$ 65)$ & $(\$ 32)$ & (\$115) & (\$58) & (\$23) \\
\hline Program Completion Security & & & & & & & & & & \\
\hline $\begin{array}{l}\text { Penaities } \\
\text { Project Revenues }\end{array}$ & & & & $\$ 1,885$ & (\$130) & 5877 & $\$ 1,381$ & $\$ 1,418$ & $\$ 1,651$ & $\$ 1,791$ \\
\hline & & & & $\$ 474$ & $\$ 130$ & $\$ 302$ & $\$ 388$ & $\$ 240$ & $\$ 357$ & $\$ 428$ \\
\hline $\begin{array}{l}\text { Net Benetits } \\
\text { BenefivCost Ratio }\end{array}$ & & & & 1.21 & 0 & 1.28 & 1.23 & 1.14 & 1.18 & 1.20 \\
\hline
\end{tabular}

\section{ORU-NJ}

Payment

Program Completion Security

Penalties

Project Revenues

Net Benefits

BenefivCost Ratio

\section{ORU-NY}

Payment

Liquidated Damages

Program Completion Security

Penalties

Project Revenues

Net Benefits

Benefiv/Cost Ratio

$\$ 36$

Cash

Puget (sample contract, 1989 RFP)

Payment

Liquidated Damages

Program Completion Security

Penalties

Project Revenuies

Net Benefits

BenefivCost Ratio

$\$ 36$

Cash

LOC so

$\begin{array}{lllllll}\$ 1,885 & \$ 0 & \$ 942 & \$ 1,413 & \$ 1, \$ 33 & \$ 1,709 & \$ 1,814\end{array}$

$\begin{array}{ll}\$ 0 & \$ 942 \\ (\$ 32) & (\$ 16)\end{array}$

(\$8)

$\begin{array}{rrr}\$ 1,885 & (\$ 32) & \$ 926 \\ \$ 474 & \$ 32 & \$ 2 \$ 3 \\ 1.21 & 0 & 123\end{array}$

so

$\begin{array}{ccc}\$ 1,885 & \$ 0 & \$ 94 \\ & (\$ 32) & (\$ 16) \\ \$ 1,885 & (\$ 32) & \$ 926 \\ \$ 474 & \$ 32 & \$ 2 \\ 1.21 & 0 & 1.23\end{array}$

$\$ 160$

$\$ 1,885$

so

\$942

$\$ 1,413$

$\$ 1,533$

$\$ 1,709$

$\$ 1,814$

$\begin{array}{rcccccc}\$ 1,885 & \$ 0 & \$ 942 & \$ 1,413 & \$ 1,533 & \$ 1,709 & \$ 1,814 \\ \$ 474 & \$ 0 & \$ 237 & \$ 356 & \$ 125 & \$ 299 & \$ 405 \\ 1.21 & 0 & 1.21 & 1.21 & 1.07 & 1.15 & 1.19\end{array}$


Table C-1. Payments, Damages, and Penalties for Various Performance Scenarios

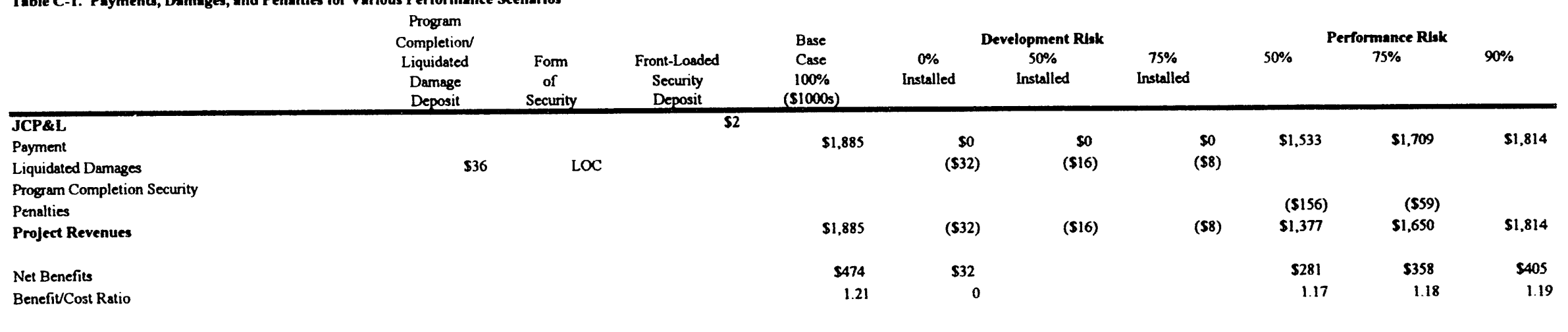

\section{PSE\&G}

Payment

Liquidated Damages

Program Completion Security

Penalties

Project Revenues

Net Benefits

Benefiv/Cost Ratio

$\bar{్}$

\section{ConEd}

Program Completion Security

Payment Reduction

Penalties

Project Revenues

Net Benefits

BenefivCost Ratio

\section{Luco}

Payment

Program Completion Security

Penalties

Project Revenues

Net Benefits

BenefivCost Ratio
LOC

$\$ 1,885$

$\begin{array}{cc}\$ 0 & \$ 942 \\ (\$ 32) & (\$ 18)\end{array}$

(\$18)

$\$ 1,413$

(\$8)

$\$ 1,885$

(\$32)

$\$ 1,533$

$\$ 1,709$

$\$ 1,814$

\section{$\$ 474$}

$$
\$ 32
$$

$\$ 160$

$\$ 30$

ILOC

$\$ 1,885$

so
$(\mathbf{S 2 7})$

91,885$$
\text { (\$27) }
$$

$\$ 474$

$$
\begin{array}{r}
\$ 27 \\
0
\end{array}
$$

$\$ 30$

ILOC
$\$ 1,885$

$\$ 1,885$
$\$ 474$
1.21 so

(\$27)

(\$27)

$\$ 27$
$\$ 924$

$\$ 1,405$

$\$ 255$

(\$71)

$\$ 1.462$

$(\$ 34)$
51.675

5364

$\$ 196$

$\$ 333$

$\$ 405$

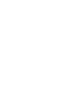

$\$ 942$
$\$ 0$

$\$ 1,413$
50

$\$ 1,885$

$\$ 1,885$

$\$ 1,885$

(\$\$48)

(\$S48) (\$274) (\$110)

(567) (\$51)

$\$ 942$

$\$ 1,413$

$\$ 1,270$

51,560

$\$ 1,775$

$\begin{array}{ccccc}\$ 237 & \$ 356 & \$ 388 & \$ 448 & \$ 444 \\ 1.21 & 1.21 & 1.25 & 1.24 & 1.21\end{array}$

$\$ 9$

$\$ 942$

$\$ 1,413$

$(\$ 7)$

$\$ 1,885$

$\$ 1,885$

$\$ 1,885$

s928

$\$ 928$

$\$ 1,406$$$
\text { S1 }
$$

$\$ 1,885$
$(\$ 227)$

$\$ 1,88$

$\$ 1,885$

$\$ 123$

$\$ 363$

$(\$ 227)$
0.90 
Table C-1. Payments, Damages, and Penalties for Vartous Performance Scenarios

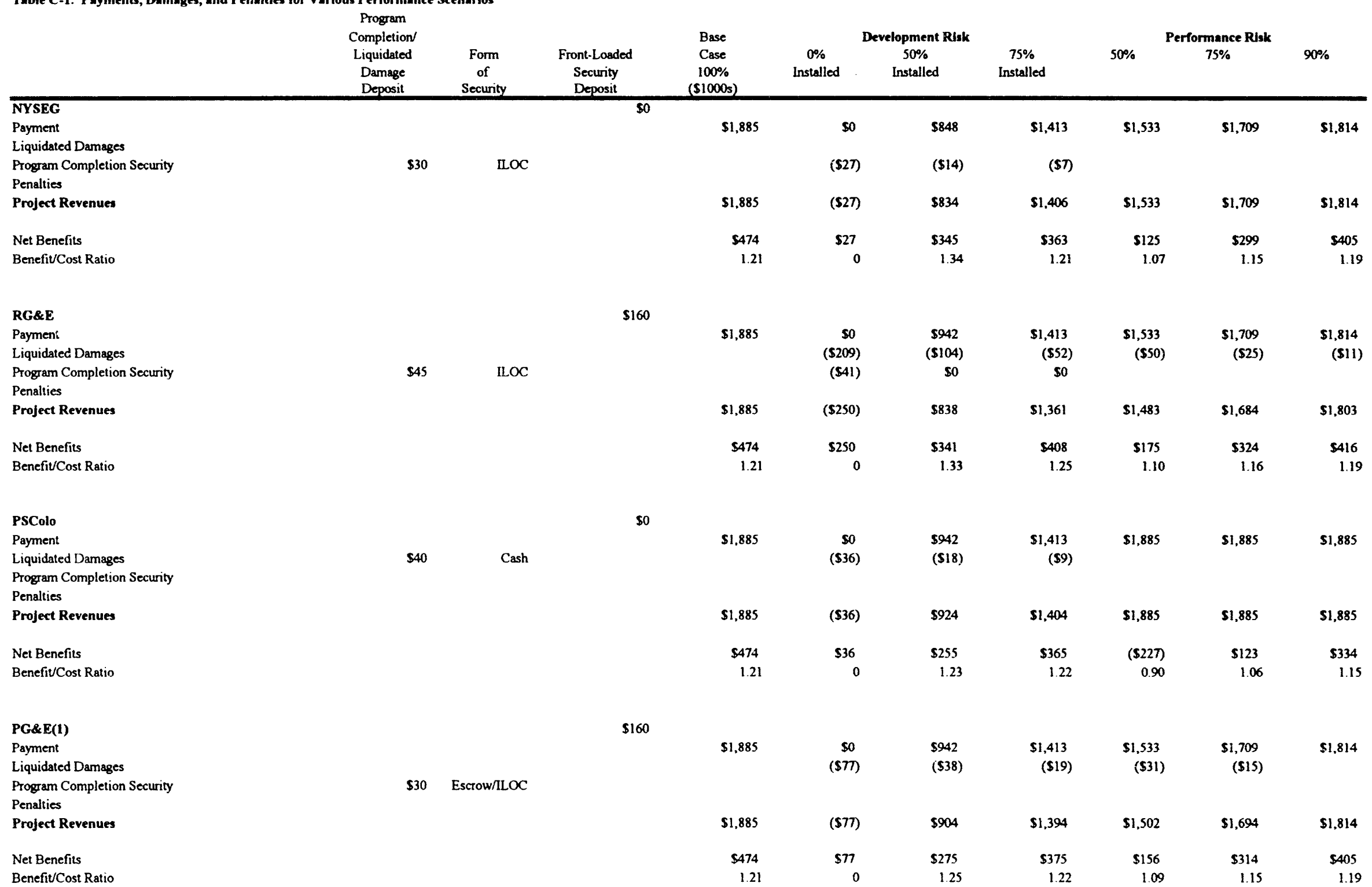


Table C-1. Payments, Damages, and Penalties for Various Performance Scenarios

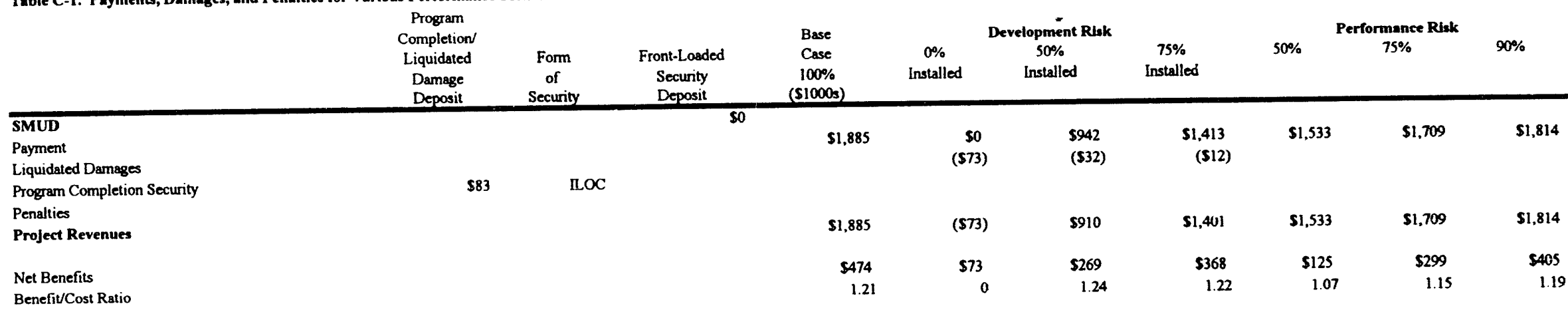



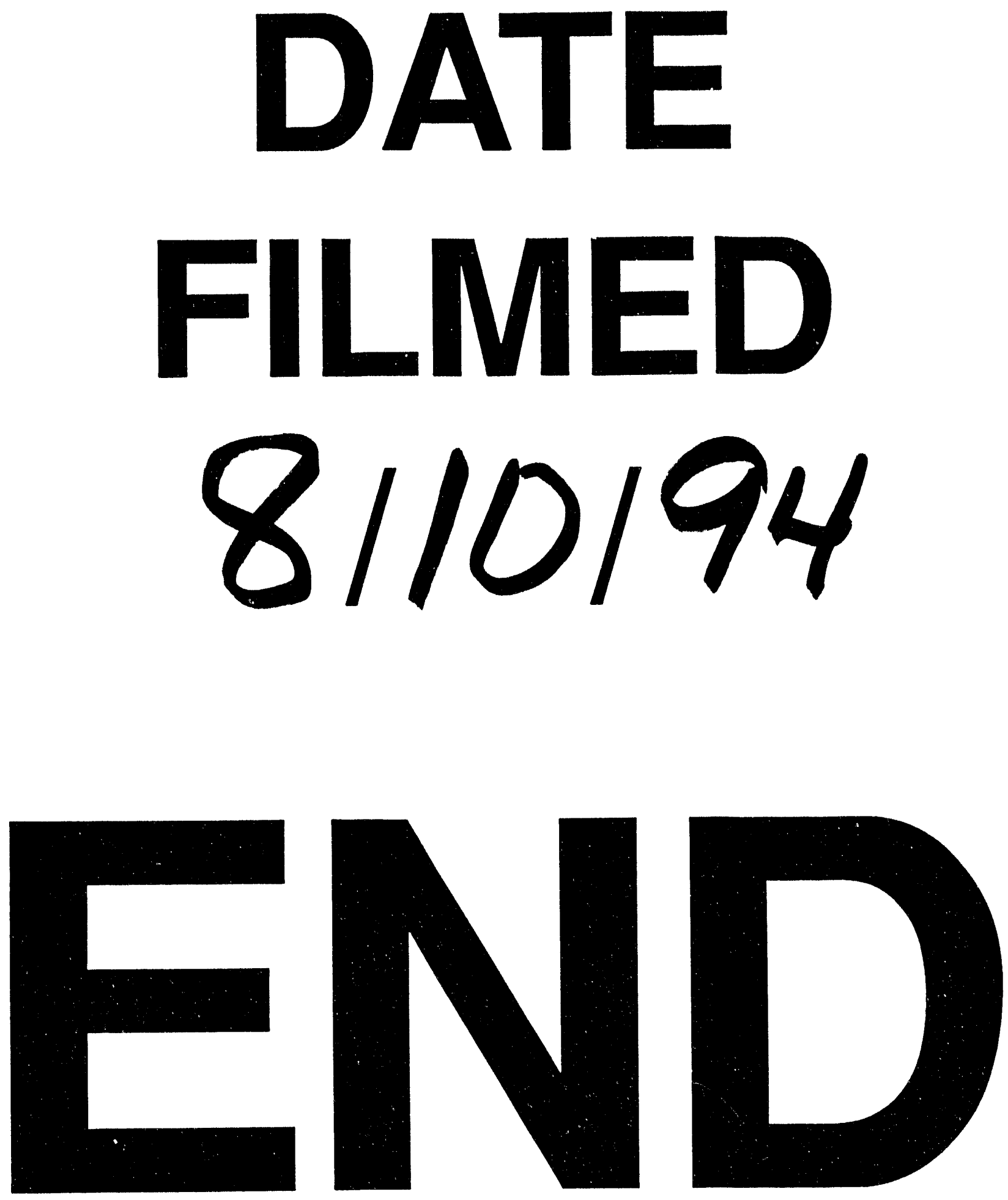
